Prepared for the U.S. Department of Energy under Contract DE-AC05-76RL01830

\title{
Climate Change Impacts on Residential and Commercial Loads in the Western U.S. Grid
}
$\mathrm{NLu}$
LR Leung
PC Wong
ML Paget
ZT Taylor
J Correia, Jr
PS Mackey
W Jiang
Y Xie

September 2008

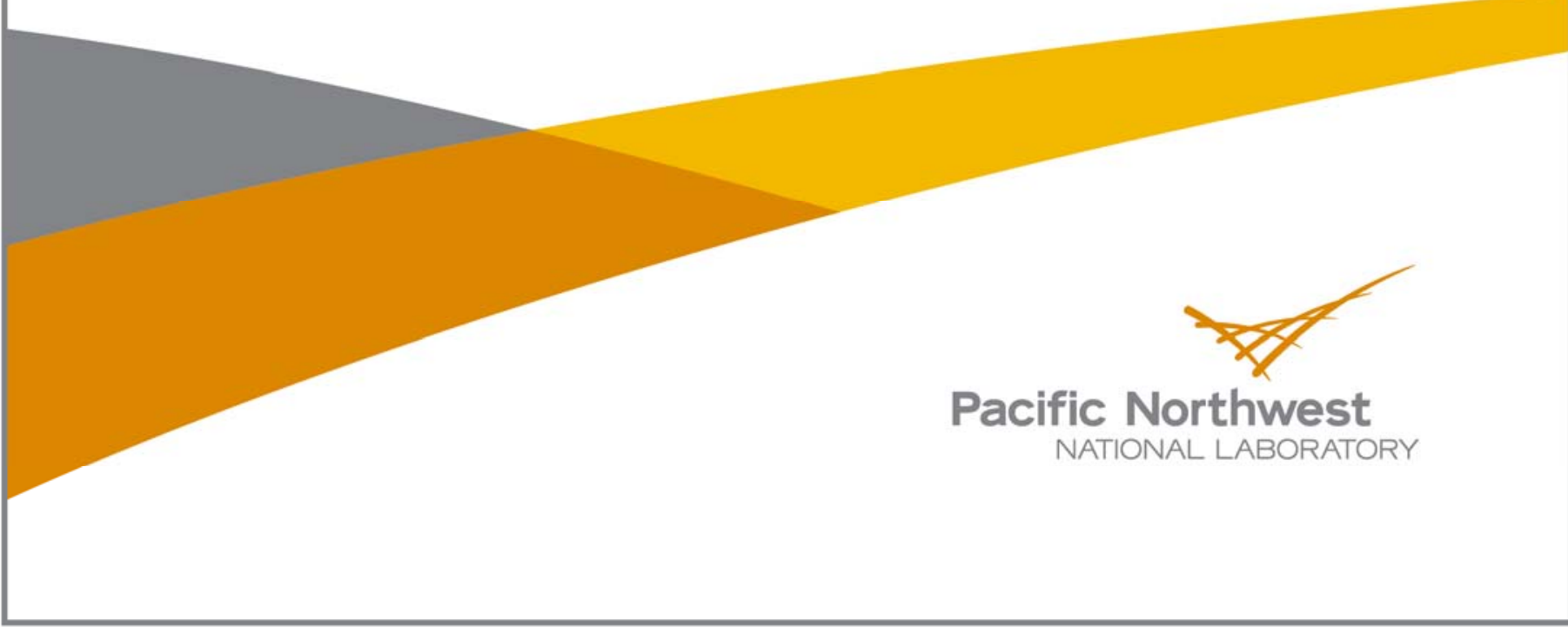





\title{
DISCLAIMER
}

This report was prepared as an account of work sponsored by an agency of the United States Government. Neither the United States Government nor any agency thereof, nor Battelle Memorial Institute, nor any of their employees, makes any warranty, express or implied, or assumes any legal liability or responsibility for the accuracy, completeness, or usefulness of any information, apparatus, product, or process disclosed, or represents that its use would not infringe privately owned rights. Reference herein to any specific commercial product, process, or service by trade name, trademark, manufacturer, or otherwise does not necessarily constitute or imply its endorsement, recommendation, or favoring by the United States Government or any agency thereof, or Battelle Memorial Institute. The views and opinions of authors expressed herein do not necessarily state or reflect those of the United States Government or any agency thereof.

\author{
PACIFIC NORTHWEST NATIONAL LABORATORY \\ operated by \\ BATTELLE \\ for the \\ UNITED STATES DEPARTMENT OF ENERGY \\ under Contract DE-AC05-76RL01830 \\ Printed in the United States of America \\ Available to DOE and DOE contractors from the \\ Office of Scientific and Technical Information, \\ P.O. Box 62, Oak Ridge, TN 37831-00062; \\ ph: (865) 576-8401 \\ fax: (865) 576-5728 \\ email: reports@adonis.osti.gov
}

\author{
Available to the public from the National Technical Information Service, \\ U.S. Department of Commerce, 5285 Port Royal Rd., Springfield, VA 22161 \\ ph: (800) 553-6847 \\ fax: (703) 605-6900 \\ email: orders@ntis.fedworld.gov \\ online ordering: http://www.ntis.gov/ordering.htm
}





\title{
Climate Change Impacts on Residential and Commercial Loads in the Western U.S. Grid
}

\author{
N. Lu \\ L.R. Leung \\ P.C. Wong \\ M. Paget \\ Z.T. Taylor \\ J. Correia, Jr P.S. Mackey \\ W. Jiang \\ Y. Xie
}

September 2008

Prepared for

U.S. Department of Energy

under Contract DE-AC05-76RL01830

as part of Techno-social Predictive Analytics Initiative

Pacific Northwest National Laboratory

Richland, Washington 99352 



\section{Summary}

This document presents a multi-disciplinary modeling approach to quickly quantify climate change impacts on energy consumption, peak load, and load composition of residential and commercial buildings. This research focuses on addressing the impact of temperature changes on the building cooling load in 10 major cities across the Western United States and Canada. Our results have shown that by the mid-century, building yearly energy consumption and peak load will increase in the Southwest. Moreover, the peak load months will spread out to not only the summer months but also spring and autumn months. The Pacific Northwest will experience more hot days in the summer months. The penetration of air conditioning (a/c) systems in this area is likely to increase significantly over the years. As a result, some locations in the Pacific Northwest may be shifted from winter peaking to summer peaking. Overall, the Western U.S. grid may see more simultaneous peaks across the North and South in summer months. Increased cooling load will result in a significant increase in the motor load, which consumes more reactive power and requires stronger voltage support from the grid. This study suggests an increasing need for industry to implement new technology to increase the efficiency of temperature-

sensitive loads and apply proper protection and control to prevent possible adverse impacts of a/c motor loads. 


\section{Acknowledgment}

The authors would like to thank Dr. Steve Unwin and Dr. Antonio Sanfilippo with Pacific Northwest National Laboratory, for providing us with many useful comments and suggestions. 


\section{Contents}

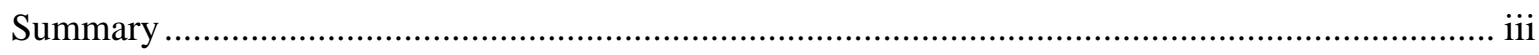

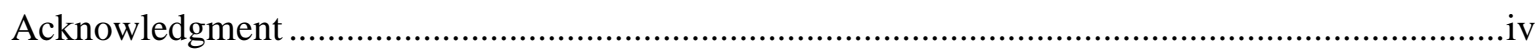

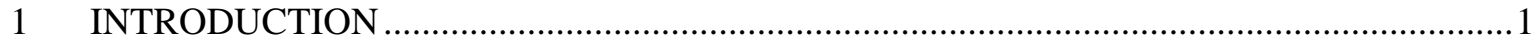

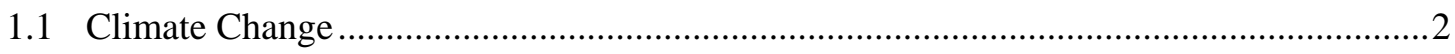

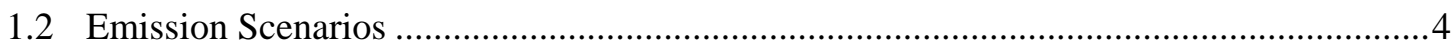

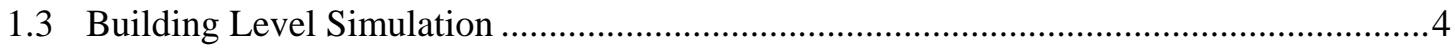

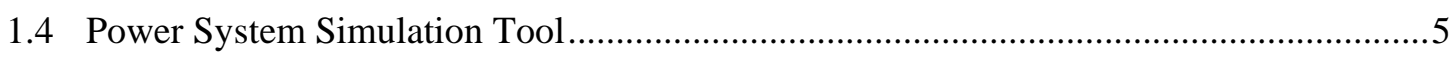

2 The Climate Change Impact on Power Distribution Grids ...................................................6

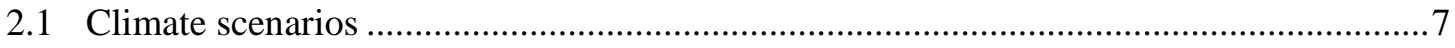

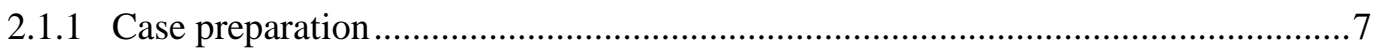

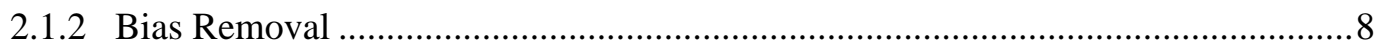

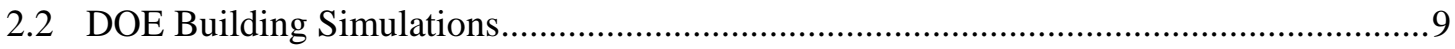

2.2.1 Building Prototypes (Hirsch 1999)...................................................................

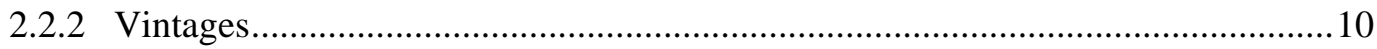

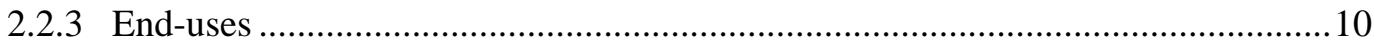

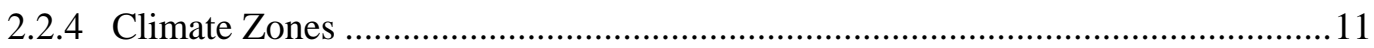

2.2.5 Weather Data in DOE-2.1E (Buhl 1999) …....................................................13

2.3 Building Level Impact Study ……………................................................................

2.3.1 The Characteristics of Temperature Correlation Curves.......................................14

2.3.2 Building Temperature Sensitivity Curve Derivation.............................................21

2.3.3 Modeling Results for Portland and Phoenix..........................................................23

2.3.4 Modeling Results for the 7 Inland Cities.............................................................29

2.4 Feeder Level Impact Study ..........................................................................................

2.4.1 Change of end-use energy consumption (Monthly and Yearly), peak load, and feeder load composition. .........................................................................................

2.4.2 Power Quality and Energy Losses.....................................................................35

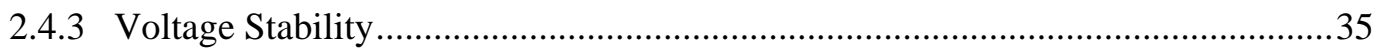

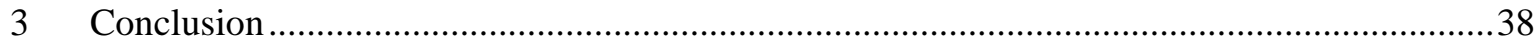

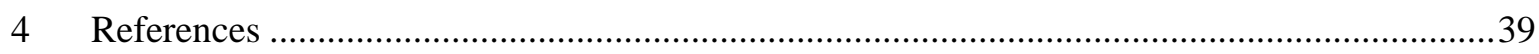

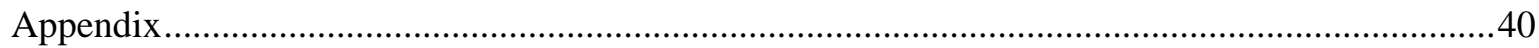

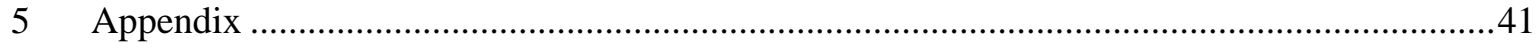




\section{Figures}

Figure 1: A simplified diagram of the power grid (HowStuffWorks, 2008) ...................................1

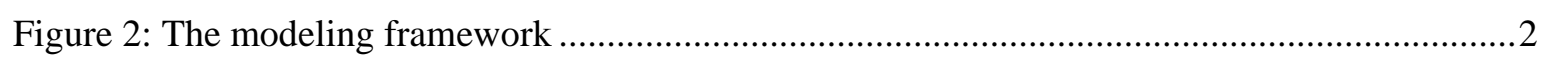

Figure 3: A block diagram of the simulation inputs and outputs ................................................

Figure 4: The monthly $T_{\max }$ of Portland area: Now $(1991-2000)$ versus Future $(2045-2054) \ldots . .9$

Figure 5: A map of the geographical location of the 78 climate zones in the Western United States

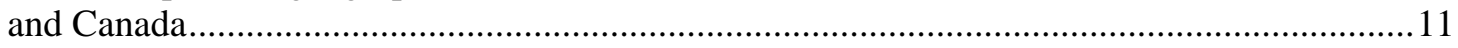

Figure 6: The temperature sensitivity of the cooling load of six typical commercial buildings in

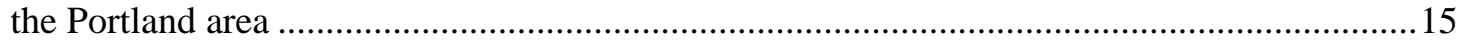

Figure 7: The temperature sensitivity of the heating load of six typical commercial buildings in

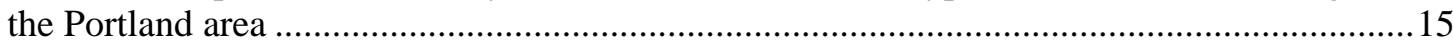

Figure 8: The temperature sensitivity of the total building load of the 23 commercial buildings in

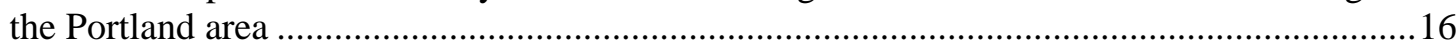

Figure 9: The temperature sensitivity of the refrigeration load of the grocery buildings in the Portland area .... .16

Figure 10: The temperature sensitivity of the supplemental load of in the Portland area ..............17

Figure 11: The temperature sensitivity of the ventilation load in the Portland area .......................17

Figure 12: The temperature sensitivity of the cooling and refrigeration load composition in Portland area

Figure 13: The temperature sensitivity of the refrigeration load and cooling load composition of grocery stores in the Portland area ….................................................................... 18

Figure 14: The temperature sensitivity of the heating load composition in the Portland area .......19

Figure 15: The temperature sensitivity of the heating load composition in the Portland area with respect to time of the day

Figure 16: The temperature sensitivity of the building peak load for Portland, Salt Lake City, Phoenix, Boulder, Billings, Vancouver, and Calgary

Figure 17: The temperature sensitivity of the building peak load for San Francisco, Los Angeles,

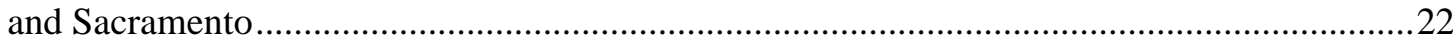

Figure 18: The influence of the type of day on the building peak load (Building vintage: post 2005).

Figure 19: The influence of building vintages on the building peak load.....................................23

Figure 20: The temperature sensitivity of the cooling load composition in Portland, Salt Lake City, Phoenix, Boulder, Billings, Vancouver, and Calgary ..................................................23

Figure 21. A comparison between the Portland and Phoenix areas .............................................28

Figure 22: Climate change impacts on the future peak load of the 26 buildings in 7 locations .......31

Figure 23: Climate change impacts on the future yearly energy consumption of the 26 buildings

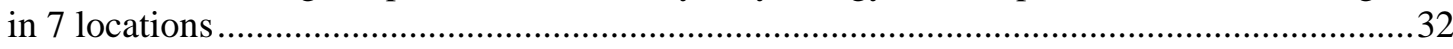

Figure 24: Climate change impacts on the future cooling load composition of the 26 buildings in 7 locations 
Figure 25: The box plot of Now (N) and Future (F) cooling load compositions of the 26 buildings in Salt Lake City in August

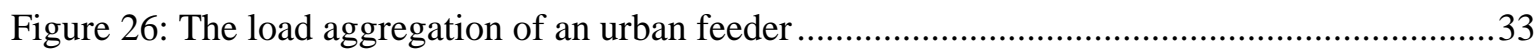

Figure 27: The feeder level weather temperature sensitivity ...................................................35

Figure 28: The voltage recovery process of a bus serving heavy a/c load after a fault in a hot

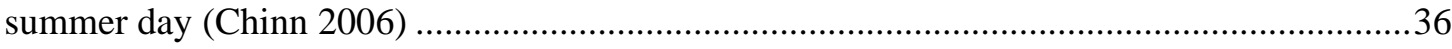

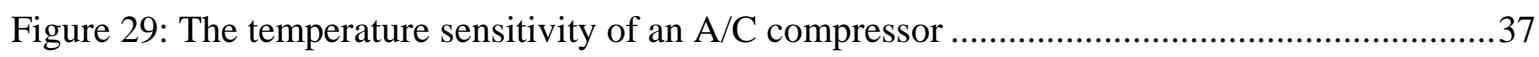

Figure 30: The temperature sensitivity of an A/C compressor ......................................................37

Figure 31: The temperature sensitivity curve of daily building consumptions for base case derived from the 7 inland cities. (Black: weekday; Blue: weekend; Red: holiday) ................................41

Figure 32: The temperature sensitivity curve of building peak load for base case derived from the 7 inland cities. (Black: weekday; Blue: weekend; Red: holiday) .............................................43

Figure 33: The temperature sensitivity curve of building peak load for base case derived from the 7 inland cities. (Black: weekday; Blue: weekend; Red: holiday) .........................................45

Figure 34: The box plot of building yearly energy consumption for base case Now and Future derived from the 7 inland cities. (Black: Now; Magenta: Future) ..........................................47

Figure 35: The box plot of building summer load composition at Hour 15 for Now and Future derived from the 7 inland cities. (Black: Now; Magenta: Future) ...........................................49

Figure 36: The box plot of building spring/autumn load composition at Hour 15 for Now and Future derived from the 7 inland cities. (Black: Now; Magenta: Future) 


\section{Tables}

Table 1: Summary Statistics for the United States, 1995 through 2006 ........................................6

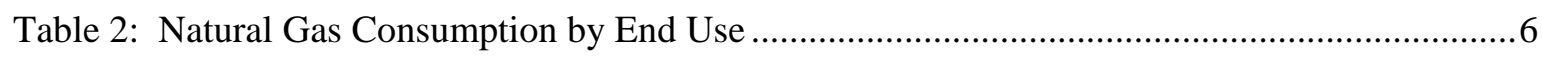

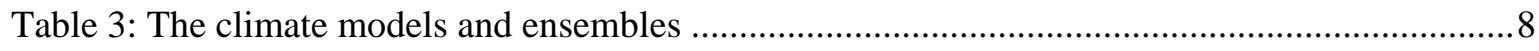

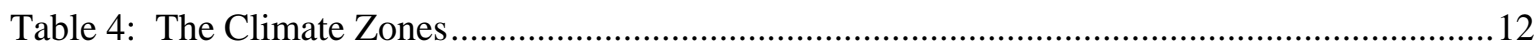

Table 5: The forecasted average increase of the monthly and yearly building total load

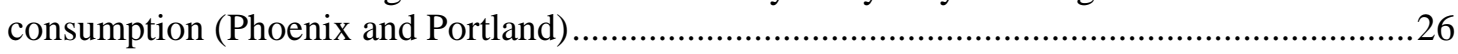

Table 6: The forecasted extreme (2.5\%): percent of increase of the monthly and yearly building

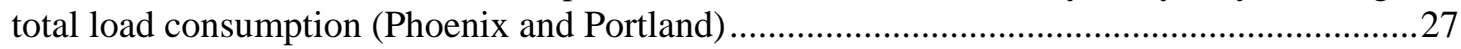

Table 7: Peak hour energy consumption (total) forecast average increase (Portland).....................29

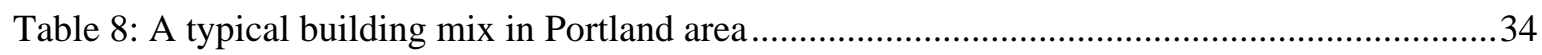

Table 9: The temperature sensitivity of air conditioner compressor units .....................................36 


\section{INTRODUCTION}

This report focuses on a simulation and evaluation of the impact of the climate change on the western US grids based on the Intergovernmental Panel on Climate Change (IPCC) Scenario A1B for two time periods: 2000 and 2050 in 10 U.S. locations within the western U.S. grids. A simplified diagram of the electric power grid is shown in Figure 1, showing that the power grid consists of three major components: generators, loads, and power transmission and distribution grids. The impact of climate change on the power distribution grid is first studied by simulation and modeling of the commercial and residential load behaviors under 26 weather models in the A1B scenario. The impact of climate change on generation resources are evaluated based on the existing modeling results. Then, aggregated impacts on load and generators are used to address the transmission level impacts on the western U.S. grid. The modeling framework has been shown in Figure 2. In the following sections, we will introduce the inputs and outputs of climate modeling, power system modeling, and social science modeling in detail.

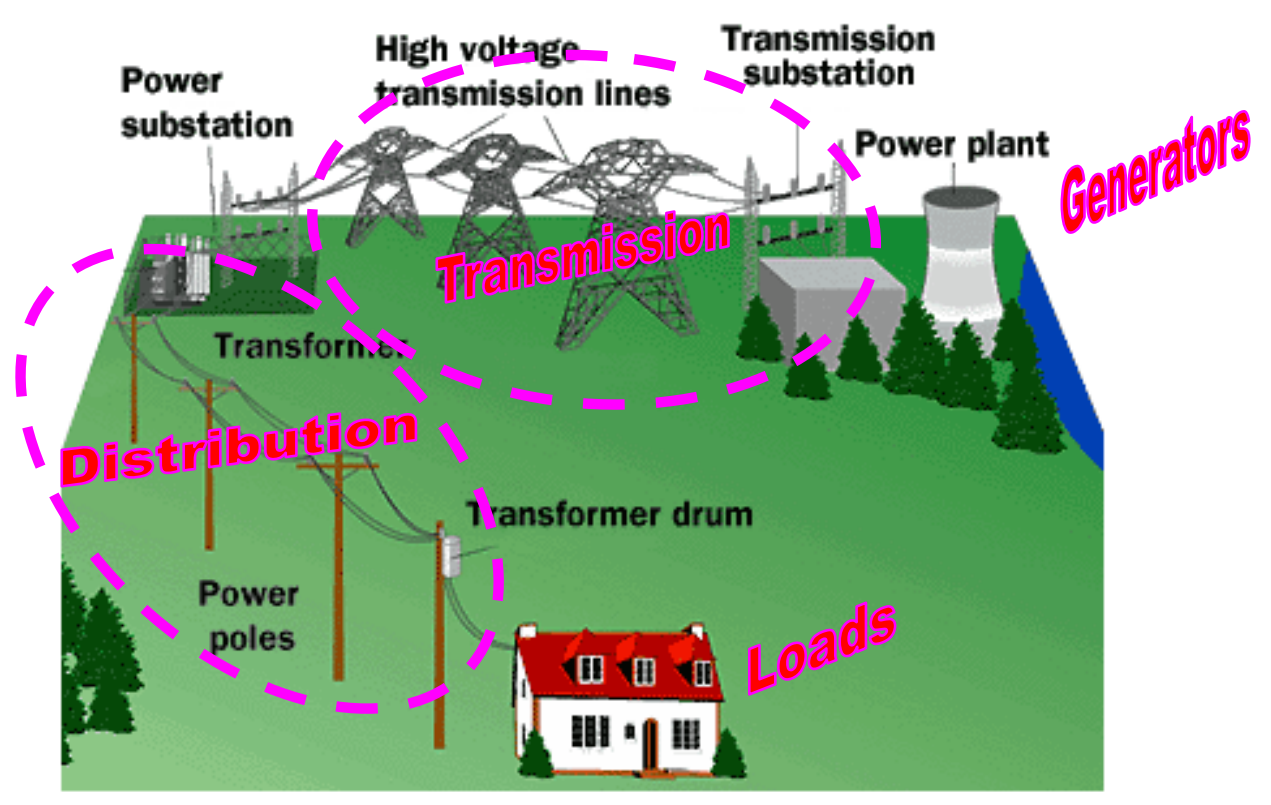

Figure 1: A simplified diagram of the power grid (HowStuffWorks, 2008) 


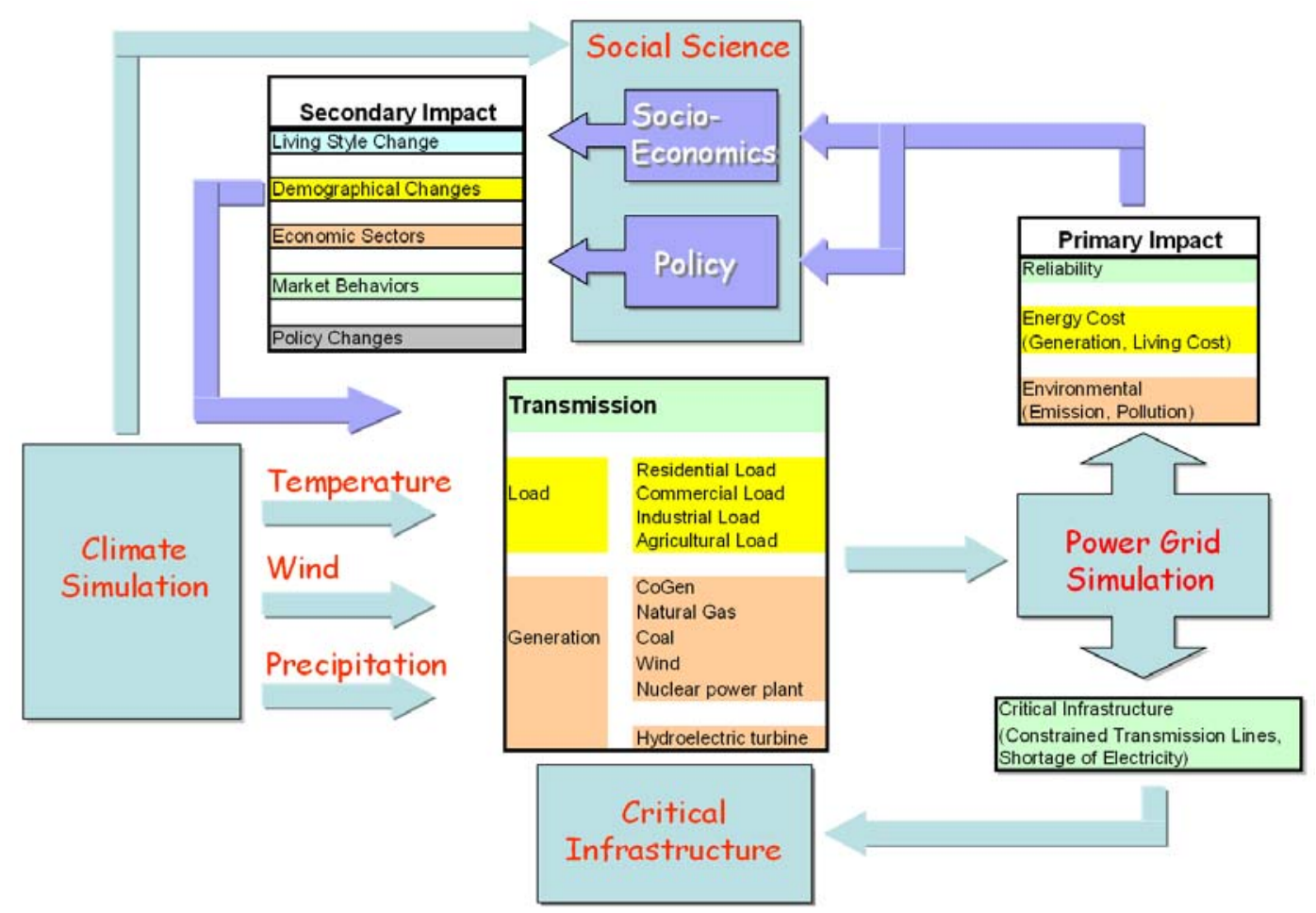

Figure 2: The modeling framework

\subsection{Climate Change}

The IPCC definitions of climate change are (IPCC, 2007):

Climate change in IPCC usage refers to a change in the state of the climate that can be identified (e.g., using statistical tests) by changes in the mean and/or the variability of its properties, and that persists for an extended period of time, typically decades or longer. It refers to any change in climate over time, whether due to natural variability or as a result of human activity. This usage differs from that in the United Nations Framework Convention on Climate Change (UNFCCC), where climate change refers to a change in climate that is attributed directly or indirectly to human activity that alters the composition of the global atmosphere and that is in addition to natural climate variability observed over comparable time periods.

As shown in the IPCC Fourth Assessment Report (IPCC, 2007), warming of the climate system is unequivocal, as is now evident from observations of increases in global average air and ocean temperatures, widespread melting of snow and ice, and rising global average sea level. In addition to the increased average temperature, scientists also predicted an increasing number of extreme climate events, such as heat waves, cold fronts, tornados, hurricanes, droughts and floods. IPCC has shown that some extreme weather events have changed in frequency and/or intensity over the last 50 years: 
- It is very likely that cold days, cold nights and frosts have become less frequent over most land areas, while hot days and hot nights have become more frequent.

- It is likely that heat waves have become more frequent over most land areas.

- It is likely that the frequency of heavy precipitation events (or proportion of total rainfall from heavy falls) has increased over most areas.

- It is likely that the incidence of extreme high sea level has increased at a broad range of sites worldwide since 1975.

Based on growing evidence, there is high confidence that the following effects on hydrological systems are occurring: increased runoff and earlier spring peak discharge in many glacier-fed and snowfed rivers; and warming of lakes and rivers in many regions, with effects on thermal structure and water quality.

Not all aspects of climate change have equal impact on electrical load. Among all the climate factors, temperature is considered to be a major factor contributing to the variation of electrical loads because cooling and heating loads may take up to $90 \%$ of the total building energy consumption. Changes in temperature, depending upon the duration and magnitude, can be categorized as:

- long-term sustained changes,

- $\quad$ short-term spikes, defined as sharp increase of peak daily temperature that lasts for a few days, and

- extreme events, such as cold/heat waves that last for days or weeks.

Their corresponding impacts on the power grid are anticipated to be as follows:

- Long-term sustained temperature changes may affect consumer behavior and lead to fundamental changes of the system load. For example, an increased number of hot summer days will increase the penetration of air conditioning (a/c) loads and, therefore, change both the magnitude and the composition of the load.

- Temperature spikes are important to estimate the peak loading condition of power systems. On a hot summer day, at the distribution level, simultaneous peaking of the cooling load may overload the distribution feeders and the transformers. At the transmission level, this may result in transmission system congestion. Moreover, the power system reserve and stability margin will be significantly reduced when electricity demand and the percentage of motor loads such as a/c units, ventilation fans, and refrigeration equipment, increases significantly. Therefore, the power grid will be prone to faults and move to an unstable state when temperature spikes.

- An extreme event, such as a heat wave or a cold front, puts the power grid on heavy loading conditions for longer durations than a temperature spike. Such events are more likely to cause 
power system overload, allowing a vast area load to peak simultaneously and causing a system-wide power shortage or widespread blackout.

In this document, the impact of long-term sustained changes and changes in short-term spikes will be studied and discussed in detail. We will address the impacts of extreme events in later publications.

\title{
1.2 Emission Scenarios
}

A description of the emission scenarios can be found in (IPCC, 2000):

\begin{abstract}
IPCC Special Report on Emissions Scenarios (SRES) refers to the scenarios described in the IPCC Special Report on Emission Scenarios (IPCC, 2000). The SRES scenarios are grouped into four scenario families (A1, A2, B1, and B2) that explore alternative development pathways, covering a wide range of demographic, economic, and technological driving forces and resulting GHG emissions. The SRES scenarios do not include additional climate policy above current ones. The emission projections are widely used in the assessments of future climate change, and their underlying assumptions with respect to socioeconomic, demographic and technological change serve as inputs to many recent climate change vulnerability and impact assessments. The A1 storyline assumes a world of very rapid economic growth, a global population that peaks in midcentury and rapid introduction of new and more efficient technologies. A1 is divided into three groups that describe alternative directions of technological change: fossil intensive (A1FI), nonfossil energy resources (A1T), and a balance across all sources (A1B). B1 describes a convergent world, with the same global population as A1, but with more rapid changes in economic structures toward a service and information economy. B2 describes a world with intermediate population and economic growth, emphasizing local solutions to economic, social, and environmental sustainability. A2 describes a very heterogeneous world with high population growth, slow economic development and slow technological change. No likelihood has been attached to any of the SRES scenarios.
\end{abstract}

In this report, A1B scenarios are applied to account for a balance of emission across all sources. There are 26 climate models in A1B scenario and 10 years are simulated for Now (1991-2000) and Future (2045-2054). Each model is weighted equally regarding their probability of occurrence.

\subsection{Building Level Simulation}

There have been a number of studies of climate impacts on U.S. residential and commercial building sectors. In [2], Huang investigated the impacts of future climate change using four IPCC climate change scenarios at three time periods for 20 U.S. locations. However, their study focused on the building energy use rather than the power grid. This study uses a similar method to study the building level energy use, but focuses on the impacts of the end use change to the power distribution grid. Aggregating the building loads together by an estimated building mix for the area studied, climate impacts on the power transmission grid can be readily modeled.

The building simulation is done using DOE-2 - an industry standard building energy use and cost analysis tool. By inputting the building layout, construction, usage, and conditioning systems (lighting, HVAC, etc.), along with weather data, DOE-2 performs hourly simulations of the building energy use and 
produces yearly building load profiles for 23 commercial and 3 residential building types for 78 cities in the Western Electricity Coordinating Council (WECC) system. In this initial study, we focus on 10 of the 78 cities. However, the methodology is readily applicable to other climate zones and areas in the Western U.S..

\subsection{Power System Simulation Tool}

The power system simulation tool we used is GE Positive Sequence Load Flow Software (PSLF). A test bed has been set up to simulate the impact of load change in terms of magnitude and composition at a distribution feeder. WECC system-wide planning models available on the WECC website are used to obtain a base case loading and generation condition for a system-wide impact study. The impacts are categorized into:

- Steady state loading: equipment stress, capacity expansion

- Voltage stability of the power distribution system

- Congestion at transmission systems

- Capacity requirements.

In this report, we focused on the distribution level study. There is a separate report on the adverse impact study on a/c load. For details, please refer to Chinn (2006) and Lu et al. (2008 and 2008a). 


\section{The Climate Change Impact on Power Distribution Grids}

Residential and commercial sectors consume more than $70 \%$ of the U.S. electricity consumption and 35\% natural gas usage according to Energy Information Administration (EIA) Survey (EIA 2007), as shown in Table 1 and Table 2. Temperature variations are the most influential climate related factor that drives the building energy consumption based on building level simulation. Therefore, by characterizing residential and commercial building energy consumption changes with respect to temperature variations, one can use the IPCC climate modeling results as inputs to quantify the peak hour energy consumption, as well as monthly and annual energy usage increases. At cumulative level, the energy demand will drive the change of the energy generation portfolio and the construction and upgrade of the energy generation, transmission and distribution infrastructure.

Table 1: Summary Statistics for the United States, 1995 through 2006

\begin{tabular}{|l|r|r|r|r|r|}
\hline \multicolumn{1}{|c|}{ End Use } & \multicolumn{1}{c|}{2002} & \multicolumn{1}{c|}{2003} & \multicolumn{1}{c|}{2004} & \multicolumn{1}{c|}{2005} & \multicolumn{1}{c|}{2006} \\
\hline Residential & $37 \%$ & $37 \%$ & $36 \%$ & $37 \%$ & $37 \%$ \\
Commercial & $32 \%$ & $34 \%$ & $35 \%$ & $35 \%$ & $35 \%$ \\
Industrial & $29 \%$ & $29 \%$ & $29 \%$ & $28 \%$ & $28 \%$ \\
Transportation & $0 \%$ & $0 \%$ & $0 \%$ & $0 \%$ & $0 \%$ \\
Other & $3 \%$ & $0 \%$ & $0 \%$ & $0 \%$ & $0 \%$ \\
All Sectors & $100 \%$ & $100 \%$ & $100 \%$ & $100 \%$ & $100 \%$ \\
\hline
\end{tabular}

(http://www.eia.doe.gov/cneaf/electricity/epa/epaxlfilees1.xls)

Table 2: Natural Gas Consumption by End Use

\begin{tabular}{|l|r|r|r|r|r|r|}
\hline \multicolumn{1}{|c|}{ End Use } & \multicolumn{1}{c|}{2002} & \multicolumn{1}{c|}{2003} & 2004 & \multicolumn{1}{c|}{2005} & \multicolumn{1}{c|}{2006} & \multicolumn{1}{c|}{2007} \\
\hline Residential & $23 \%$ & $24 \%$ & $23 \%$ & $23 \%$ & $21 \%$ & $22 \%$ \\
Commercial & $15 \%$ & $15 \%$ & $15 \%$ & $14 \%$ & $14 \%$ & $14 \%$ \\
Industrial & $35 \%$ & $35 \%$ & $35 \%$ & $33 \%$ & $33 \%$ & $31 \%$ \\
Vehicle Fuel & $0 \%$ & $0 \%$ & $0 \%$ & $0 \%$ & $0 \%$ & $0 \%$ \\
Electric Power & $27 \%$ & $25 \%$ & $27 \%$ & $29 \%$ & $32 \%$ & $32 \%$ \\
Total & $100 \%$ & $100 \%$ & $100 \%$ & $100 \%$ & $100 \%$ & $100 \%$ \\
\hline
\end{tabular}

(http://tonto.eia.doe.gov/dnav/ng/ng_cons_sum_dcu_nus_a.htm)

A block diagram of the simulation process is shown in Figure 3. To study the impact of climate change on load, DOE-2 building energy simulations are run to obtain weather sensitivities. This allows fast processing of the data thorough the interpolation of curves. Typical meteorological year (TMY) weather files developed by the National Renewable Energy Laboratory (NREL) are used as baseline historical weather data for each city. It is also used by the climate model to remove bias of the modelgenerated current and future temperature series. For each building type, we develop a set of energy, peak load, and load composition versus $T_{\max }$ and $T_{\min }$ curves based on TMY weather data. Then the IPCC forecasted $T_{\max }$ and $T_{\min }$ for Now and Future are used to generate the building daily energy consumption, peak load, and load composition based on these sensitivity curves derived from the TMY data. 


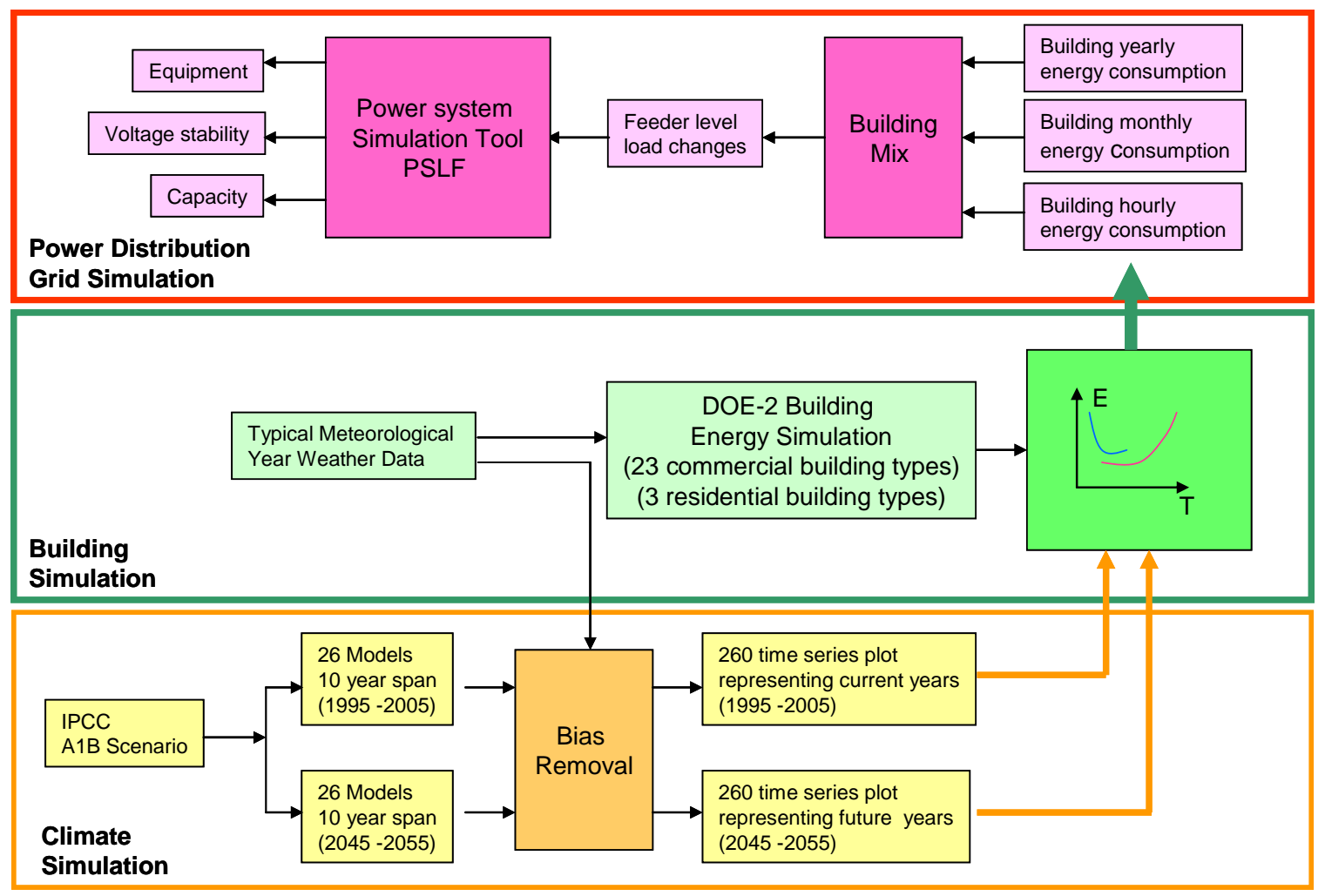

Figure 3: A block diagram of the simulation inputs and outputs

\subsection{Climate scenarios}

\subsubsection{Case preparation}

A large number of global climate simulations have been archived for IPCC 2007. These simulations are grouped by the greenhouse gas emission scenarios that were used to drive the global climate models. These scenarios fall into four families (A1, A2, B1, and B2) that explore alternative development pathways, covering a wide range of demographic, economic, and technological driving forces and resulting greenhouse gas emissions. A detailed description of these scenarios can be found in the IPCC Special Report on Emission Scenarios (http://www.ipcc.ch/pdf/assessmentreport/ar4/syr/ar4_syr_topic1.pdf.). We selected the mid-century as the focus of this analysis. This choice is motivated by the desire for climate change signals that are sufficiently large to emerge from the noise (natural variability), while keeping our analysis relevant for a future time horizon when our understanding and modeling tools of the energy infrastructure still apply. For the mid-century, different emission scenarios have very little impact on the projected climate, so in the initial stage of our research, the A1B scenario is selected to account for a balance of emission across all sources.

The IPCC archive for the A1B scenario includes 26 sets of climate simulation outputs from 23 global climate models. To address uncertainty, all available climate simulations are included in our analysis, and each simulation is considered equally likely in representing the climate system. For each simulation, daily time series of temperature are extracted for 10 years each to represent Now (1991-2000) and the Future 
(2045-2054). This results in 260 time series of daily maximum and daily minimum surface temperature each for Now and the Future.

The climate model and ensembles are listed in Table 3. There are 17 models from different institutions with different modeling structure and initial conditions. However, they are all under the same carbon emission scenario, which is A1B: assuming a balanced distribution across fossil and non-fossil energy resources. In total, there are 26 models. Within each, there are 10 years of daily $T_{\max }$ and $T_{\min }$ being forecast.

Table 3: The climate models and ensembles

\begin{tabular}{|l|c|c|c|c|c|}
\hline Model & Ensemble 1 & Ensemble 2 & Ensemble 3 & Ensemble 4 & Ensemble 5 \\
\hline aom & $\mathrm{X}$ & & & & \\
\hline cgcm232a & $\mathrm{X}$ & $\mathrm{X}$ & $\mathrm{X}$ & $\mathrm{X}$ & $\mathrm{X}$ \\
\hline cgcm31t47 & $\mathrm{X}$ & $\mathrm{X}$ & $\mathrm{X}$ & & \\
\hline cgcm31t63 & $\mathrm{X}$ & & & & \\
\hline cm20 & $\mathrm{X}$ & & & & \\
\hline cm21 & $\mathrm{X}$ & & & & \\
\hline cm3 & $\mathrm{X}$ & & & & \\
\hline cm4 & $\mathrm{X}$ & & & & \\
\hline echam4 & $\mathrm{X}$ & & & & \\
\hline echam5 & & & & $\mathrm{X}$ & \\
\hline echog & $\mathrm{X}$ & $\mathrm{X}$ & $\mathrm{X}$ & & \\
\hline $\mathrm{fgoals}$ & & & $\mathrm{X}$ & & \\
\hline hires & $\mathrm{X}$ & & & & \\
\hline medres & & $\mathrm{X}$ & $\mathrm{X}$ & & \\
\hline mk30 & & & & & \\
\hline mk35 & & & & & \\
\hline modeler & & & & \\
\hline
\end{tabular}

\subsubsection{Bias Removal}

To do the regression based daily analysis between TMY and climate data, the climate model data are bias corrected. The bias correction methodology is as follows:

1. Create monthly means and standard deviations of $T_{\max }$ and $T_{\min }$ for both TMY and the individual climate models for the current climate.

2. Use the mean difference between TMY and individual climate models for Now, and TMY standard deviation to generate a probability density function (PDF) from which random numbers would be drawn to serve as correction factors. These correction factors were then applied to climate model daily $T_{\max }$ and $T_{\min }$ for Now and saved.

3. Assume that if the climate forecast produces bias in Now, then the same modeling bias will exist in Future forecasted values, the saved correction factors were then applied to the future climate daily $T_{\max }$ and $T_{\min }$. 
Figure 4 shows an example of the bias corrected climate model temperature outputs for Now (red) and Future (blue). The temperature trends summarized from the 26 climate simulations are for Portland, OR. Our analysis shows that the median of $T_{\max }$ will increase in all months in the future, with the biggest increases occurring in August through October.

Note that some of the maxima and minima produced by this methodology are quite extreme but rare. For example, Portland does not have record $T_{\max }$ near $50{ }^{\circ} \mathrm{C}$ in August, but some models will produce such values, as show in Figure 4. However, the methodology produces climate model monthly means and standard deviations that agree much better with TMY data (on the order of 1 to $2{ }^{\circ} \mathrm{C}$ ) for the current climate.

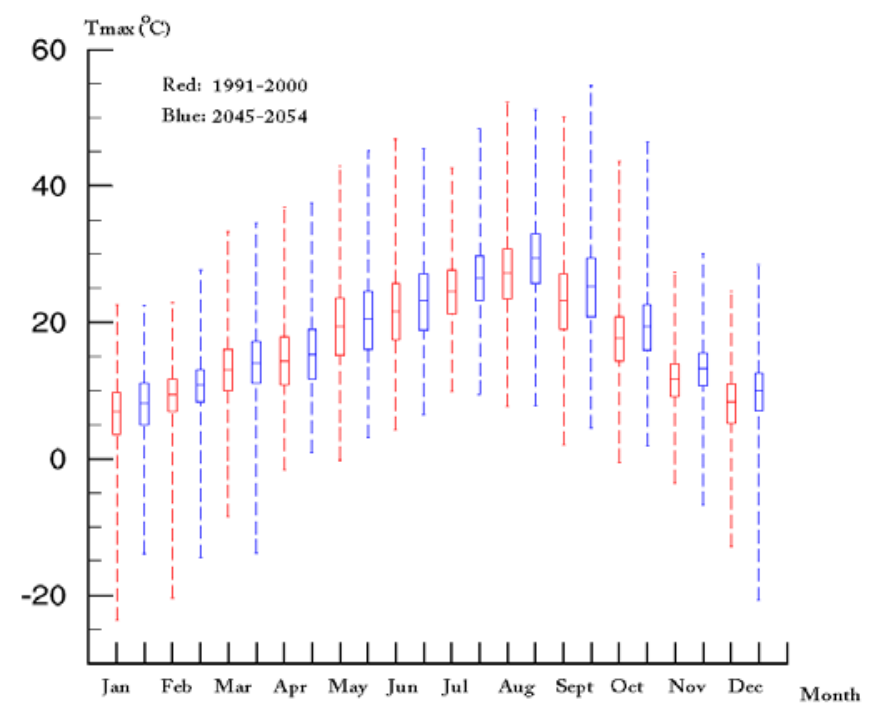

Figure 4: The monthly $T_{\max }$ of Portland area: Now (1991 - 2000) versus Future (2045 - 2054)

\subsection{DOE Building Simulations}

The DOE-2.2 program is used to simulate building electric energy end-use. DOE-2 uses a description of the building layout, construction, usage, conditioning systems (lighting, HVAC, etc.) and utility rates provided by the user, along with weather data, to perform an hourly simulation of the building and to estimate utility bills. A detailed description of the software and its functionality can be found in DOE-2 website (Hirsch 1999). The commercial building prototypes are from the Database for Energy Efficient Resources (DEER). The DOE-2 model uses building prototypes and measures characterization information by building type, vintage, and climate zone in its estimation of measure savings.

\subsubsection{Building Prototypes (Hirsch 1999)}

There are 23 commercial and 3 residential prototypes included in the DEER analysis software. Prototype characteristics are fully described in the 2004-2005 DEER Update Study Final Report.

1. Assembly,

2. Education - Primary School,

3. Education - Secondary School,

4. Education-Community College,

5. Education - University,

6. Education - Relocatable Classroom, 

7. Grocery,
8. Health/Medical - Hospital,
9. Health/Medical - Nursing Home,
10. Lodging - Hotel,
11. Lodging - Motel,
12. Manufacturing - Bio/Tech,
13. Manufacturing - Light Industrial,
14. Office - Large,
15. Office - Small,
16. Restaurant - Sit-Down,
17. Restaurant - Fast-Food,
18. Retail - three-Story Large,
19. Retail - Single-Story Large,
20. Retail - Small,
21. Storage - Conditioned,
22. Storage - Unconditioned, and
23. Storage - Refrigerated Warehouse.
24. Single Family Home,
25. Multi-Family Housing, and
26. Manufactured Home.

\subsubsection{Vintages}

Each prototype's characteristics also varies by the following vintages and 16 California climate zones.
1. Before 1978,
2. $1978-1992$,
3. $1993-2001$,
4. $2002-2005$,
5. After 2005.

\subsubsection{End-uses}

In this study, these 23 commercial building prototypes and 5 vintages are first simulated using DEER analysis program in one climate zone (Los Angeles Area, CZ06). Then these $115(23 * 5)$ buildings are simulated using DOE-2.2 at all the climate locations selected for this study. The results of the simulation are building energy enduses including

1. Lighting,

2. Task lighting,

3. Miscellaneous equipment,

4. Space heating,

5. Space cooling,

6. Heat rejection,

7. Pump auxiliary,

8. Ventilation fan,

9. Refrigeration,

10. Supplemental heat pump ,

11. Domestic hot water. 


\subsubsection{Climate Zones}

A total of 78 climate locations are selected for the simulation to cover the WECC region. As a first stage study, the following 10 cities are selected to conduct the research: the Vancouver, Portland, Calgary, San Francisco, Salt Lake, Sacramento, Los Angeles, Phoenix, Boulder, and Billings, as shown in the highlighted cities in Figure 5 and Table 4.

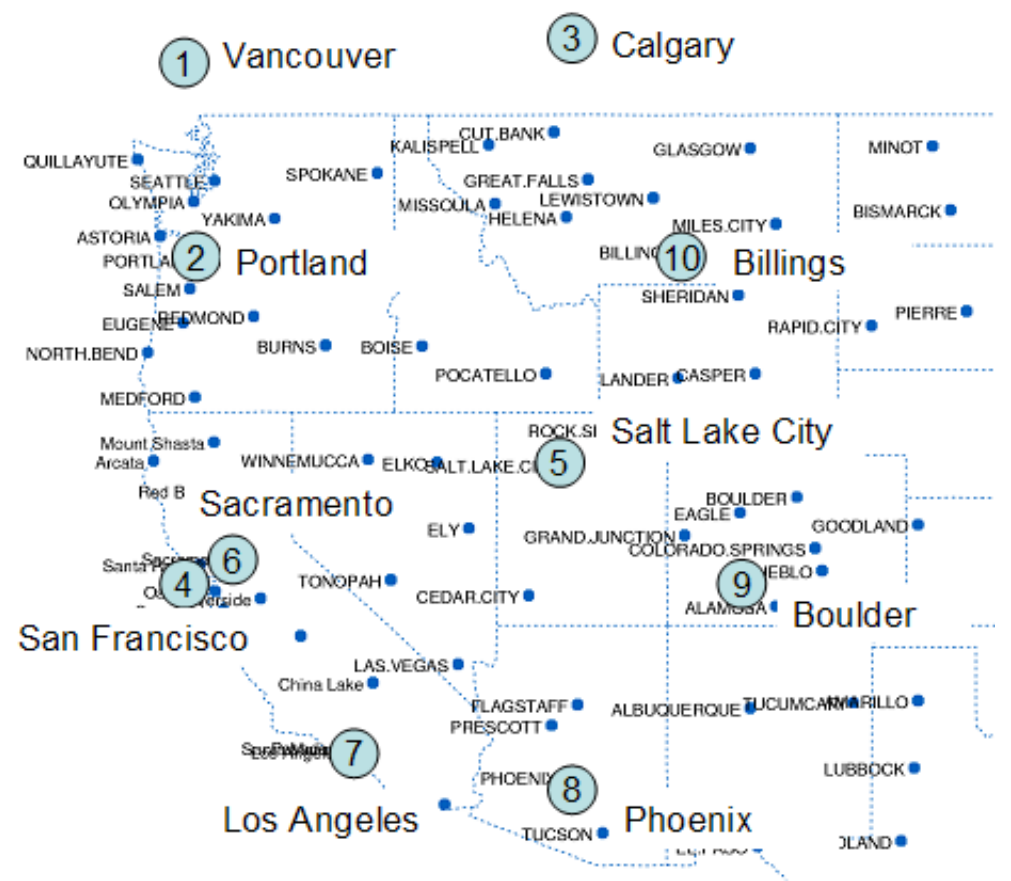

Figure 5: A map of the geographical location of the 78 climate zones in the Western United States and Canada 
Table 4: The Climate Zones

\begin{tabular}{|c|c|c|c|}
\hline \multirow[t]{4}{*}{$\mathrm{AZ}$} & Flagstaff & OR & Astoria \\
\hline & Phoenix & & Burns \\
\hline & Prescott & & Eugene \\
\hline & Tucson & & Medford \\
\hline \multirow[t]{16}{*}{ CA } & Arcata Area (CZ01) & & North \\
\hline & Blythe Area (CZ15) & & Pendleton \\
\hline & China Lake Area (CZ14) & & Portland \\
\hline & El Toro Area (CZ08) & & Redmond \\
\hline & Fresno Area (CZ13) & & Salem \\
\hline & Los Angeles Area (CZ06) & SD & Pierre \\
\hline & $\begin{array}{l}\text { Mount Shasta Area } \\
\text { (CZ16) }\end{array}$ & & Rapid \\
\hline & Oakland Area (CZ03) & $\mathrm{TX}$ & Amarillo \\
\hline & Pasadena Area (CZ09) & & El \\
\hline & Red Bluff Area (CZ11) & & Lubbock \\
\hline & Sacramento Area (CZ12) & & Midland \\
\hline & $\begin{array}{l}\text { San Bernardino Area } \\
\text { (CZ10) }\end{array}$ & UT & Cedar \\
\hline & San Diego Area (CZ07) & & Salt Lake \\
\hline & Santa Maria Area (CZ05) & WA & Olympia \\
\hline & Santa Rosa Area (CZ02) & & Quillayute \\
\hline & Sunnyvale Area (CZ04) & & Seattle-Tacoma \\
\hline \multirow[t]{6}{*}{$\mathrm{CO}$} & Alamosa & & Spokane \\
\hline & Boulder & & Yakima \\
\hline & Colorado & WY & Casper \\
\hline & Eagle & & Cheyenne \\
\hline & Grand & & Lander \\
\hline & Pueblo & & Rock \\
\hline \multirow[t]{2}{*}{ ID } & Boise & & Sheridan \\
\hline & Pocatello & CANADA & Calgary \\
\hline KS & Goodland & & Vancouver \\
\hline \multirow[t]{9}{*}{ MT } & Billings & ND & Bismarck \\
\hline & Cut & & Minot \\
\hline & Glasgow & NM & Albuquerque \\
\hline & Great & & Tucumcari \\
\hline & Helena & $\mathrm{NV}$ & Elko \\
\hline & Kalispell & & Ely \\
\hline & Lewistown & & Las \\
\hline & Miles & & Reno \\
\hline & Missoula & & Tonopah \\
\hline $\mathrm{NE}$ & Scottsbluff & & Winnemucca \\
\hline
\end{tabular}




\subsubsection{Weather Data in DOE-2.1E (Buhl 1999)}

The loads and HVAC simulations in DOE-2 require hourly weather data, which are contained in DOE-2 weather files. These weather files are created from source hourly data by the DOE-2 weather processor program doewth. The weather variables are listed below.

\subsubsection{Hourly Variables}

The DOE-2 weather file contains hourly data for 1 year (8760 hours). Leap years are ignored and all DOE-2 weather files are 365 days long. The hourly data on the weather files are:

- Dry-bulb temperature $\left({ }^{\circ} \mathrm{F}\right)$

- Wet-bulb temperature $\left({ }^{\circ} \mathrm{F}\right)$

- Atmospheric pressure (inches of Hg times 100)

- Wind speed (knots)

- Wind direction (compass points $0-15$, with 0 being north, 1 NNE, etc.)

- Cloud amount ( 0 to 10 , with $0=$ clear and $10=$ totally overcast)

- $\quad$ Cloud type $(0,1$, or 2$) 0$ is cirrus or cirrostratus, the least opaque;

-- 1 is stratus or stratus fractus, the most opaque; and

-- 2 is all other cloud types, of medium opacity

- Humidity ratio (lb of water per lb of dry air)

- Density of the air $\left(\mathrm{lb} / \mathrm{ft}^{3}\right)$

- Specific enthalpy of the air (Btu/lb)

- Rain flag (0 means it is not raining; 1 means it is)

- Snow flag (0 means it is not snowing; 1 means it is).

\subsubsection{Hourly Solar Variables}

There are two types of DOE-2 weather files: those with hourly solar values and those without. In the case of the files without solar data, DOE-2 calculates solar values using the American Society of Heating, Refrigerating, and Air-Conditioning Engineers (ASHRAE) clear sky model and the clearness numbers, cloud amounts, and cloud types from the DOE-2 weather file. The solar DOE-2 weather files contain the following hourly values:

- Total horizontal solar radiation (Btu/hr- $\left.\mathrm{ft}^{2}\right)$

- Direct normal solar radiation $\left(\mathrm{Btu} / \mathrm{hr}-\mathrm{ft}^{2}\right)$.

\subsubsection{Monthly Variables}

- Clearness number (dimensionless)

- Ground temperature (Rankin).

\subsubsection{Source Data and Data Format}

There are two primary sources of meteorological data used in the building energy simulation program DOE-2 - historical data and typical weather year (http://gundog.lbl.gov/dirun/2001weath.pdf). Historical data are measured or sometimes modeled data for a particular location for a given period of time. Typical 
years are ersatz years assembled to match the historical data using a particular statistical measure. The use of typical year (TMY) data is preferred to study building energy consumption and peak load because they represent actual weather sequences. We used the Typical Meteorological Year version 2 (TMY2) derived from the SAMSON database by the National Renewable Energy Laboratory.

\subsection{Building Level Impact Study}

The DOE-2 simulation yields hourly building energy consumption by end use for a whole year using a TMY weather tape. From the $24 \times 365$ data points for each city, temperature sensitivities for 26 building types, 5 building vintages, and 2 day types are derived. Three-segment polynomial curve-fitting techniques have been used to derive the energy, peak-load, and load-composition temperature sensitivity curves. Three second-degree polynomials have been used to fit each segment. Three day types are considered: weekday, weekend, and holidays. The following sections will discuss the process in details.

\subsubsection{The Characteristics of Temperature Correlation Curves}

As discussed above, the TMY2 weather data are used to develop the building weather sensitivity curve serving as a baseline energy consumption bench mark for each climate zone. As an example, the load weather sensitivity curves of each of the 23 modeling commercial building prototypes in the Portland area have been shown in Figure 6 through Figure 15. Please note that the blue-dot data points are weekends and the red-plus data points are weekdays. The Holidays have been excluded from the data samples.
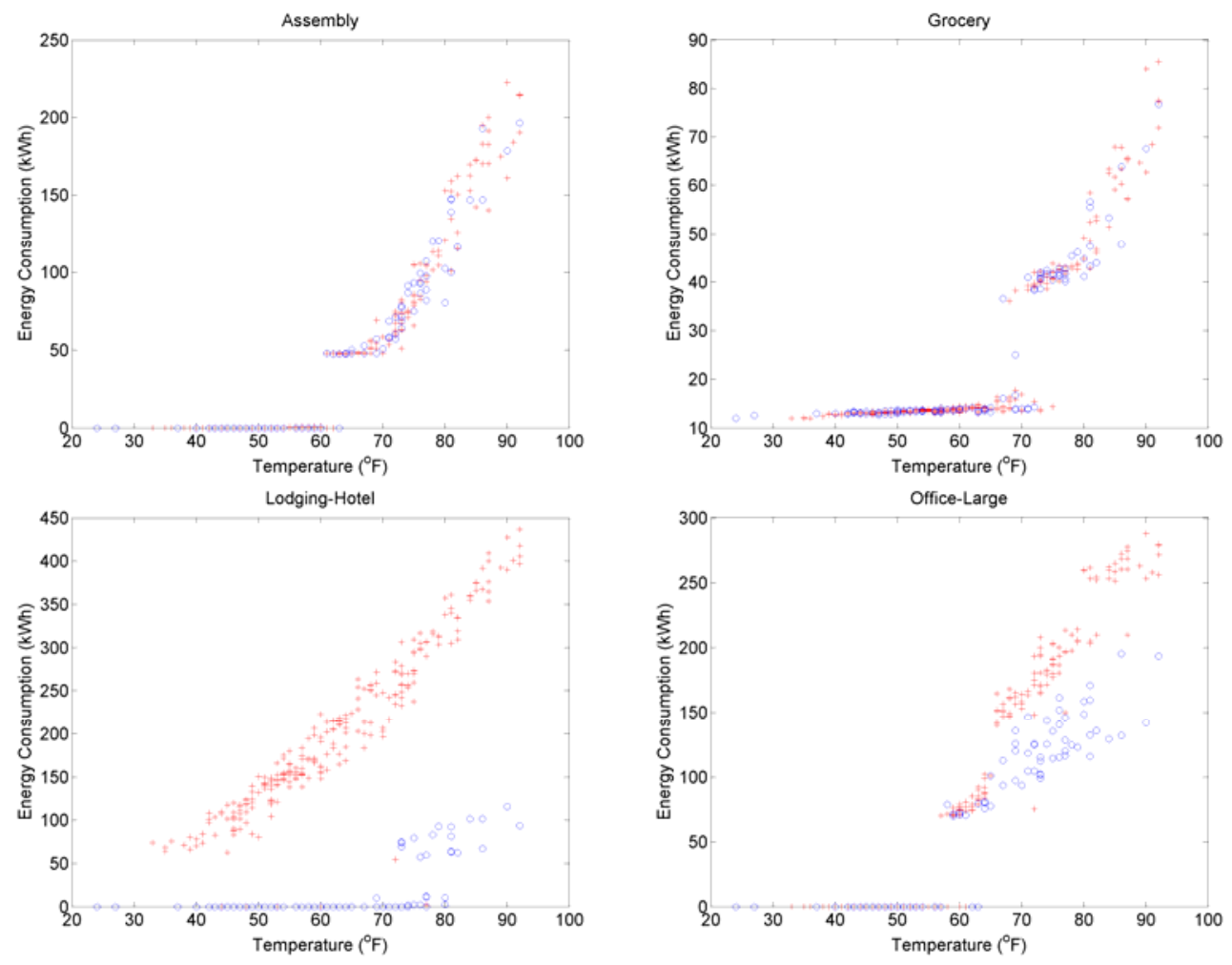

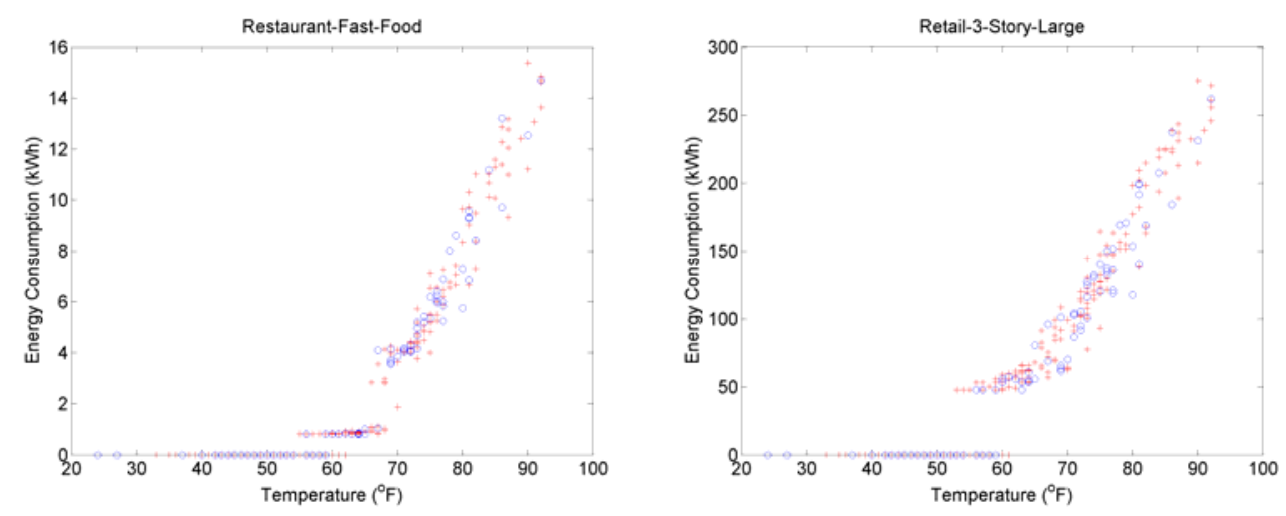

Figure 6: The temperature sensitivity of the cooling load of six typical commercial buildings in the Portland area
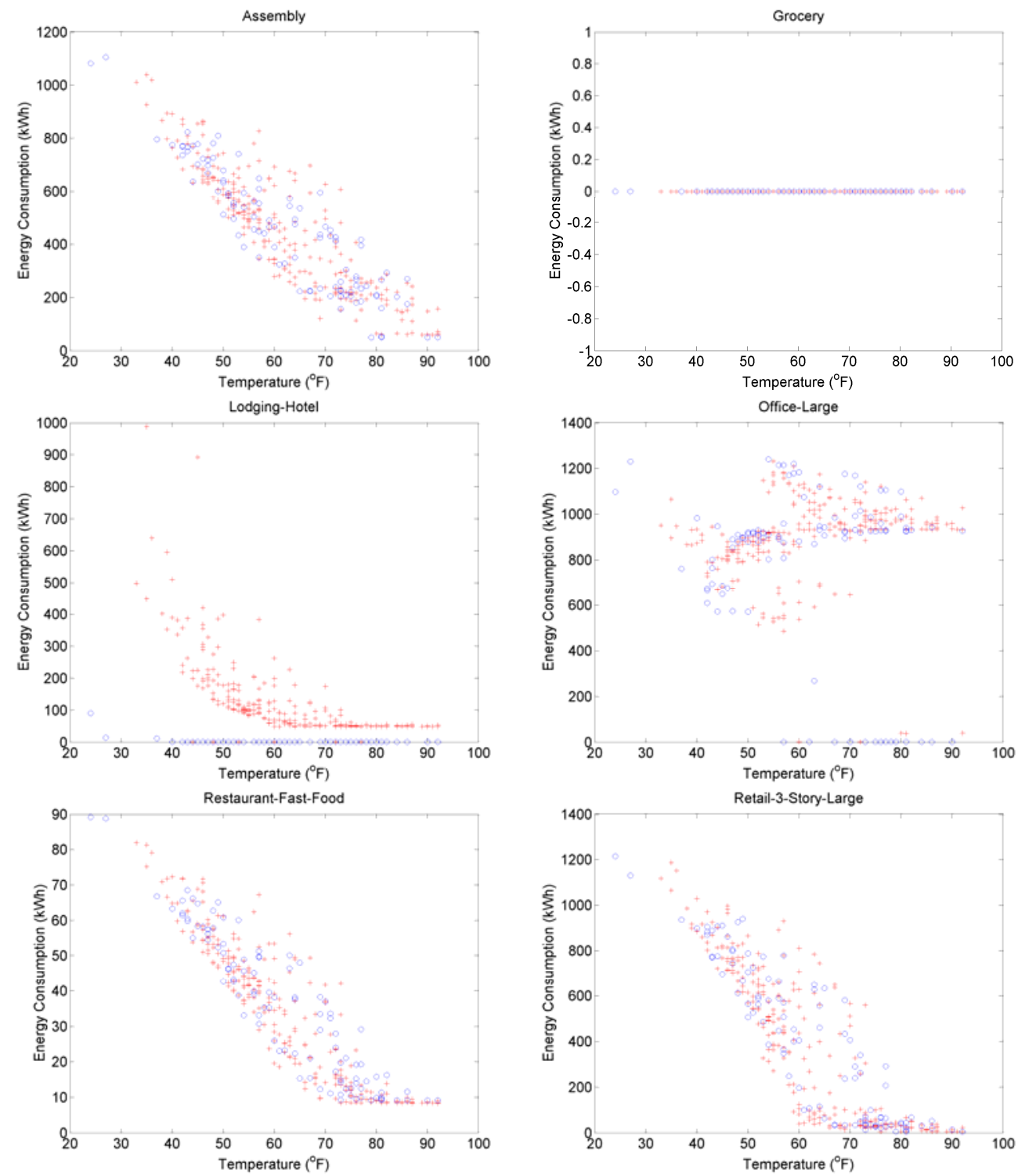

Figure 7: The temperature sensitivity of the heating load of six typical commercial buildings in the Portland area 

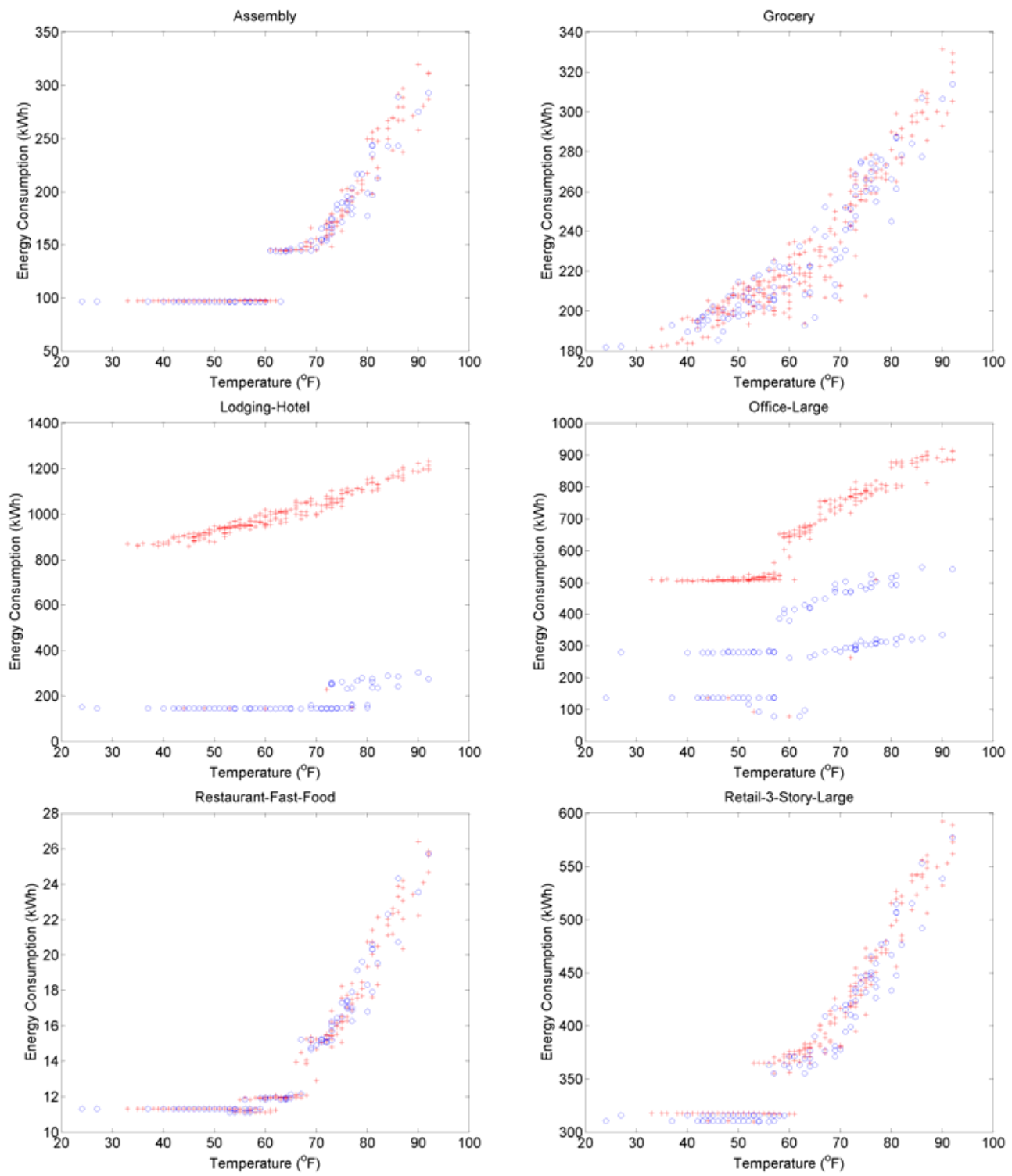

Figure 8: The temperature sensitivity of the total building load of the 23 commercial buildings in the Portland area

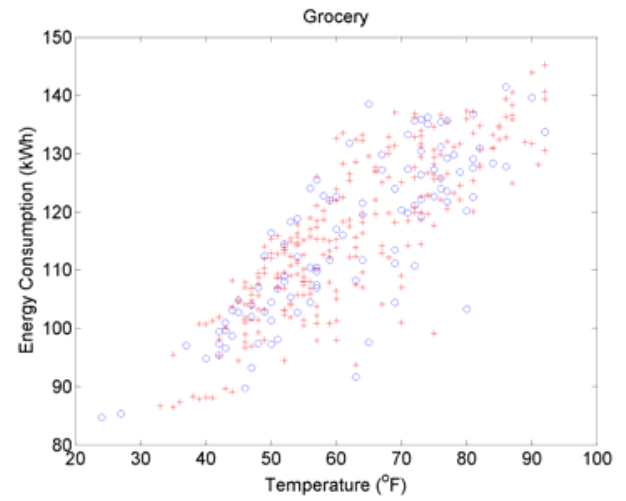

Figure 9: The temperature sensitivity of the refrigeration load of the grocery buildings in the Portland area 


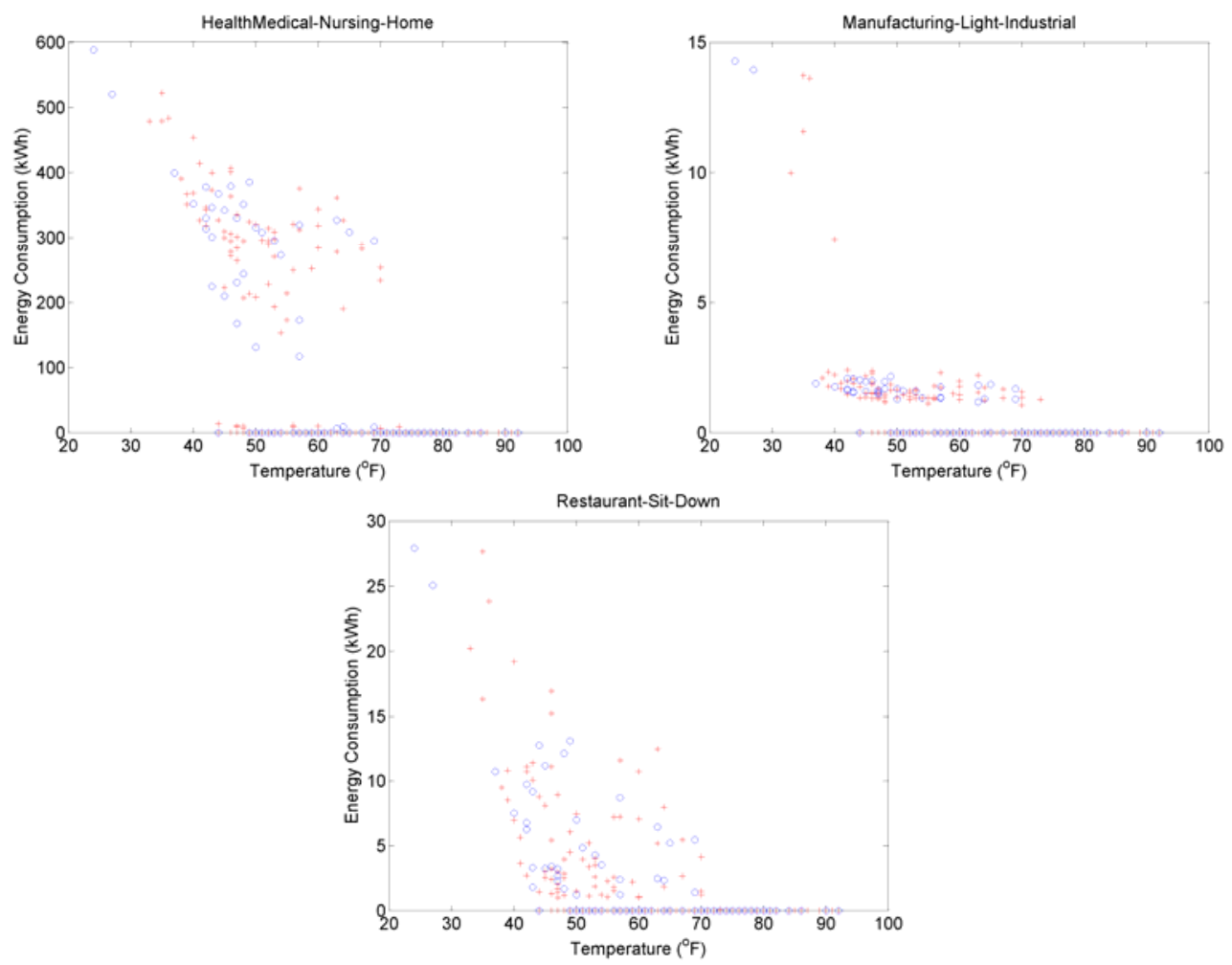

Figure 10: The temperature sensitivity of the supplemental load of in the Portland area

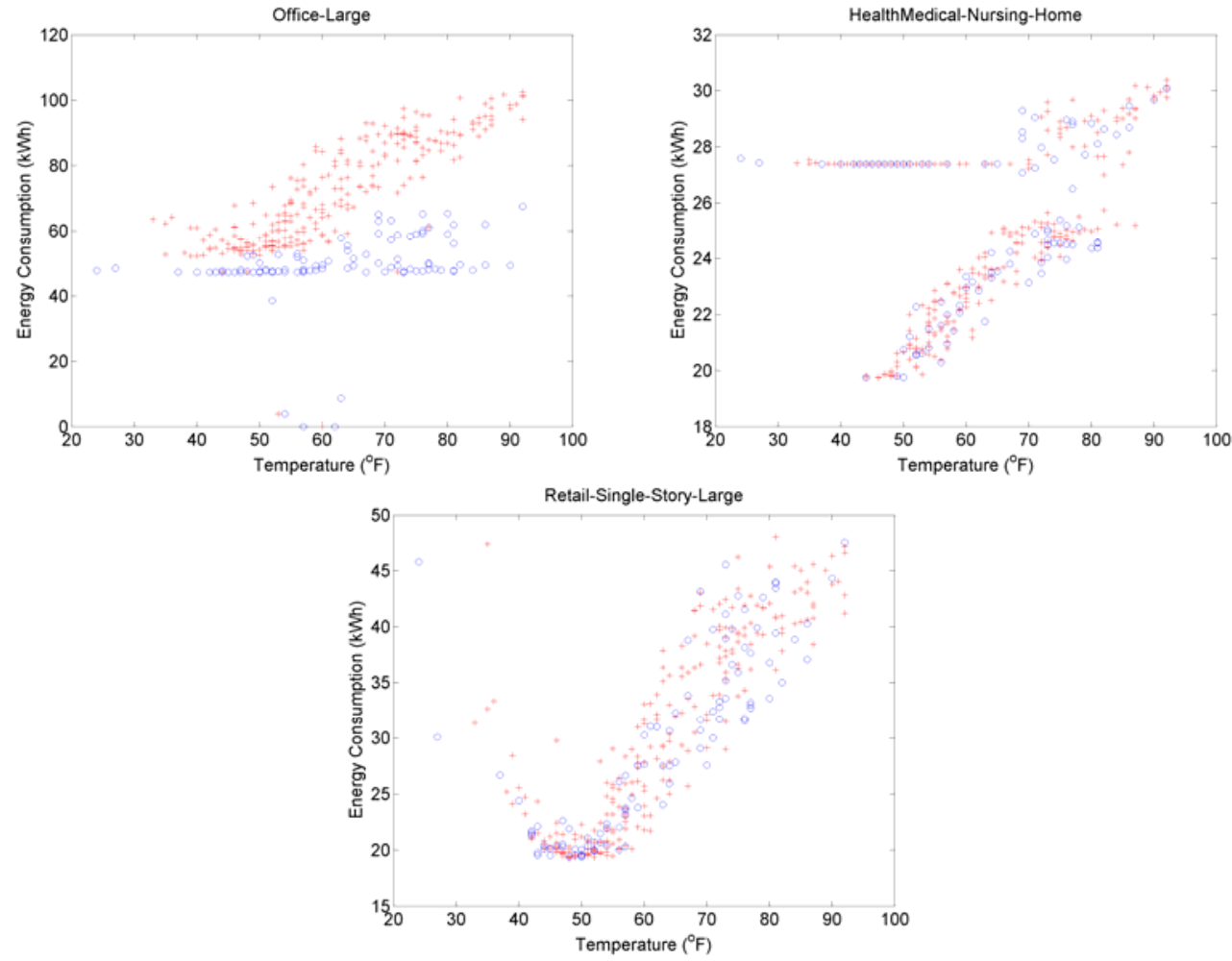

Figure 11: The temperature sensitivity of the ventilation load in the Portland area 

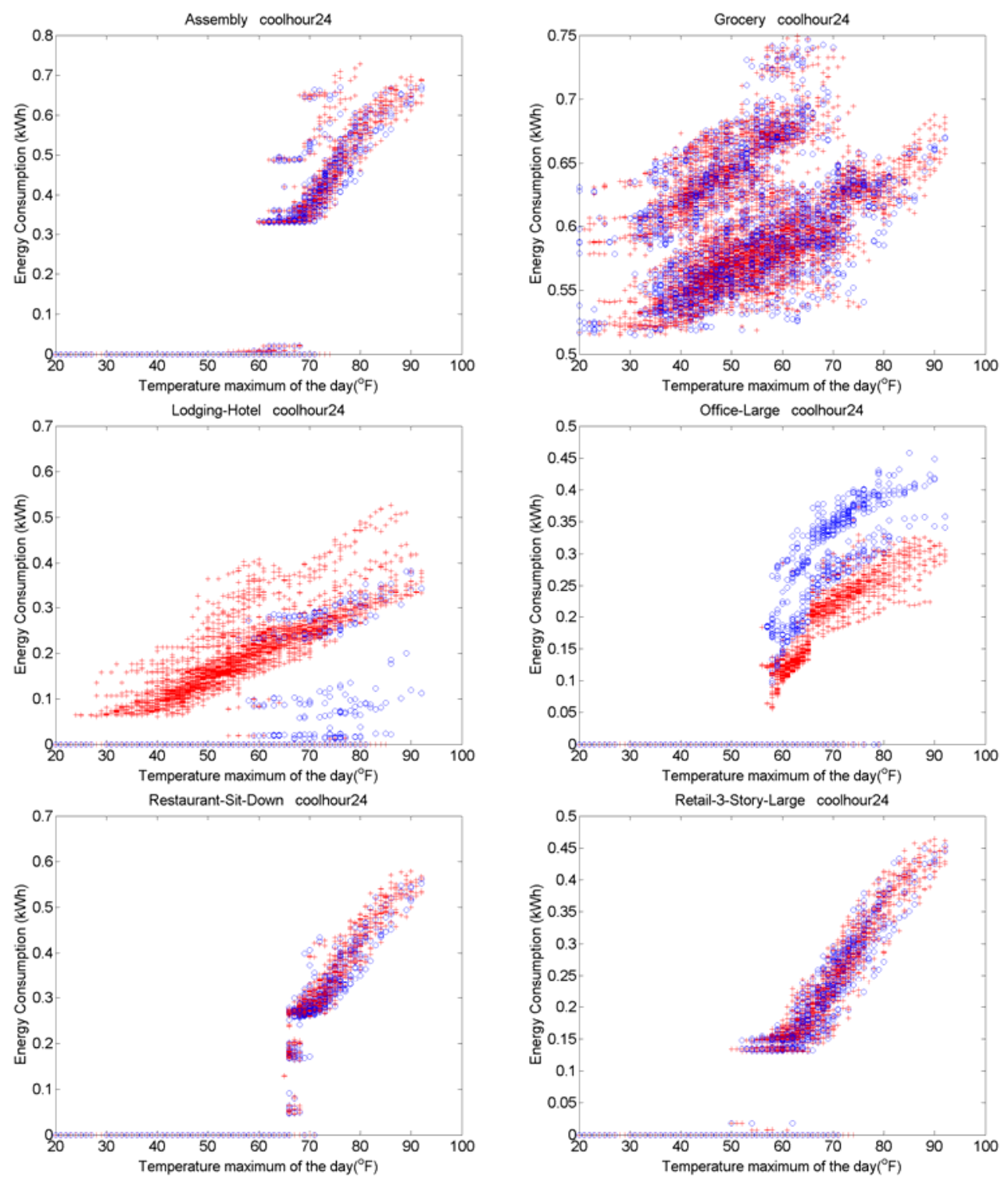

Figure 12: The temperature sensitivity of the cooling and refrigeration load composition in Portland area
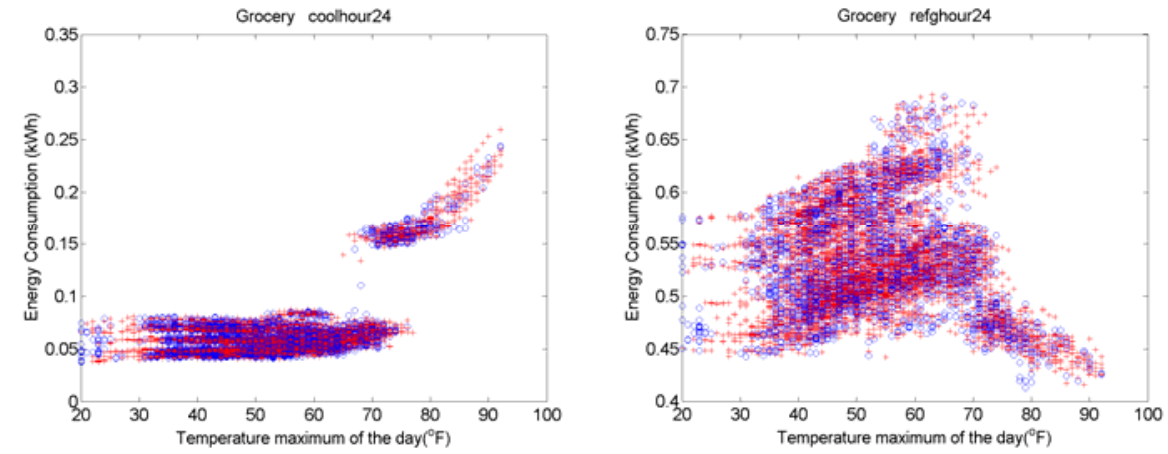

Figure 13: The temperature sensitivity of the refrigeration load and cooling load composition of grocery stores in the Portland area 

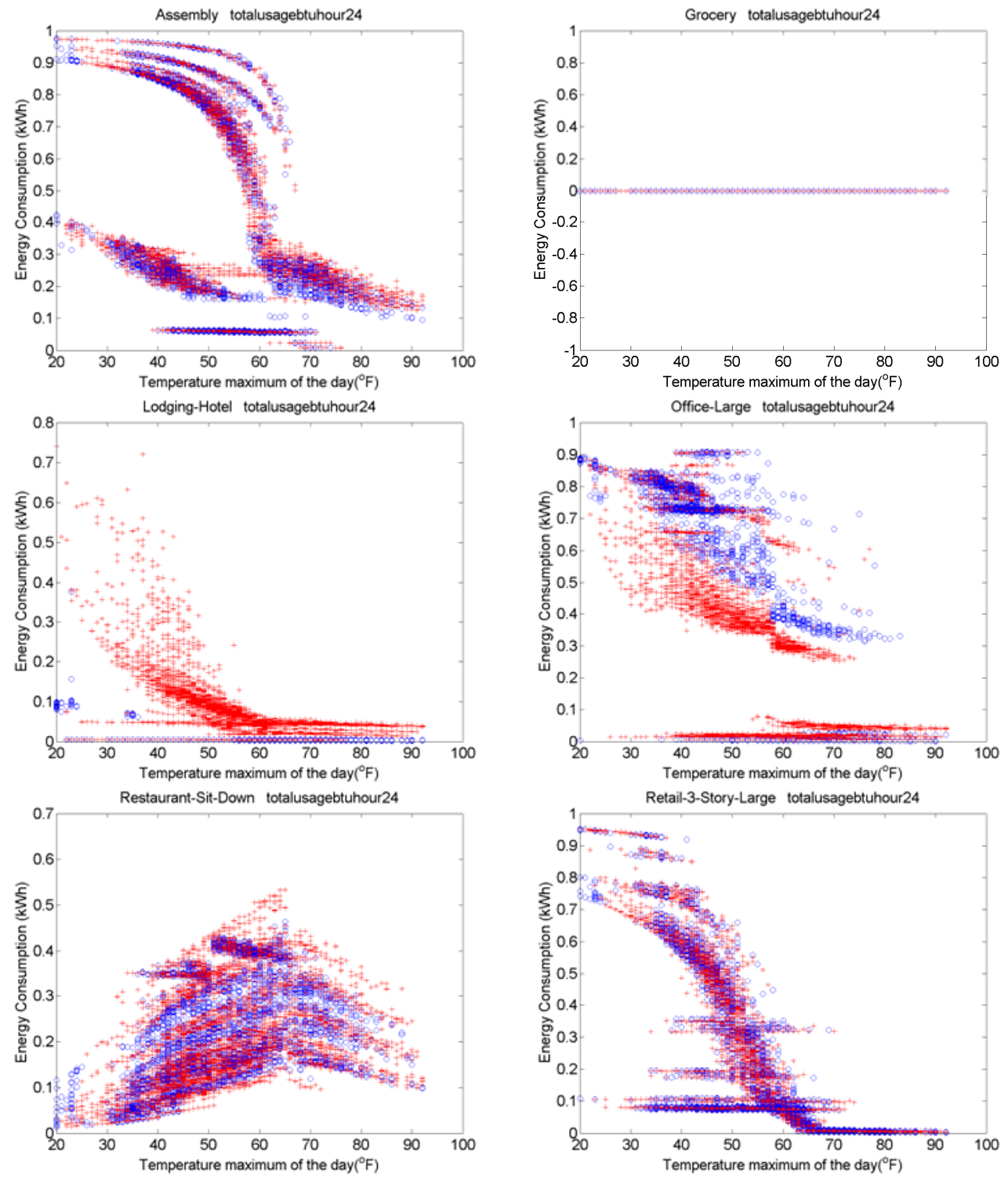

Figure 14: The temperature sensitivity of the heating load composition in the Portland area

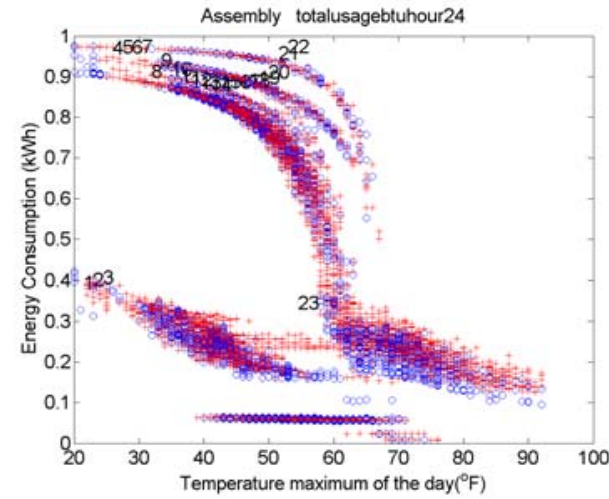

Figure 15: The temperature sensitivity of the heating load composition in the Portland area with respect to time of the day 
From the above results, there are several observations:

- As shown in the base case simulation, Figure 6 through Figure 8, which were derived by using the TMY2 data set as the input weather tape, the dominant building weather sensitive loads are the heating and cooling loads.

- Because refrigeration loads are usually indoors with an almost constant room temperature all year round, the refrigeration loads are not sensitive to outdoor temperature changes. Only for the grocery stores, where in the DOE-2 simulation the refrigeration load are simulated as independent cooling units, the refrigeration load shows weather sensitivity, as shown in Figure 9. Lighting and task lighting loads are insensitive to temperature variations.

- Supplemental (emergency) heating units only turn on when the primary heat pump system can not provide enough heating. As shown in Figure 10, the temperature sensitivity of supplemental heating units is more prominent for estimation of energy use for nursing homes. For other types of commercial buildings, it is only a small portion of energy use and can be ignored.

- As shown in Figure 11, ventilation shows some temperature sensitivities; however, the power consumption is not significant compared with the heating and cooling loads. Also, the ventilation loads usually are related with the control settings of the HVAC system. When set at fixed schedule, the ventilation loads are insensitive to temperature.

- The correlation of the load to temperature is generally good except for buildings within the education category because of the variation caused by the spring, winter, and summer breaks.

- The load composition is another factor that is highly associated with temperature change, as well as the time of the day. In distribution systems, a higher percentage of a/c compressor motor type load can cause slow voltage recovery phenomena when voltage sag happens. Because shown in Figure 12, cooling load increases significantly when temperature rises above $85^{\circ} \mathrm{F}$. As the refrigeration load and cooling load have been modeled separated in DOE2 for grocery stores, we showed in Figure 13 separate plots for the load composition for cooling and refrigeration loads. From the plot, the refrigeration load scattered around a wider range. This is because the setting of it is changing with respect to the time of the day.

- Figure 14 shows the heating load composition with respect to total load (the gas heating load plus the total electrical load of a building). Even at the same temperature, depending on at which hour of the day, the heating load may require a different percentage of the total load. To describe it, in Figure 15, we plot out the assembly building heating load composition. Hour 23, 1, 2, and 3 have similar load composition plots, and the rest of the hours have similar load composition plots. This clearly shows the relationship of load composition with respect to heating load schedule.

- Because of schedule differences, the energy consumption of the weekdays, weekends, and holidays is different. Therefore, we derived three sets of curves cover the three day types: Weekday, Weekend, and Holiday. Note that Holiday includes 10 national holidays and Sundays plus a few special occasions. 


\subsubsection{Building Temperature Sensitivity Curve Derivation}

The DOE-2 simulation yields hourly building energy consumption by end use for a whole year using a TMY weather tape. From the $24 \times 365$ data points for each city, temperature sensitivities for 26 building types, 5 building vintages, and 2 day types are derived. A few observations are noteworthy from the simulation results:

- Geographical location: Figure 16 and Figure 17 show that, in general, for the seven inland cities, the peak hourly electricity usage correlates well with temperature. However, for the coastal cities in California, because of the marine influence (e.g., cloudiness), the temperature-building energy consumption correlations are not well established, as evidenced by the larger scattering of the data points. Therefore, it is important to separate the California coastal areas when deriving the sensitivity curves using temperature as the only meteorological input.

- Day types: Figure 18 shows the temperature sensitivity of building hourly energy consumption with respect to day types (i.e., weekday, weekend, and holiday). For most commercial buildings, the energy consumption on weekdays is much higher than on weekends. For educational buildings, such as universities and schools, holidays also result in a different sensitivity curve.

- Vintages: Figure 19 shows the influence of the five different building vintages. The results show that by using newer energy-saving technology for cooling/heating devices and using better insulation materials, the building energy spending can be greatly reduced to mitigate the impacts brought by the temperature increases.

- Load composition: Figure 20 shows an example of the load composition temperature sensitivities for a weekday at hour 15 . The cooling load increases significantly in building total load consumption. Our studies have shown that the cooling load compositions are well correlated with the temperature changes.

- Three-segment polynomial curve-fitting techniques have been used to derive the energy, peak-load, and load-composition temperature sensitivity curves. Three second-degree polynomials have been used to fit each segment. Three day types are considered: weekday, weekend, and holidays. An example of the fitted curves (green lines) has been shown in Figure 18 and Figure 20. 


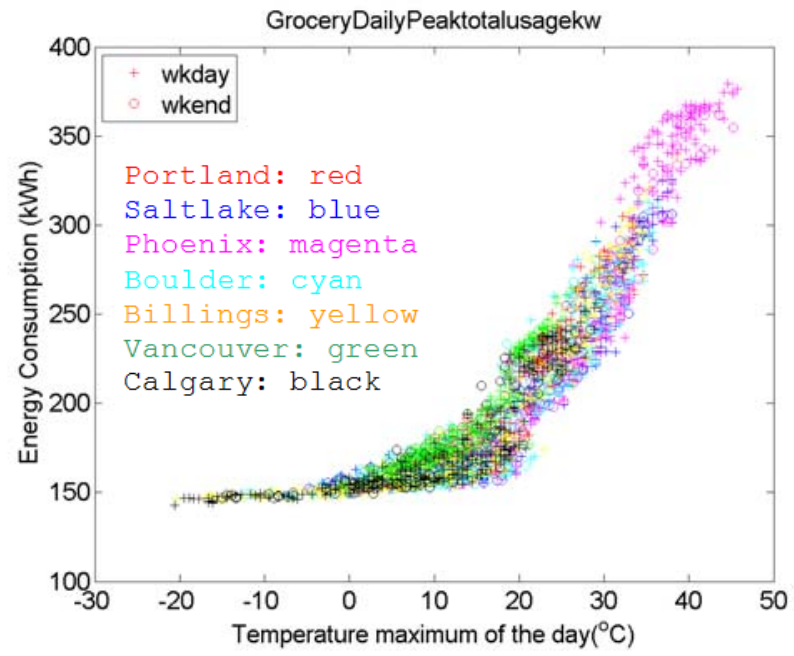

Figure 16: The temperature sensitivity of the building peak load for Portland, Salt Lake City, Phoenix, Boulder, Billings, Vancouver, and Calgary

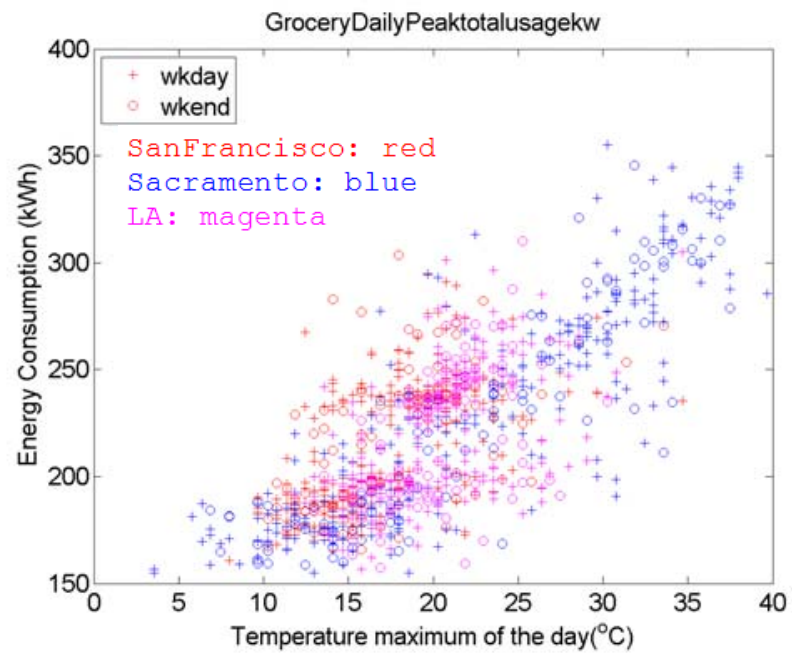

Figure 17: The temperature sensitivity of the building peak load for San Francisco, Los Angeles, and Sacramento Education-Primary-School -- $P_{\text {peak }}$

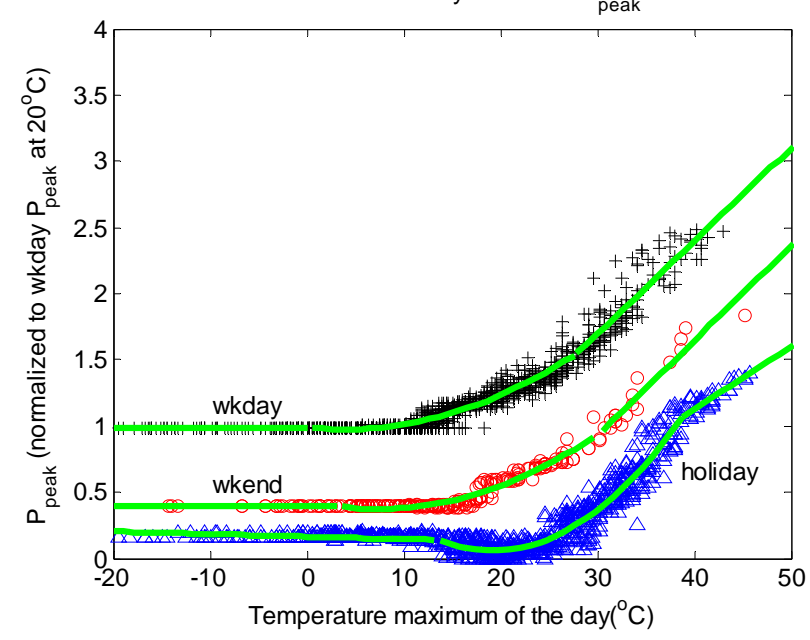


Figure 18: The influence of the type of day on the building peak load (Building vintage: post 2005)

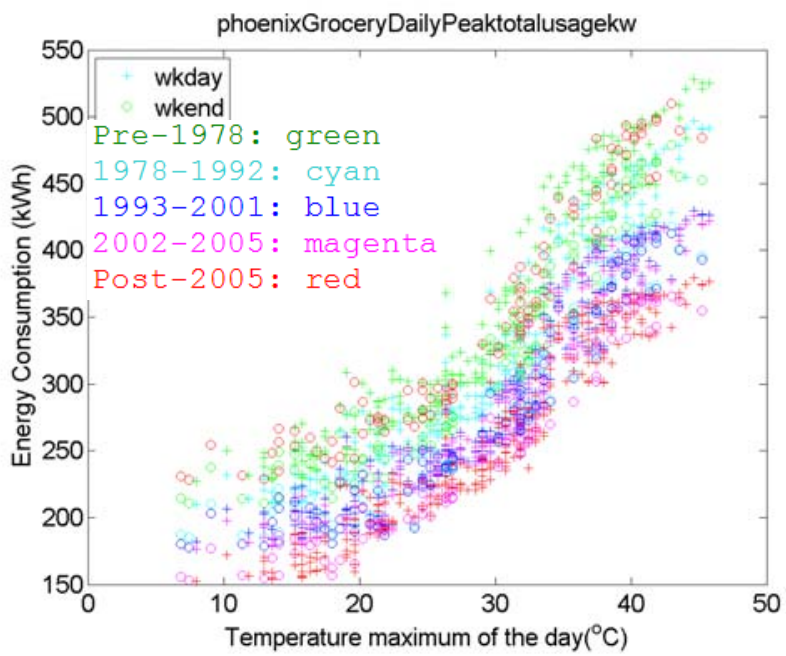

Figure 19: The influence of building vintages on the building peak load

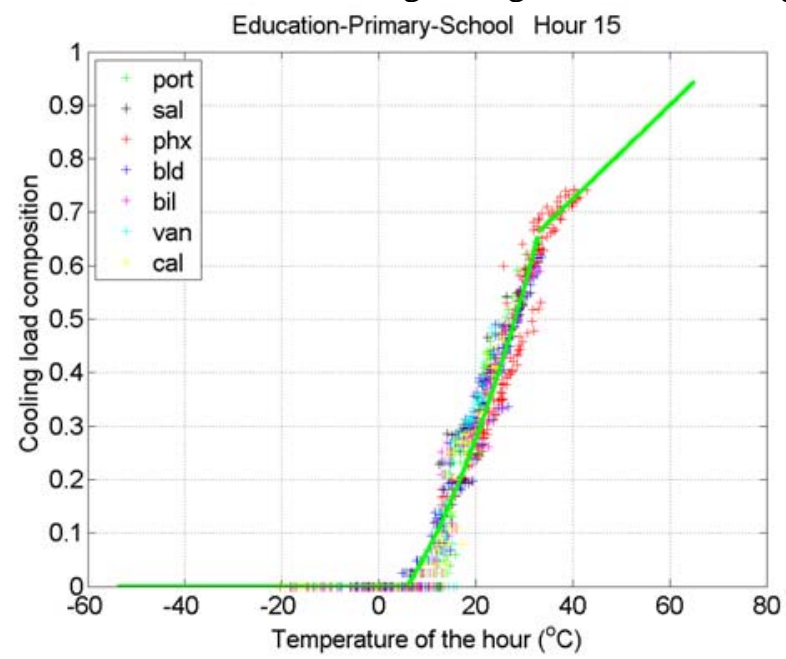

Figure 20: The temperature sensitivity of the cooling load composition in Portland, Salt Lake City, Phoenix, Boulder, Billings, Vancouver, and Calgary

\subsubsection{Modeling Results for Portland and Phoenix}

The bias-corrected IPCC modeling results of year 1991-2000 represent the temperature profile for period Now. For each day in a year within this period, there are $260 T_{\max }$ and $T_{\min }$. The 260 data points are bias corrected using TMY data. The bias-corrected IPCC modeling results of year 2045-2054 represent the temperature profiles for the period Future. Building level energy consumption is then calculated using these temperature profiles as inputs.

The following assumptions are made to produce the baseline result for future building energy consumption: 
- Assume that the $260 T_{\max }$ and $T_{\min }$ predicted for a specific day in a year by the 26 IPCC climate models for a 10 year span are treated equally, i.e, they have equally likely chance of occurrence.

- For the base Future case, no new technology and no new policy are implemented. Everything stays the same for the building simulated over the next 50-year period.

- Heating loads are supplied by natural gas in DOE-2 model and in the unit of btu. At this stage, we only study the influence of the cooling loads because it is the cooling load that put stress on the power system when average temperatures in each region are increased.

- The percentage changes are calculated by the following formula: $k_{a v e}^{E}=\frac{E_{a v e}^{f}-E_{a v e}^{n}}{E_{a v e}^{n}}$

- where $E_{a v e}^{n}$ is the monthly average consumption of the year $1991-2000 ; E_{a v e}^{f}$ is the monthly average consumption of the year 2045 - 2054 for all the 260 model produced monthly energy consumptions. 
Table 5 and Table 6 presents the average and extreme case of the building energy consumption increase based on IPCC predicted temperature profiles for 2050. The brown shaded area represents increases more than $10 \%$ but less than $30 \%$. The red shaded areas show increases more than $30 \%$. The comparisons are made towards the Now average for both the Future average and extreme, a comparison of the Now extreme and Future extreme is also provided in Table 7.

A few observations:

- Residential buildings see more increases because a/c load consists of a large percent of total building loads.

- Phoenix sees more increase than Portland. However, as shown in Figure 21, Portland will experience more load increase in summer months, while Phoenix will experience more load increase in spring and autumns. This is because in Phoenix, the summer is already very hot now, in the future, the hotter days will extend to the spring and autumn months. In Portland, where a mild summer is usually expected, one will see more hot days.

- During winter, energy consumption may drop because of a projected drop of heating load.

- Because summers are going to be hotter, the a/c penetration in the Portland area will increase in the future.

- The total building energy consumption for Portland area experiences a very small increase because of the decrease of winter load and the mild increase of summer load for an average year. 
Table 5: The forecasted average increase of the monthly and yearly building total load consumption (Phoenix and Portland)

\begin{tabular}{|c|c|c|c|c|c|c|c|c|c|c|c|c|c|c|}
\hline Phoenix & & Jan & Feb & Mar & Apr & May & Jun & Jul & Aug & Sep & Oct & Nov & Dec & Total \\
\hline \multirow{23}{*}{ commercial } & Assembly & 8.1 & 11.1 & 13 & 14.4 & 12.2 & 9.2 & 5.9 & 10 & 14.8 & 18.1 & 14.2 & 8.5 & 11.4 \\
\hline & EduCommcoll & 2.9 & 4.8 & 4.5 & 4 & 3.6 & 8.4 & 2.8 & 2.6 & 3.4 & 5.8 & 5 & 5.5 & 4.3 \\
\hline & EduPrimary & 3.4 & 8.9 & 9.9 & 10.1 & 9 & 10.2 & 13.6 & 8.5 & 10.3 & 14.4 & 12 & 7.3 & 10.1 \\
\hline & EduReloc & 4 & 9.9 & 9.4 & 10.2 & 9.3 & 10.1 & 12.3 & 10 & 11.5 & 14 & 11.1 & 7.8 & 10.3 \\
\hline & EduSecondary & 4.6 & 9.9 & 11.3 & 11.7 & 9.6 & 9.5 & 11.2 & 7.9 & 10.1 & 15.7 & 13.6 & 8.9 & 10.4 \\
\hline & EduUniversity & 2.5 & 3.1 & 2.7 & 2.6 & 2.4 & 4.5 & 2.1 & 2 & 2.1 & 3.2 & 3.6 & 4.4 & 2.8 \\
\hline & Grocery & 1.6 & 2.8 & 3.7 & 4.6 & 4 & 3 & 2.4 & 3.7 & 4.8 & 5.8 & 3.9 & 1.8 & 3.6 \\
\hline & Hospital & 2.2 & 3 & 2.7 & 2.8 & 2.3 & 2 & 1 & 2 & 2.7 & 3.5 & 3.1 & 2.4 & 2.4 \\
\hline & Hotel & 0.9 & 1 & 4.2 & 5.7 & 5.3 & 4.9 & 3.7 & 5.7 & 6.6 & 7 & 4.5 & -0.1 & 4.4 \\
\hline & MfrBiotech & 0.6 & 3.8 & 3.8 & 3.5 & 4 & 5.6 & 1 & 4.6 & 3.1 & 5.8 & 2.5 & 1.3 & 3.3 \\
\hline & MfrLightind & 2.3 & 4.9 & 7.5 & 7.7 & 9 & 9.7 & 3.6 & 10.6 & 9.3 & 13 & 8.2 & 2.2 & 7.6 \\
\hline & Motel & -3.7 & -3.7 & 1.6 & 4.6 & 5.4 & 5.6 & 4.8 & 7.1 & 7.9 & 6.5 & 1 & -5 & 2.9 \\
\hline & NursingHome & 1.8 & 3 & 5.3 & 7.3 & 7.1 & 6.5 & 5.4 & 8.6 & 9.4 & 9.4 & 5.7 & 1.9 & 6.3 \\
\hline & OffLarge & 2.6 & 4.2 & 3.6 & 2.7 & 3.1 & 3.9 & 1.5 & 3.5 & 4.2 & 4.7 & 4.8 & 3.3 & 3.4 \\
\hline & OffSmall & 2.7 & 6.1 & 6.1 & 4.1 & 6.1 & 7.8 & 4.2 & 6.7 & 8.8 & 9.4 & 7.5 & 3.5 & 6.2 \\
\hline & ResFastfood & 0 & 0 & 0 & 0 & 0 & 0 & 0 & 0 & 0 & 0 & 0 & 0 & 0 \\
\hline & ResSitdown & 4.4 & 7 & 8.9 & 10.7 & 9.5 & 6.6 & 5.5 & 9.3 & 11.8 & 13.3 & 9.9 & 4.9 & 8.6 \\
\hline & RetLarge & 3.7 & 5 & 6.3 & 7.6 & 7 & 5.3 & 4.5 & 7.1 & 8.9 & 9.7 & 6.9 & 4.3 & 6.5 \\
\hline & RetMultistory & 3.7 & 5.4 & 5.7 & 6.4 & 5.8 & 5 & 3.5 & 6 & 7.1 & 8.6 & 6.2 & 4.6 & 5.7 \\
\hline & RetSmall & 5.3 & 7.6 & 9.1 & 10.3 & 9.1 & 6.9 & 5.4 & 8.5 & 10.3 & 13.1 & 10.1 & 5.9 & 8.5 \\
\hline & StorCond & 0.6 & 5.3 & 9.6 & 10.7 & 11 & 11.5 & 6.7 & 15.7 & 13.4 & 17.3 & 9.8 & 1.1 & 10.2 \\
\hline & StorUncond & 0 & 0 & 0 & 0 & 0 & 0 & 0 & 0 & 0 & 0 & 0 & 0 & 0 \\
\hline & WarRefrig & 0.4 & 0.5 & 0.6 & 0.8 & 0.7 & 0.5 & 0.5 & 0.9 & 0.8 & 1 & 0.5 & 0.4 & 0.6 \\
\hline \multirow[b]{3}{*}{ residential } & DbIWideMobile & 16.7 & 28.6 & 33.3 & 29.6 & 20.5 & 13.5 & 17.9 & 25 & 32.1 & 44.4 & 41.7 & 16.7 & 24.5 \\
\hline & MultiFamily & 2.9 & 4.7 & 8.7 & 10.3 & 9.5 & 8.5 & 8.3 & 11.7 & 14.8 & 14.5 & 9.6 & 2.9 & 9.4 \\
\hline & SingleFamily & 6.5 & 8.9 & 13.1 & 14.9 & 12.4 & 10.6 & 9.7 & 13.9 & 16.2 & 18.8 & 15.2 & 8.1 & 12.9 \\
\hline \multirow{3}{*}{ Temperature } & $1990-1999$ & 18.44 & 20.07 & 25.43 & 29.93 & 33.40 & 39.42 & 39.97 & 38.10 & 36.70 & 30.87 & 24.76 & 17.25 & \\
\hline & 2045-2054 & 20.18 & 22.07 & 27.44 & 32.18 & 35.47 & 41.55 & 42.18 & 40.46 & 39.34 & 33.39 & 27.02 & 19.18 & \\
\hline & Percent of increase & 0.09 & 0.10 & 0.08 & 0.08 & 0.06 & 0.05 & 0.06 & 0.06 & 0.07 & 0.08 & 0.09 & 0.11 & \\
\hline
\end{tabular}

\begin{tabular}{|c|c|c|c|c|c|c|c|c|c|c|c|c|c|c|}
\hline Portland & & Jan & Feb & Mar & Apr & May & Jun & Jul & Aug & Sep & Oct & Nov & Dec & Total \\
\hline \multirow{23}{*}{ commercial } & Assembly & 0.3 & 0.9 & 2.6 & 2.9 & 4.6 & 8 & 10.8 & 13.2 & 11.7 & 7.7 & 1.9 & 0.7 & 6.5 \\
\hline & EduCommcoll & -0.9 & 0.4 & 2.2 & 0.2 & 0.8 & 0.5 & 9.3 & -0.2 & 4.1 & 2.3 & 1.2 & -0.7 & 1.7 \\
\hline & EduPrimary & 0.3 & 0.5 & 1.6 & 0.7 & 0.8 & 4.8 & 33.8 & 2.3 & 4.4 & 2.8 & 1 & 0.5 & 2.2 \\
\hline & EduReloc & 0 & 0 & 1.4 & 1.7 & 1.1 & 8.3 & 25 & 4.8 & 7.5 & 3.9 & 0 & 0 & 3.5 \\
\hline & EduSecondary & 0.1 & 0.3 & 0.9 & 0.6 & 0.9 & 4.9 & 32.3 & 4.6 & 4.5 & 2.7 & 0.6 & 0.4 & 2.2 \\
\hline & EduUniversity & 0.7 & 0.4 & 0.9 & 0.8 & 1.1 & 2.8 & 4.2 & 1.6 & 2.2 & 1.9 & 0.6 & 0.4 & 1.4 \\
\hline & Grocery & 0.2 & 0.2 & 0.5 & 0.6 & 0.9 & 1.8 & 2.5 & 3.1 & 2.7 & 1.4 & 0.3 & 0.2 & 1.3 \\
\hline & Hospital & 0.9 & 1.2 & 1.3 & 1.1 & 1.3 & 2.1 & 2.8 & 3.4 & 2.9 & 2.4 & 1.3 & 1.5 & 1.9 \\
\hline & Hotel & -6.3 & -6.8 & -3 & -1.6 & 0.9 & 2.1 & 3.3 & 4.6 & 3.4 & 0.8 & -3.1 & -7.6 & -1.4 \\
\hline & MfrBiotech & 0 & 1.8 & 2.2 & 0.6 & 1 & 2.7 & 7 & -1.3 & 4.8 & 1.4 & 2 & 0.8 & 2 \\
\hline & MfrLightind & 0.1 & 0.2 & 0.4 & 0.4 & 1.5 & 2.8 & 5.3 & 0.9 & 5.8 & 1.7 & 0.4 & 0.1 & 1.7 \\
\hline & Motel & -5.8 & -8 & -6.8 & -5.2 & -2.7 & -1.5 & 1.1 & 2.8 & -0.6 & -6.4 & -7.7 & -8.1 & -4.9 \\
\hline & NursingHome & -0.7 & -0.6 & 0.1 & 0.2 & 1 & 2.2 & 3.7 & 4.8 & 3.6 & 1.2 & -0.1 & -0.8 & 1.3 \\
\hline & OffLarge & 0 & 0.5 & 2 & 1.2 & 1.9 & 2.7 & 5.6 & 2 & 6.1 & 3.8 & 1.6 & -0.3 & 2.4 \\
\hline & OffSmall & 0.3 & 0.9 & 1.9 & 0.8 & 1.7 & 1.7 & 6.5 & 4.5 & 7.7 & 3.6 & 1.5 & 0.3 & 2.9 \\
\hline & ResFastfood & 0 & 0 & 0 & 0 & 0 & 0 & 0 & 0 & 0 & 0 & 0 & 0 & 0 \\
\hline & ResSitdown & -0.9 & -0.5 & 0.5 & 1 & 2.9 & 5.3 & 7.2 & 9.9 & 7.9 & 3.6 & 0 & -0.9 & 3.3 \\
\hline & RetLarge & 0.2 & 0.6 & 1.2 & 1.6 & 2.3 & 4.3 & 5.3 & 6.8 & 5.9 & 3.8 & 1.2 & 0.4 & 3.1 \\
\hline & RetMultistory & 0.2 & 0.7 & 1.7 & 1.8 & 2.1 & 3.8 & 4.8 & 4.6 & 5.2 & 3.7 & 1.4 & 0.1 & 2.7 \\
\hline & RetSmall & -0.4 & -0.4 & 0.8 & 2 & 2.6 & 5.8 & 6.3 & 9 & 8.2 & 5.1 & 0.4 & -1.1 & 3.7 \\
\hline & StorCond & 0 & 0 & 0.2 & 0.2 & 1.3 & 3.4 & 4.6 & 2.5 & 6.5 & 1.2 & 0 & 0 & 1.7 \\
\hline & StorUncond & 0 & 0 & 0 & 0 & 0 & 0 & 0 & 0 & 0 & 0 & 0 & 0 & 0 \\
\hline & WarRefrig & 0.3 & 0.3 & 0.2 & 0.2 & 0.2 & 0.4 & 0.4 & 0.5 & 0.4 & 0.3 & 0.3 & 0.3 & 0.3 \\
\hline \multirow[b]{3}{*}{ residential } & DblWideMobile & -10 & 0 & 0 & 0 & 0 & 16.7 & 33.3 & 40 & 60 & 0 & -25 & -12.5 & 12.7 \\
\hline & MultiFamily & -0.9 & -0.7 & -0.3 & 0 & 1.3 & 2.9 & 5 & 6.3 & 5.6 & 1.3 & -0.3 & -1.2 & 1.6 \\
\hline & SingleFamily & -2.2 & -2.7 & -1.4 & 1.4 & 2.7 & 6.5 & 9.8 & 11.2 & 10 & 2.7 & 0 & -2.4 & 3.3 \\
\hline \multirow{3}{*}{ Temperature } & $1990-1999$ & 6.74 & 9.33 & 13.38 & 14.73 & 19.88 & 21.98 & 24.66 & 27.31 & 23.29 & 17.89 & 11.66 & 8.18 & \\
\hline & 2045-2054 & 8.06 & 10.83 & 14.53 & 15.69 & 20.87 & 23.45 & 26.62 & 29.53 & 25.42 & 19.55 & 13.11 & 9.75 & \\
\hline & Percent of increase & 0.20 & 0.16 & 0.09 & 0.06 & 0.05 & 0.07 & 0.08 & 0.08 & 0.09 & 0.09 & 0.13 & 0.19 & \\
\hline
\end{tabular}


Table 6: The forecasted extreme (2.5\%): percent of increase of the monthly and yearly building total load consumption (Phoenix and Portland)

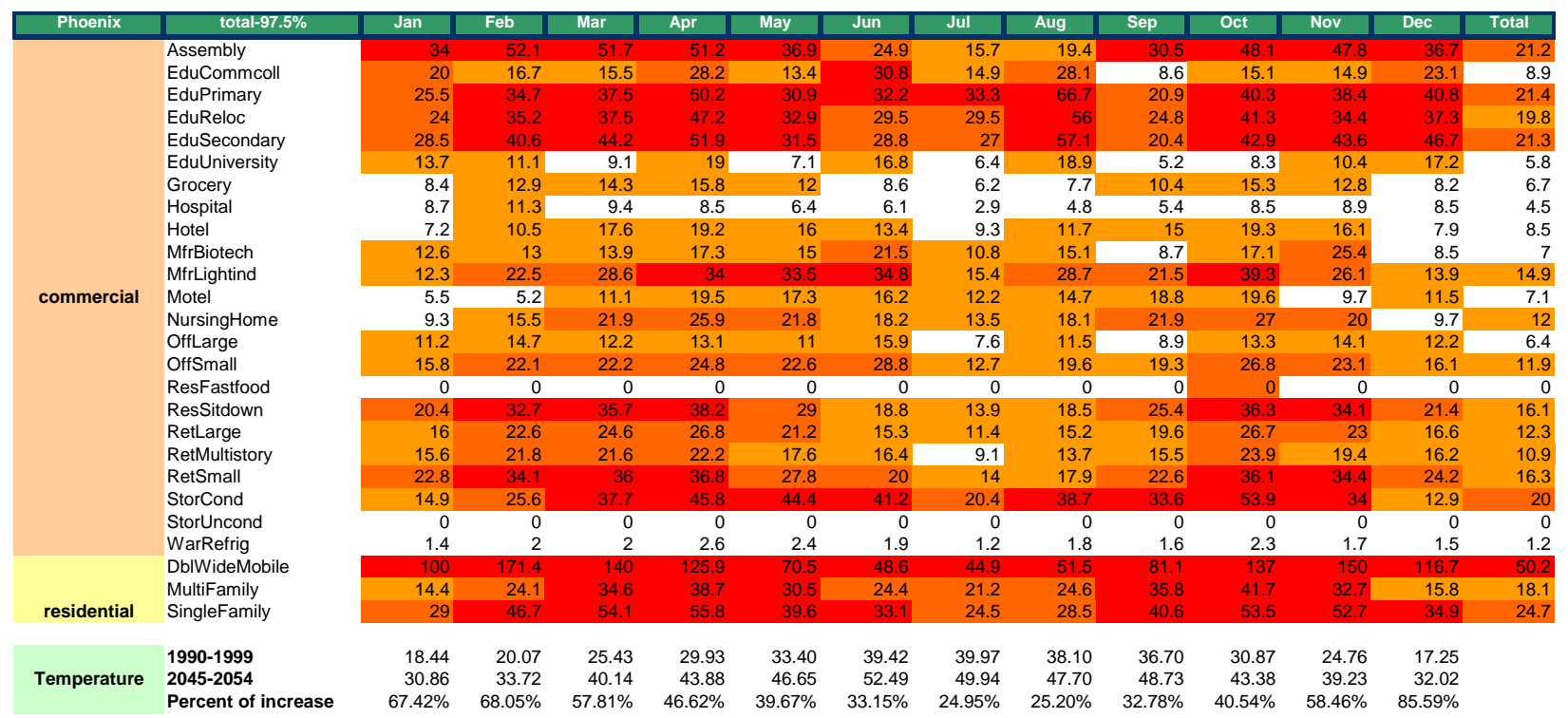

\begin{tabular}{|c|c|c|c|c|c|c|c|c|c|c|c|c|c|c|}
\hline Portland & total-97.5\% & Jan & Feb & Mar & Apr & May & Jun & Jul & Aug & Sep & Oct & Nov & Dec & Total \\
\hline \multirow{23}{*}{ commercial } & Assembly & 2 & 5.9 & 18.1 & 20.9 & 26.5 & 32.7 & 32.7 & 36.2 & 38.2 & 32.1 & 9.6 & 3.5 & 15.9 \\
\hline & EduCommcoll & 13 & 3.3 & 10.9 & 5.9 & 13.3 & 38.9 & 47.8 & 10.1 & 14.4 & 8.8 & 5.7 & 7.1 & 6.1 \\
\hline & EduPrimary & 1.3 & 3.1 & 7.7 & 6 & 14.5 & 23.3 & 124.3 & 25.5 & 17.4 & 10.8 & 3.9 & 2.5 & 6.1 \\
\hline & EduReloc & 1.6 & 3.2 & 9.9 & 8.6 & 15.7 & 31.2 & 71.4 & 30.6 & 23.8 & 15.6 & 3 & 2.1 & 9.3 \\
\hline & EduSecondary & 0.8 & 1.6 & 4.8 & 5.1 & 13 & 23.9 & 120.7 & 27.6 & 17 & 11.2 & 2.6 & 1.5 & 6 \\
\hline & EduUniversity & 6.2 & 2.1 & 4.6 & 5.6 & 6.6 & 12.1 & 10.3 & 7.5 & 7.1 & 6.3 & 2.5 & 2.8 & 3.5 \\
\hline & Grocery & 0.6 & 0.9 & 3 & 4 & 5.5 & 7.1 & 7.4 & 8.3 & 8.6 & 6.2 & 1.3 & 0.9 & 3.1 \\
\hline & Hospital & 3.2 & 4.2 & 6.8 & 6 & 5.9 & 7.1 & 6.7 & 7.7 & 8.4 & 7.9 & 4.9 & 4.3 & 4 \\
\hline & Hotel & 21.2 & 12.8 & 7.9 & 4 & 6.5 & 8.8 & 9.5 & 11.3 & 11 & 6.2 & 12.2 & 12.3 & 3.6 \\
\hline & MfrBiotech & 6.7 & 6 & 8.5 & 4.8 & 13.5 & 12.2 & 38.3 & 7.5 & 15.5 & 6.3 & 7.1 & 3.2 & 5.9 \\
\hline & MfrLightind & 0.5 & 1.2 & 3.7 & 3.9 & 9.4 & 13.8 & 29.8 & 11.4 & 18.3 & 9.3 & 2 & 0.7 & 5.4 \\
\hline & Motel & 30.1 & 11.6 & 17 & 12.1 & 7.6 & 4.4 & 6.3 & 9.7 & 5.8 & 7.2 & 12.8 & 11 & 3.6 \\
\hline & NursingHome & 3 & 1.7 & 1.5 & 3.1 & 6.9 & 10.5 & 11.7 & 13.6 & 12.5 & 7.1 & 1.4 & 1.9 & 3.6 \\
\hline & OffLarge & 4.7 & 4.1 & 11.2 & 8.9 & 11.5 & 14.2 & 19.4 & 11.2 & 18 & 13.1 & 7.8 & 3.9 & 5.9 \\
\hline & OffSmall & 1.6 & 5.4 & 10.1 & 6.9 & 15.1 & 22.9 & 26.5 & 17.2 & 23.2 & 12.7 & 6.4 & 2.5 & 8.1 \\
\hline & ResFastfood & 0 & 0 & 0 & 0 & 0 & 0 & 0 & 0 & 0 & 0 & 0 & 0 & 0 \\
\hline & ResSitdown & 8.4 & 1.6 & 5.7 & 9.1 & 16.8 & 21.1 & 22.6 & 25.3 & 25.6 & 17.4 & 1.5 & 3.3 & 8.5 \\
\hline & RetLarge & 2.5 & 4.1 & 9.4 & 10.7 & 12.2 & 15.3 & 15.1 & 17.9 & 18.5 & 14.5 & 5.7 & 2.2 & 7.1 \\
\hline & RetMultistory & 3.1 & 5.1 & 11.1 & 10.5 & 9.9 & 12.8 & 13.2 & 12.5 & 15.5 & 12.6 & 6.7 & 4.8 & 6.1 \\
\hline & RetSmall & 2 & 1.8 & 10.3 & 13.1 & 15.5 & 20.9 & 18.4 & 23.2 & 25.2 & 19.5 & 4.6 & 9.5 & 8.9 \\
\hline & StorCond & 0 & 0.1 & 1.7 & 3.1 & 9.9 & 16 & 16.9 & 15.8 & 21.7 & 8.9 & 0.5 & 0.1 & 5.2 \\
\hline & StorUncond & 0 & 0 & 0 & 0 & 0 & 0 & 0 & 0 & 0 & 0 & 0 & 0 & 0 \\
\hline & WarRefrig & 1.3 & 1.1 & 1.2 & 1.2 & 0.9 & 1.2 & 1.1 & 1.3 & 1.3 & 1.1 & 1.1 & 1.3 & 0.7 \\
\hline \multirow[b]{3}{*}{ residential } & DbIWideMobile & 40 & 20 & 25 & 25 & 125 & 116.7 & 111.1 & 120 & 220 & 133.3 & 25 & 50 & 42.3 \\
\hline & MultiFamily & 4.9 & 1 & 1.3 & 3.4 & 9.8 & 13.5 & 15.6 & 18.6 & 18.6 & 9.2 & 1 & 4.7 & 4.7 \\
\hline & SingleFamily & 11.1 & 1.4 & 2.7 & 8.6 & 23 & 29.9 & 29.3 & 33.7 & 37.5 & 20.5 & 2.9 & 10.6 & 9.9 \\
\hline \multirow{3}{*}{ Temperature } & 1990-1999 & 6.74 & 9.33 & 13.38 & 14.73 & 19.88 & 21.98 & 24.66 & 27.31 & 23.29 & 17.89 & 11.66 & 8.18 & \\
\hline & 2045-2054 & 16.76 & 18.26 & 24.10 & 26.13 & 34.17 & 35.77 & 36.72 & 40.38 & 38.62 & 31.75 & 20.33 & 17.82 & \\
\hline & Percent of increase & $148.78 \%$ & $95.63 \%$ & $80.08 \%$ & $77.33 \%$ & $71.92 \%$ & $62.74 \%$ & $48.91 \%$ & $47.85 \%$ & $65.86 \%$ & $77.45 \%$ & $74.47 \%$ & $117.91 \%$ & \\
\hline
\end{tabular}



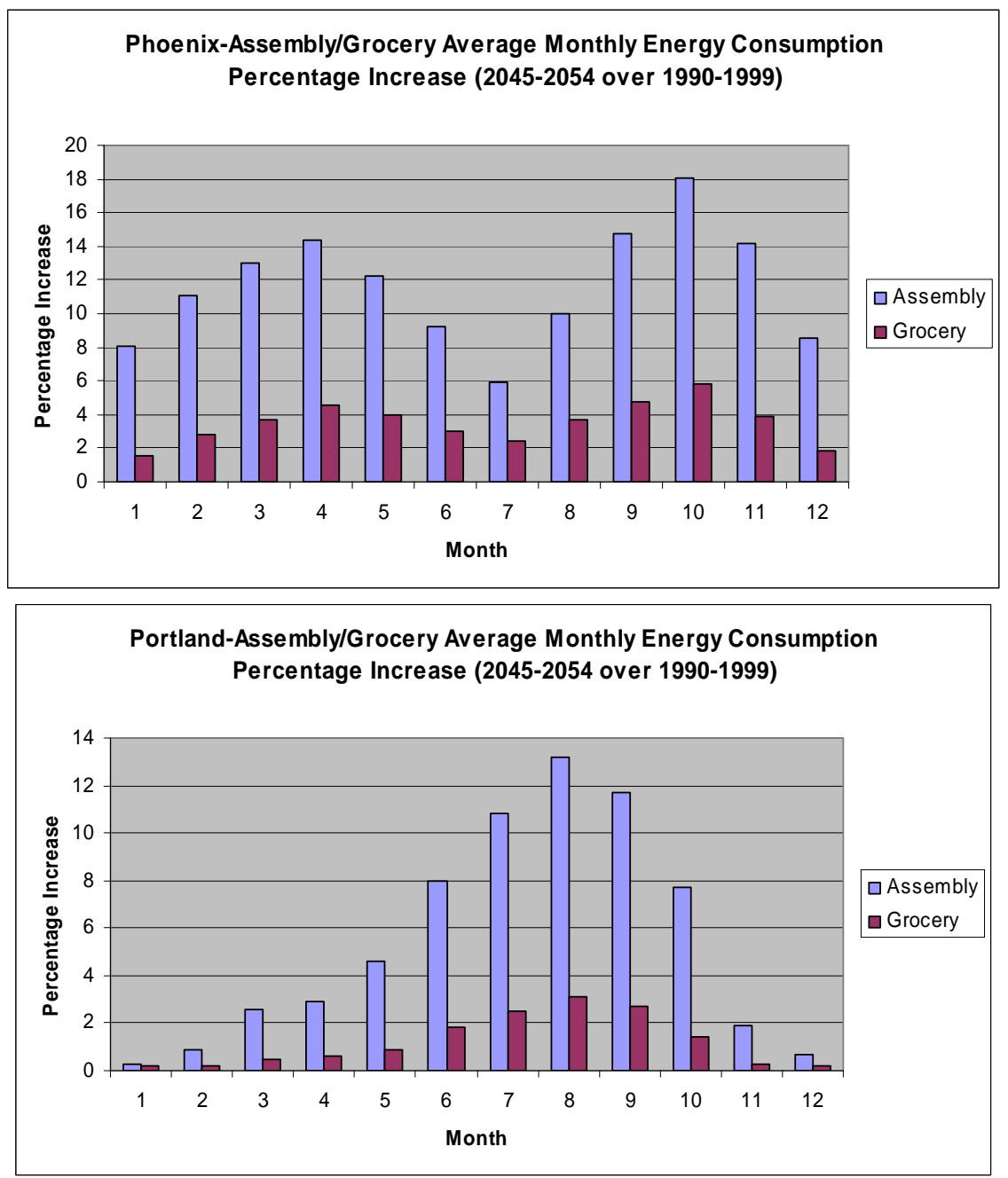

Figure 21. A comparison between the Portland and Phoenix areas 
Table 7: Peak hour energy consumption (total) forecast average increase (Portland)

\begin{tabular}{|c|c|c|c|c|c|c|c|c|c|c|c|c|c|c|}
\hline Phoenix & Building Type & Jan & Feb & Mar & Apr & May & Jun & Jul & Aug & Sep & Oct & Nov & Dec & Total \\
\hline \multirow{23}{*}{ commercial } & Assembly & 9.7 & 11.6 & 11.6 & 10.8 & 8.3 & 4.3 & 2.1 & 4 & 7.3 & 12.6 & 12.9 & 8 & 7.7 \\
\hline & EduCommcoll & 3.9 & 5.8 & 4.2 & 2.7 & 1.4 & 7.5 & 3.2 & 0.8 & 2.4 & 4.2 & 5.4 & 8.1 & 3.7 \\
\hline & EduPrimary & 4.9 & 8.8 & 7.2 & 5.2 & 5.3 & 5.8 & 9 & 3.6 & 4.6 & 8.2 & 9 & 11.6 & 6.4 \\
\hline & EduReloc & 6 & 9.9 & 8.1 & 7.6 & 6.4 & 6.8 & 9.4 & 5.1 & 5.7 & 9 & 9.4 & 13.5 & 7.6 \\
\hline & EduSecondary & 5.5 & 8.9 & 7.8 & 6.4 & 5.8 & 7.1 & 10.7 & 5.1 & 5.5 & 9.4 & 10 & 10.9 & 7.4 \\
\hline & EduUniversity & 3 & 3.8 & 2.8 & 2.1 & 1.8 & 4.5 & 2.6 & 1.5 & 1.6 & 2.6 & 4.3 & 4.7 & 2.8 \\
\hline & Grocery & 3.9 & 5 & 4.5 & 5.4 & 4.3 & 2 & 1.4 & 2.8 & 3.2 & 6.2 & 5 & 4.2 & 3.8 \\
\hline & Hospital & 2.1 & 2.8 & 2 & 1.9 & 1.8 & 1.8 & 1 & 1.8 & 2 & 2.4 & 2 & 2.3 & 2 \\
\hline & Hotel & 2.2 & 2.7 & 3.4 & 4.5 & 4.9 & 4.1 & 3.9 & 4.8 & 4.7 & 4.8 & 3.5 & 2.3 & 3.9 \\
\hline & MfrBiotech & 0.8 & 4.8 & 4 & 3.1 & 3.2 & 4.3 & 0.3 & 3.3 & 1.3 & 4.8 & 2.6 & 1.5 & 2.8 \\
\hline & MfrLightind & 4 & 5.8 & 6.4 & 5.5 & 6.4 & 5.4 & 1.3 & 5.1 & 3.5 & 9.1 & 7 & 4.1 & 5.1 \\
\hline & Motel & -2.9 & -3.9 & -1.3 & 0.1 & 3.1 & 4.3 & 4.1 & 4.9 & 4.2 & 1.2 & -2.1 & -4.3 & 0.5 \\
\hline & NursingHome & 3.5 & 4.8 & 6 & 7 & 6.5 & 6.1 & 5.6 & 7.9 & 7.4 & 8.4 & 6.4 & 3.6 & 6.3 \\
\hline & OffLarge & 3.2 & 5.6 & 3.4 & 1.5 & 2.5 & 4.5 & 0.7 & 1.7 & 2.7 & 3.7 & 4.9 & 3.2 & 3 \\
\hline & OffSmall & 3.8 & 7.1 & 5.7 & 2.6 & 4.6 & 6.3 & 2.4 & 3.3 & 5.3 & 6.9 & 7.5 & 3.1 & 4.8 \\
\hline & ResFastfood & 0 & 0 & 0 & 0 & 0 & 0 & 0 & 0 & 0 & 0 & 0 & 0 & 0 \\
\hline & ResSitdown & 7 & 9.1 & 9.4 & 9.9 & 7.4 & 2.7 & 1.9 & 3.5 & 5.8 & 11.1 & 10 & 7.5 & 6.5 \\
\hline & RetLarge & 4.3 & 5.7 & 6.5 & 7.1 & 6 & 3.3 & 2.7 & 4.5 & 5.2 & 8.6 & 7.4 & 5.2 & 5.4 \\
\hline & RetMultistory & 3.1 & 3.8 & 4.7 & 5.6 & 4.1 & 1.8 & 1.8 & 3.2 & 3.9 & 6.4 & 5.2 & 2.9 & 3.8 \\
\hline & RetSmall & 5.3 & 6.7 & 7 & 7.3 & 6 & 3.2 & 2.6 & 4.3 & 4.5 & 8.3 & 8.2 & 5.5 & 5.5 \\
\hline & StorCond & 4 & 7.4 & 11.2 & 9.9 & 10.1 & 8.1 & 3.5 & 9.3 & 7.8 & 16 & 13.1 & 4.4 & 8.6 \\
\hline & StorUncond & 0 & 0 & 0 & 0 & 0 & 0 & 0 & 0 & 0 & 0 & 0 & 0 & 0 \\
\hline & WarRefrig & 0.6 & 0.8 & 1.2 & 1.7 & 1.2 & -0.3 & 0.7 & 1.2 & 1.1 & 2.2 & 1.2 & 0.6 & 1 \\
\hline \multirow[b]{3}{*}{ residential } & DblWideMobile & 23.3 & 22.2 & 25.9 & 20.4 & 17.5 & 9.4 & 13.2 & 16.5 & 19.4 & 26.5 & 31.4 & 25 & 17.7 \\
\hline & MultiFamily & 5.8 & 7.3 & 9.8 & 8.6 & 8.4 & 4.3 & 5.3 & 6.4 & 8.7 & 10.9 & 11.7 & 5.6 & 7.6 \\
\hline & SingleFamily & 10.4 & 12.1 & 12.3 & 11.4 & 8.8 & 4.9 & 4.6 & 6.2 & 7.2 & 11.1 & 14.2 & 13.2 & 8.8 \\
\hline \multirow{3}{*}{ Temperature } & 1990-1999 & 33.64 & 35.82 & 43.36 & 45.64 & 49.62 & 54.33 & 50.93 & 48.73 & 49.99 & 44.02 & 41.11 & 34.75 & \\
\hline & 2045-2054 & 34.79 & 38.04 & 45.17 & 47.26 & 49.97 & 56.71 & 53.32 & 51.15 & 52.06 & 46.26 & 44.08 & 37.54 & \\
\hline & Percent of increase & $3.44 \%$ & $6.20 \%$ & $4.17 \%$ & $3.54 \%$ & $0.70 \%$ & $4.37 \%$ & $4.70 \%$ & $4.97 \%$ & $4.13 \%$ & $5.08 \%$ & $7.23 \%$ & $8.04 \%$ & \\
\hline
\end{tabular}

\begin{tabular}{|c|c|c|c|c|c|c|c|c|c|c|c|c|c|c|}
\hline Portland & Building Type & Jan & Feb & Mar & Apr & May & Jun & Jul & Aug & Sep & Oct & Nov & Dec & Total \\
\hline \multirow{23}{*}{ commercial } & Assembly & 1 & 2.2 & 3.7 & 4.3 & 5.3 & 11.1 & 12.3 & 14.8 & 13.6 & 10.2 & 4.7 & 1.7 & 8.7 \\
\hline & EduCommcoll & -0.5 & 0.3 & 2.2 & -0.1 & 1 & -2 & 8.1 & 0.4 & 4.1 & 2.2 & 1.4 & 0.2 & 1.6 \\
\hline & EduPrimary & 0.3 & 1.7 & 3.5 & 0.1 & 0.4 & 7.2 & 26.8 & 2.6 & 6.1 & 3.4 & 2.6 & 1.3 & 3.3 \\
\hline & EduReloc & 1.8 & 3.4 & 5.8 & 3.1 & 1.3 & 9.3 & 16.7 & 4.5 & 7.3 & 4.3 & 3.9 & 3.9 & 5.2 \\
\hline & EduSecondary & 0.5 & 0.9 & 1.8 & 1 & 1.2 & 6.5 & 28.8 & 6 & 5.5 & 3.9 & 1.3 & 1.1 & 3.3 \\
\hline & EduUniversity & 0 & 0.8 & 2 & 1.8 & 1.8 & 4.5 & 5.7 & 0.4 & 2.9 & 3.1 & 1.4 & 0.1 & 2.1 \\
\hline & Grocery & 0.4 & 0.6 & 1 & 1.7 & 2 & 3.6 & 4.3 & 5.3 & 4.8 & 3.4 & 0.9 & 0.6 & 2.6 \\
\hline & Hospital & 1.2 & 0.8 & 1.3 & 1.4 & 1.2 & 2.2 & 2.1 & 1.8 & 2.5 & 2.6 & 1.1 & 0.8 & 1.6 \\
\hline & Hotel & -5.2 & -6.9 & -3.4 & -3.9 & 0.5 & 2.3 & 3 & 4.1 & 3.1 & -1.8 & -5.4 & -7.4 & -2.1 \\
\hline & MfrBiotech & -0.1 & 2.3 & 3 & 0.7 & 1.1 & 3.5 & 7.9 & -2.2 & 5.9 & 1.7 & 2.6 & 1 & 2.4 \\
\hline & MfrLightind & 0.2 & 0.4 & 0.8 & 0.6 & 1.7 & 4.2 & 7.1 & -0.2 & 6.8 & 2.6 & 0.7 & 0.3 & 2.3 \\
\hline & Motel & 0.3 & 0.7 & 0.7 & 1.2 & 1.5 & 3.4 & 4 & 4.6 & 4.2 & 2.6 & 1.1 & 0.5 & 1.8 \\
\hline & NursingHome & -0.1 & 0.3 & 1.3 & 1.2 & 2.1 & 4.3 & 5.8 & 6.9 & 5.9 & 2.9 & 1.1 & 0.5 & 2.9 \\
\hline & OffLarge & 1.6 & 3.3 & 4.2 & 2 & 1.7 & 3 & 6.2 & 1.3 & 6 & 4.2 & 3.6 & 1.7 & 3.3 \\
\hline & OffSmall & 0.8 & 2.2 & 3.3 & 1.4 & 1.9 & 2.4 & 7.8 & 4.3 & 8.7 & 4.3 & 3.2 & 1 & 3.7 \\
\hline & ResFastfood & 0 & 0 & 0 & 0 & 0 & 0 & 0 & 0 & 0 & 0 & 0 & 0 & 0 \\
\hline & ResSitdown & 0.3 & 0.7 & 2.1 & 2.3 & 4.5 & 7.6 & 9.4 & 13.5 & 10.4 & 6.4 & 1.3 & 0.3 & 5.9 \\
\hline & RetLarge & 0.6 & 1.3 & 1.8 & 2.7 & 2.9 & 5.8 & 6.5 & 8.4 & 7.3 & 4.6 & 2.3 & 0.8 & 4.2 \\
\hline & RetMultistory & -0.7 & -0.1 & 0.7 & 1.3 & 1.7 & 3.5 & 3.6 & 7.3 & 4.3 & 2.4 & 0.4 & -0.9 & 2.1 \\
\hline & RetSmall & 0.8 & 1.7 & 2 & 3.6 & 3.3 & 6.7 & 6.4 & 10.1 & 8.3 & 5.8 & 2.7 & 1 & 5 \\
\hline & StorCond & 0 & 0.1 & 0.6 & 0.6 & 2.1 & 4.5 & 9.3 & 0.9 & 10.9 & 2.7 & 0.1 & 0 & 3 \\
\hline & StorUncond & 0 & 0 & 0 & 0 & 0 & 0 & 0 & 0 & 0 & 0 & 0 & 0 & 0 \\
\hline & WarRefrig & 0.4 & 0.4 & 0.3 & 0.3 & 0.3 & 0.7 & 0.6 & 0.7 & 0.7 & 0.5 & 0.4 & 0.4 & 0.5 \\
\hline \multirow[b]{3}{*}{ residential } & DblWideMobile & -7.1 & -11.1 & 0 & 8.3 & 20 & 13.9 & 32.1 & 25.4 & 44.8 & 36.4 & -14.3 & -9.1 & 20.9 \\
\hline & MultiFamily & -0.5 & -0.8 & 0.4 & 1.4 & 4.2 & 7.4 & 11.3 & 13 & 13.6 & 4.9 & 0 & -1 & 5.2 \\
\hline & SingleFamily & -1.4 & -1.6 & 1.5 & 3.9 & 7.6 & 11.5 & 15.9 & 13.4 & 17.8 & 10.3 & 0 & -1.4 & 8.1 \\
\hline \multirow{3}{*}{ Temperature } & 1990-1999 & 18.50 & 19.10 & 26.55 & 29.38 & 37.86 & 39.21 & 38.27 & 43.16 & 41.79 & 35.48 & 22.29 & 19.48 & \\
\hline & 2045-2054 & 20.06 & 20.63 & 27.32 & 30.34 & 39.29 & 40.39 & 40.45 & 45.33 & 44.23 & 36.02 & 23.67 & 20.98 & \\
\hline & Percent of increase & $8.40 \%$ & $8.04 \%$ & $2.90 \%$ & $3.29 \%$ & $3.80 \%$ & $3.01 \%$ & $5.68 \%$ & $5.03 \%$ & $5.82 \%$ & $1.52 \%$ & $6.20 \%$ & $7.67 \%$ & \\
\hline
\end{tabular}

\subsubsection{Modeling Results for the 7 Inland Cities}

Using the temperature sensitivity curves, climate change impacts for Now and Future are studied by the method shown in Figure 3 for the 26 building types. The peak load and the energy consumption for all 26 buildings with the heating load excluded are shown in Figure 22 and Figure 23. 
The following specifics are noted:

- The simulation is done for the seven cities that show high temperature correlations with building energy consumption, peak load, and load composition. The three locations in California are excluded because of the poor temperature correlation, as noted above.

- Buildings 1 to 23 are commercial buildings, and Buildings 24 to 26 are residential buildings. The building names are listed in Figure 22.

- In most building models, the heating loads are assumed to be gas-heating. We will address the heating load influence in the future.

- The building vintage used is "post 2005.” We assume that the current technology will be adapted to the older buildings in the future.

The results indicate the following:

- Regarding the load types: The temperature increases exert a greater impact on the residential buildings than the commercial buildings. The mobile homes and the single-family houses are by far the most temperature sensitive loads. On average, the residential buildings will see more than a $10 \%$ increase in their peak load. Among the commercial buildings, the assembly, educational buildings (such as primary and secondary schools), as well as the small retail and restaurants have moderate a/c loads; therefore, they will see an increase between $5 \%$ and $10 \%$ in their peak loads. Other commercial buildings will see an increase lower than $5 \%$. Note that Building 22, which represents unconditioned storage buildings, is not sensitive to temperature variations.

- Regarding the peak loads: Because we excluded the gas-heating load, making the cooling related load the major temperature sensitive load, the winter and autumn/spring peak load increases are in general less than 10\%, except in the Phoenix area. This shows that in Phoenix, peak loading conditions may occur in spring and autumn months. In Salt Lake City and Boulder, similar trends have been observed; however, the peak load increase is around $5 \%$. The yearly total load consumption confirmed that the three cities will see more energy demand increases related to climate change by 2050.

- Regarding the energy consumption: In most areas, during July and August, the energy consumption increases significantly. The total load increase is greater than $10 \%$ for most buildings and for most of the seven cities studied. This shows that during these months, the Western grid is very likely to see simultaneous peaks all over the grid. In spring, the Southwest will see more demand increase, while the Pacific Northwest will only experience moderate increase in demand.

- Because of the increase of warmer winter and spring days, the yearly total energy consumption by buildings may decrease. In our simulation, cooling load is our major concern, so for most of the buildings, the major heating load is assumed to be provided by gas heating, except Buildings 9,12, and 16. Therefore, when counting the heating load reduction, 
the total energy consumed by the three building types will actually decrease in all cities except Phoenix.

- Regarding the load composition: As shown in Figure 24, because of the increased cooling load, the a/c motor load composition will increase $2 \%$ to $10 \%$ for commercial loads and $5 \%$ to $12 \%$ for residential loads for most areas across the Western United States in the summer. Because in this simulation we didn't account for the heating load (which, in some areas is electrical), the winter and spring load compositions will not increase as dramatically. Figure 25 shows a box plot of the cooling load composition in Salt Lake City in August. The distribution of the data points suggests that, statistically, both the median and the extremes will be increased in the future.
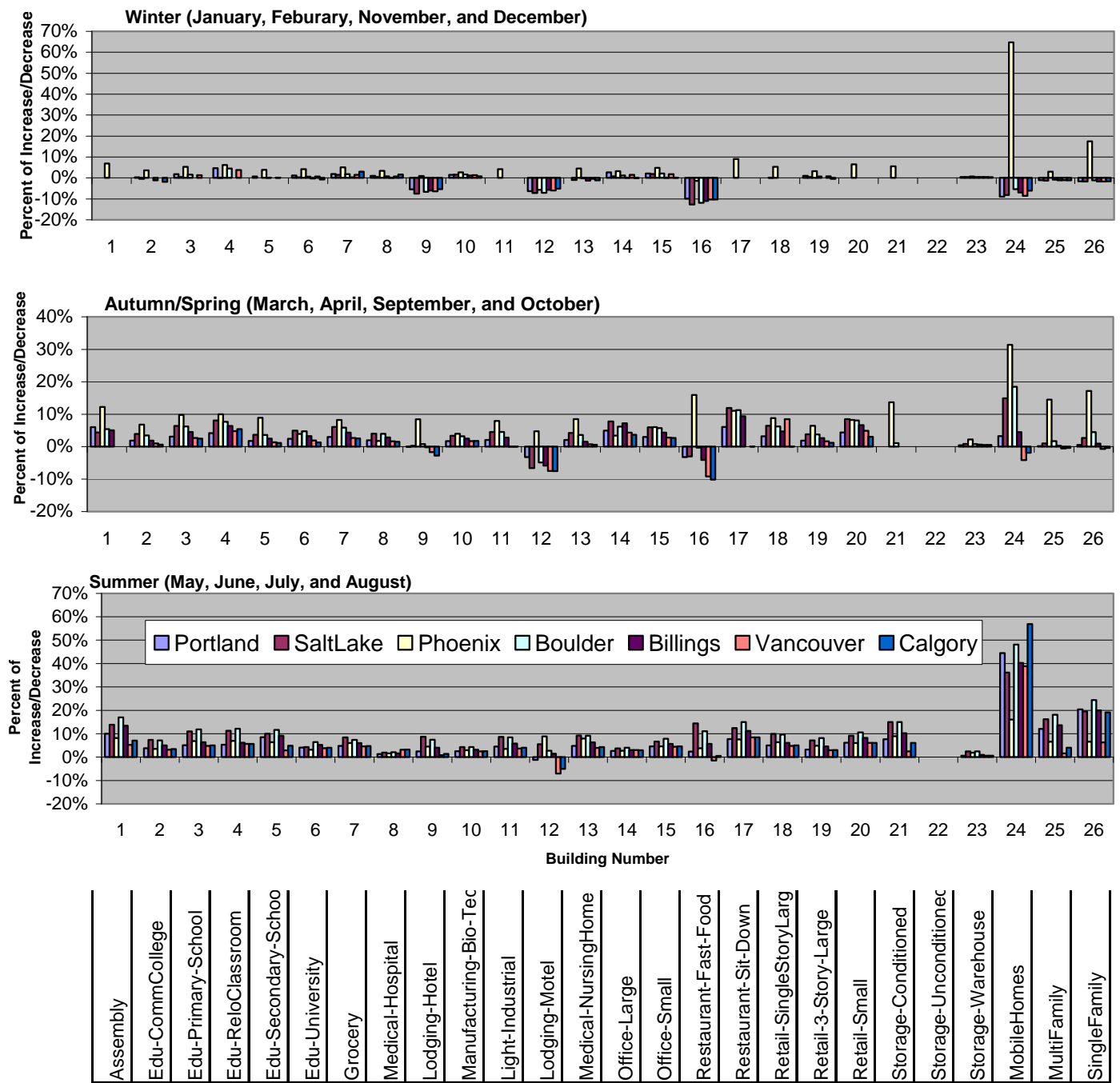

Figure 22: Climate change impacts on the future peak load of the 26 buildings in 7 locations 
Summer (July and August) Energy Consumption
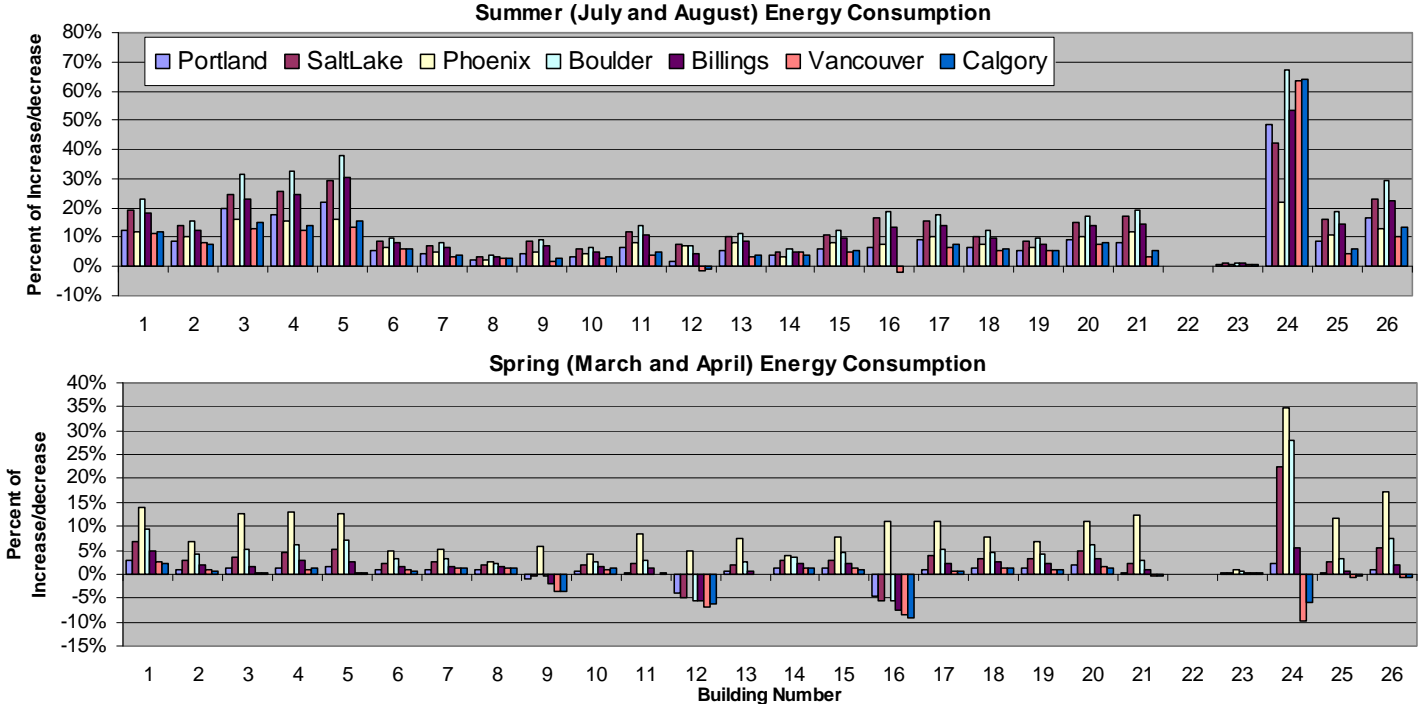

Figure 23: Climate change impacts on the future yearly energy consumption of the 26 buildings in 7 locations
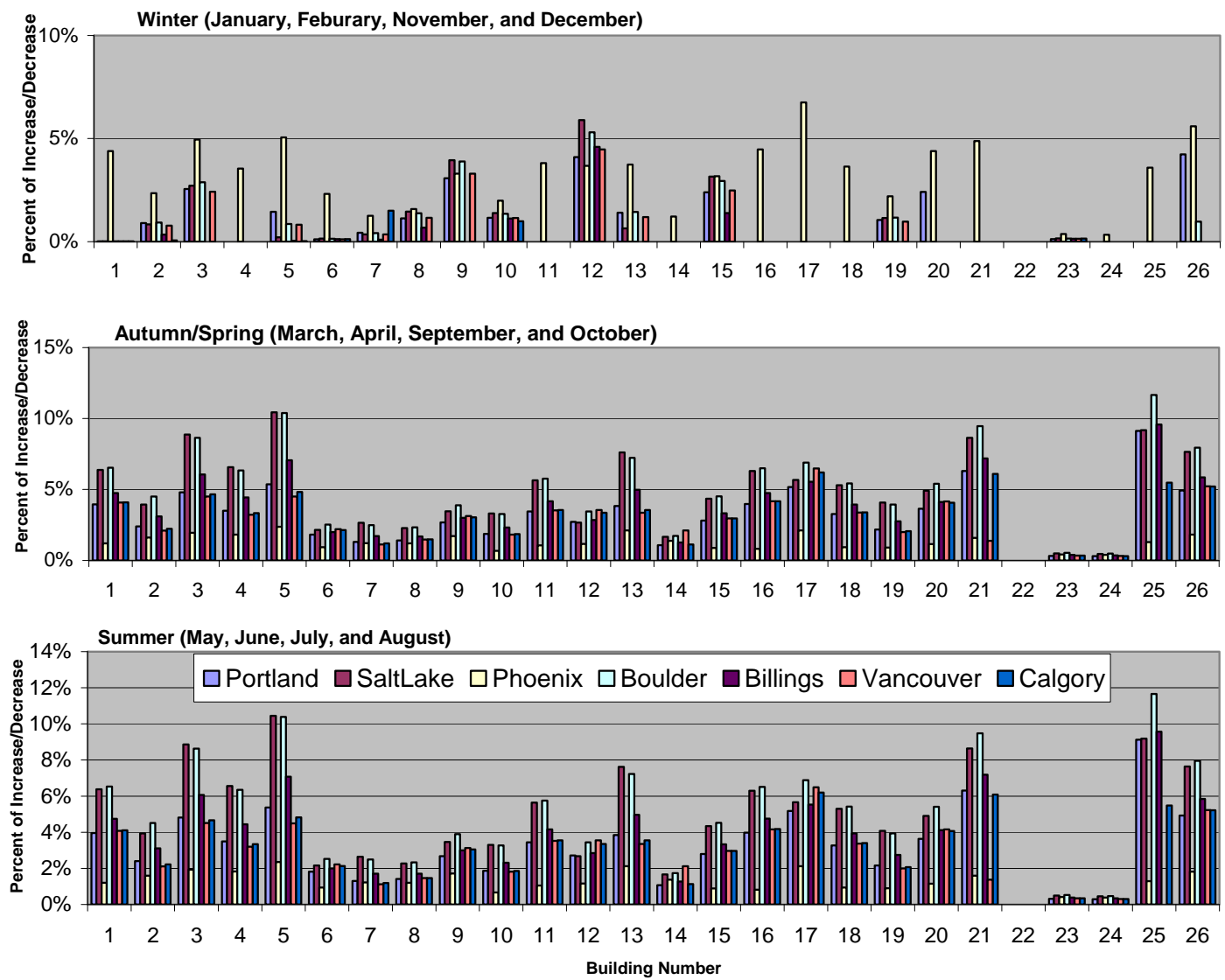

Figure 24: Climate change impacts on the future cooling load composition of the 26 buildings in 7 locations 


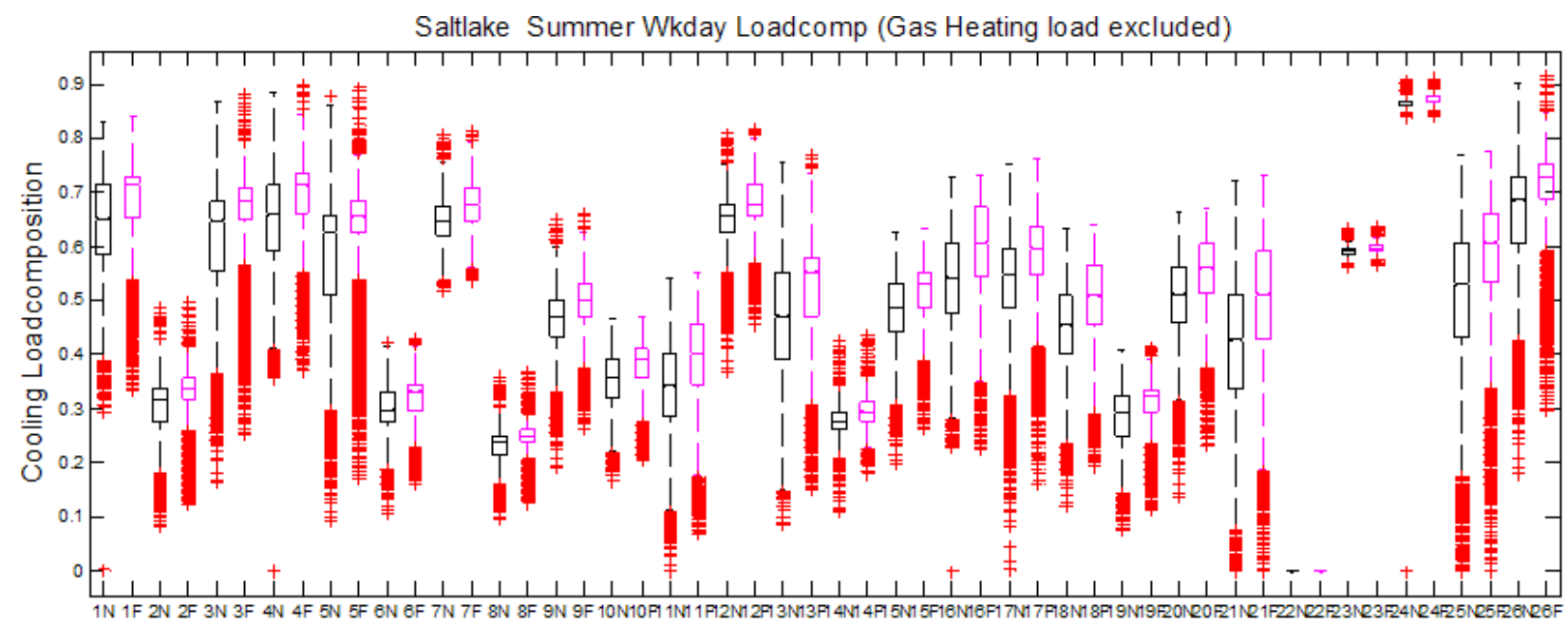

Figure 25: The box plot of Now $(\mathrm{N})$ and Future (F) cooling load compositions of the 26 buildings in Salt

Lake City in August

\subsection{Feeder Level Impact Study}

A distribution feeder usually supplies a variety of load as shown in Figure 26. In Section 2.3, we have studied the climate impact on individual building types. By knowing the building fraction of a distribution feeder, one can estimate how much impact will be at the distribution feeder level.

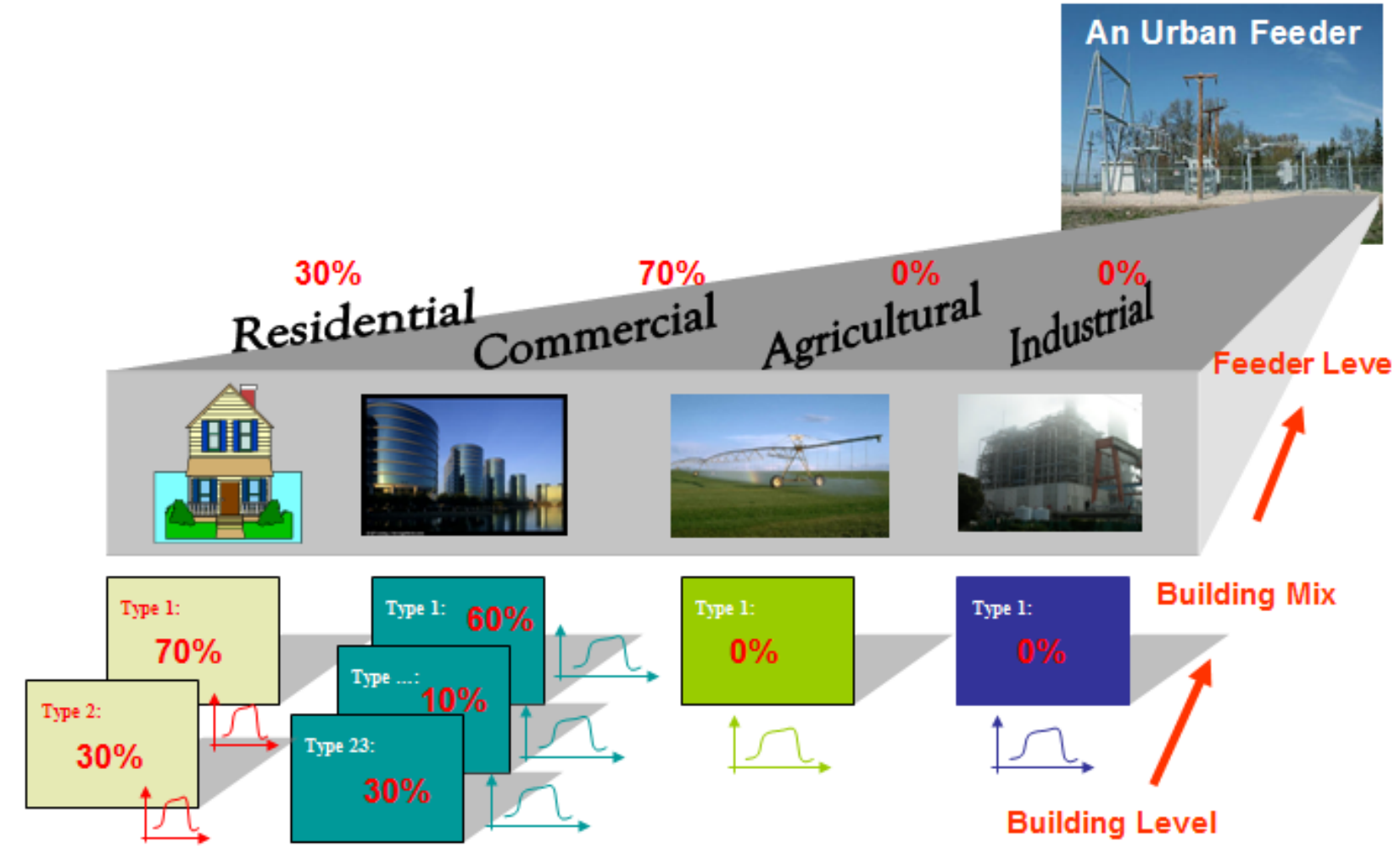

Figure 26: The load aggregation of an urban feeder 


\subsubsection{Change of end-use energy consumption (Monthly and Yearly), peak load, and feeder load composition.}

The impact can be obtained by multiplying the building mix of a feeder of interest. For example, in Portland area, if we assume a building mix as shown in Table 8, we can covert Table 5 through Table 7 to feeder level impact table by multiplying Table 8 . An example of the feeder level study has been given in Figure 27.

Table 8: A typical building mix in Portland area

\begin{tabular}{|l|r|r|r|r|r|}
\hline & $\begin{array}{r}\text { Heavy } \\
\text { Office }\end{array}$ & $\begin{array}{c}\text { Heavy } \\
\text { Large } \\
\text { Office }\end{array}$ & $\begin{array}{c}\text { Heavy } \\
\text { Small } \\
\text { Office }\end{array}$ & $\begin{array}{c}\text { Heavy } \\
\text { Dinning }\end{array}$ & $\begin{array}{c}\text { Heavy } \\
\text { Hotel }\end{array}$ \\
\hline Assembly & 0.15 & 0.40 & 0.03 & 0.02 & 0.00 \\
\hline Education - Primary School & 0.00 & 0.00 & 0.00 & 0.00 & 0.00 \\
\hline Education - Secondary School & 0.00 & 0.00 & 0.00 & 0.00 & 0.00 \\
\hline Education - Community College & 0.00 & 0.00 & 0.00 & 0.00 & 0.00 \\
\hline Education - University & 0.00 & 0.00 & 0.00 & 0.00 & 0.00 \\
\hline Education - Relocatable Classroom & 0.00 & 0.00 & 0.00 & 0.00 & 0.00 \\
\hline Grocery & 0.00 & 0.03 & 0.05 & 0.05 & 0.04 \\
\hline Health/Medical - Hospital & 0.00 & 0.00 & 0.00 & 0.00 & 0.00 \\
\hline Health/Medical - Nursing Home & 0.00 & 0.00 & 0.00 & 0.00 & 0.00 \\
\hline Lodging - Hotel & 0.00 & 0.00 & 0.00 & 0.03 & 0.40 \\
\hline Lodging - Motel & 0.00 & 0.00 & 0.00 & 0.03 & 0.30 \\
\hline Manufacturing - Bio/Tech & 0.00 & 0.00 & 0.00 & 0.00 & 0.00 \\
\hline Manufacturing - Light Industrial & 0.00 & 0.00 & 0.00 & 0.00 & 0.00 \\
\hline Office - Large & 0.30 & 0.40 & 0.02 & 0.00 & 0.00 \\
\hline Office- Small & 0.40 & 0.04 & 0.70 & 0.01 & 0.00 \\
\hline Restaurant - Sit-Down & 0.05 & 0.04 & 0.05 & 0.40 & 0.10 \\
\hline Restaurant - Fast-Food & 0.05 & 0.04 & 0.05 & 0.30 & 0.10 \\
\hline Retail - 3-Story Large & 0.00 & 0.00 & 0.00 & 0.06 & 0.02 \\
\hline Retail - Single-Story Large & 0.00 & 0.00 & 0.00 & 0.06 & 0.02 \\
\hline Retail - Small & 0.05 & 0.04 & 0.10 & 0.06 & 0.02 \\
\hline Storage - Conditioned & 0.00 & 0.00 & 0.00 & 0.00 & 0.00 \\
\hline Storage - Unconditioned & 0.00 & 0.00 & 0.00 & 0.00 & 0.00 \\
\hline Storage - Refrigerated Warehouse & 0.00 & 0.00 & 0.00 & 0.00 & 0.00 \\
\hline
\end{tabular}



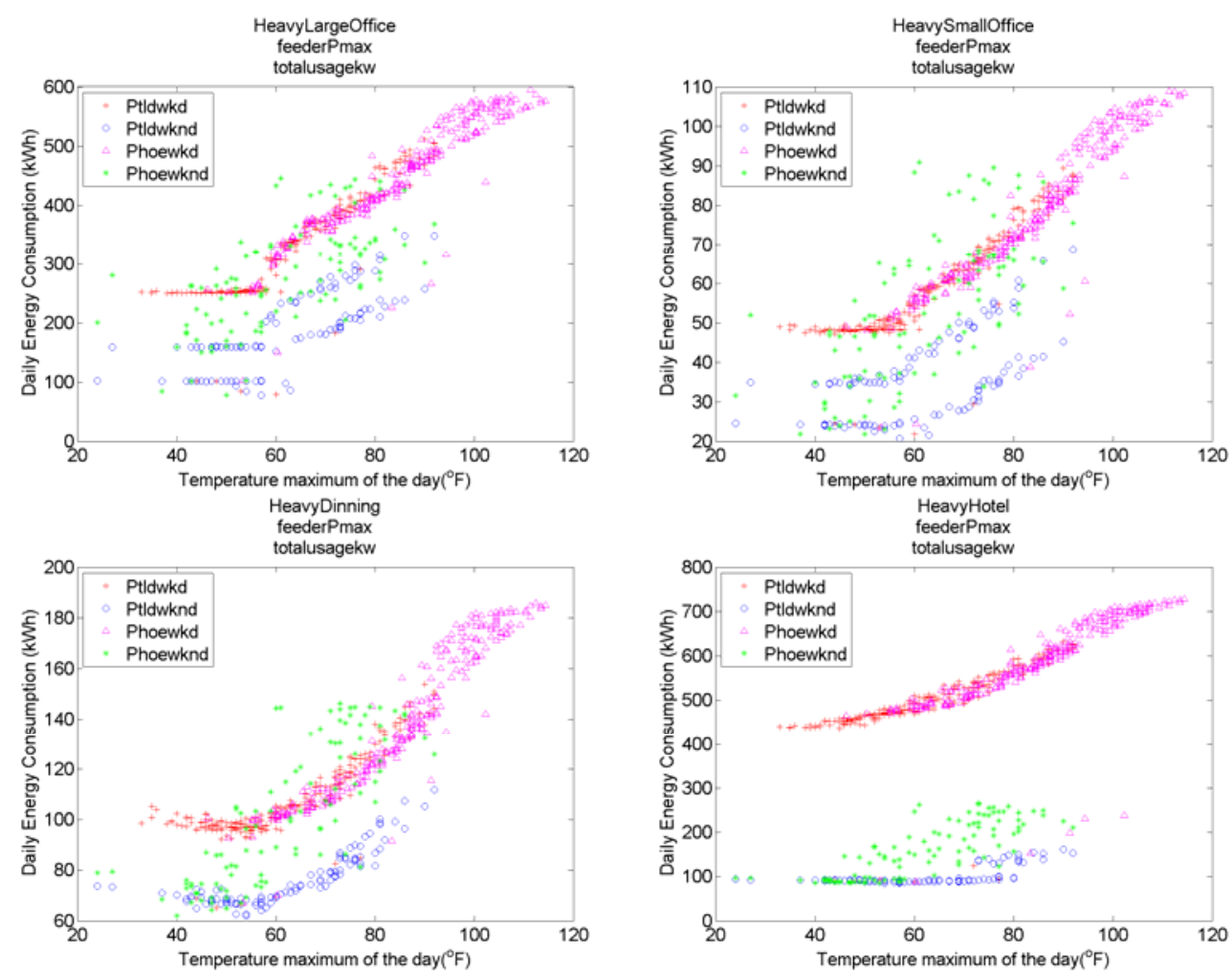

Figure 27: The feeder level weather temperature sensitivity

\subsubsection{Power Quality and Energy Losses}

Higher temperature will lead to higher penetration of HVAC systems. Motors and variable frequency drives used in the HVAC auxiliary systems will cause the following power quality problems:

- harmonics

- lower voltage at the user end

- heavier losses in power distribution systems. At distribution feeder level, wires and transformers are usually oversized to accommodate the load increase. However, increased energy consumption will certainly increase the losses in distribution system because of increased current. Note that the loss is: $E=I^{2} X_{\text {Line }}$

\subsubsection{Voltage Stability}

If the air conditioning load consists of more than $80 \%$ feeder load, then it is very likely to experience slow voltage recovery when a fault happens, as shown in. As shown in Figure 28 and Table 9, the a/c motor loading will increase approximately $2.8 \% /{ }^{\circ} \mathrm{F}$ when temperature increases from $100{ }^{\circ} \mathrm{F}$ to $115{ }^{\circ} \mathrm{F}$. This will significantly increase the percent of motor loads of a hot day. In addition, as shown in Figure 29, the motor stalling voltage will increase when temperature increases. Therefore, when a voltage sag happens, the distribution feeders with $60 \%$ to $70 \%$ a/c compressor load may be likely to stall on a hot day 
and cause the feeder voltage to remain low for minutes, which is called slow voltage recovery phenomena. This phenomena can lead to equipment failure as well as widespread system fault if it is not properly handled.

\section{VALLEY 115 KV - THIRTY SECOND PLOT}

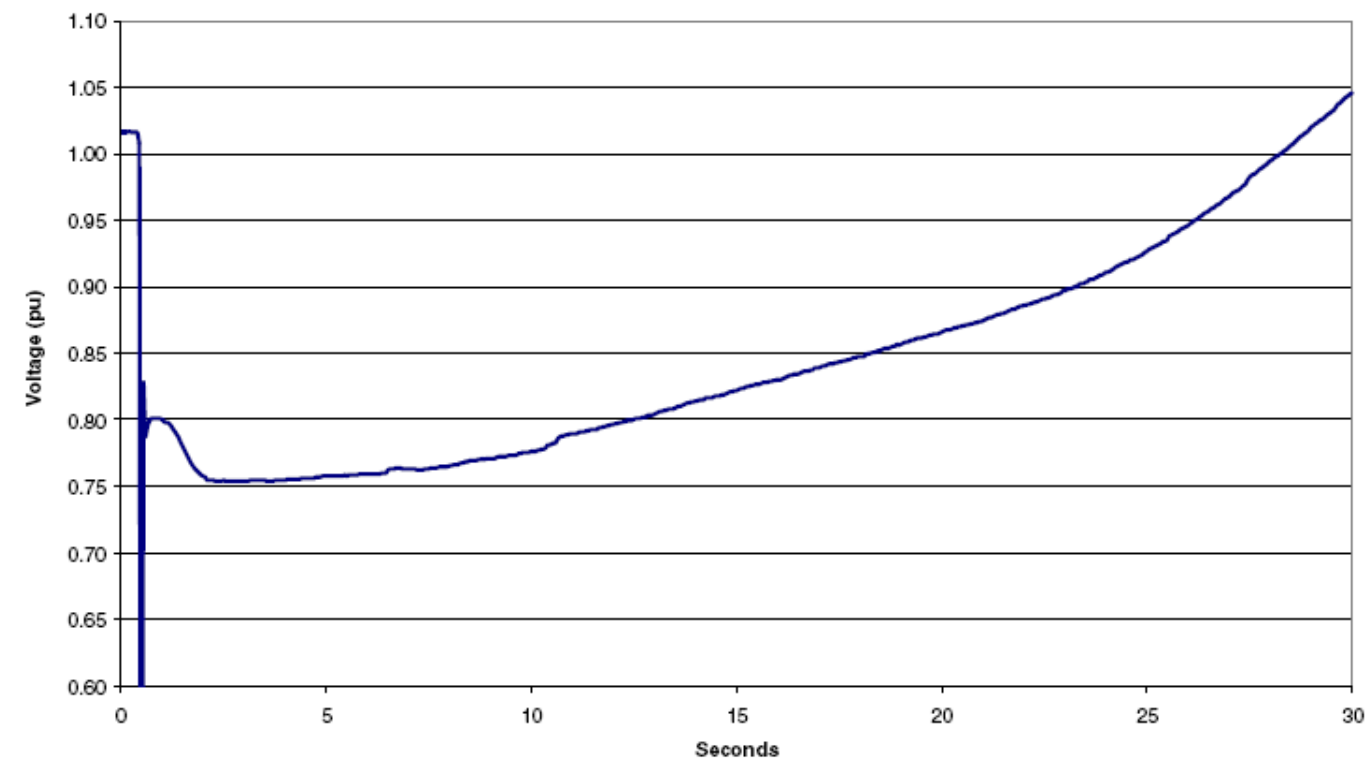

Figure 28: The voltage recovery process of a bus serving heavy a/c load after a fault in a hot summer day (Chinn 2006)

Table 9: The temperature sensitivity of air conditioner compressor units

\begin{tabular}{|l|r|r|r|}
\hline $\begin{array}{l}\text { A/C compressor output } \\
(\mathrm{w})\end{array}$ & 3600 & 2700 & 2100 \\
\hline Outdoor temperature $\left({ }^{\circ} \mathrm{F}\right)$ & 115 & 100 & 80 \\
\hline Sensitivity & & $2.80 \%$ & $1.40 \%$ \\
\hline
\end{tabular}



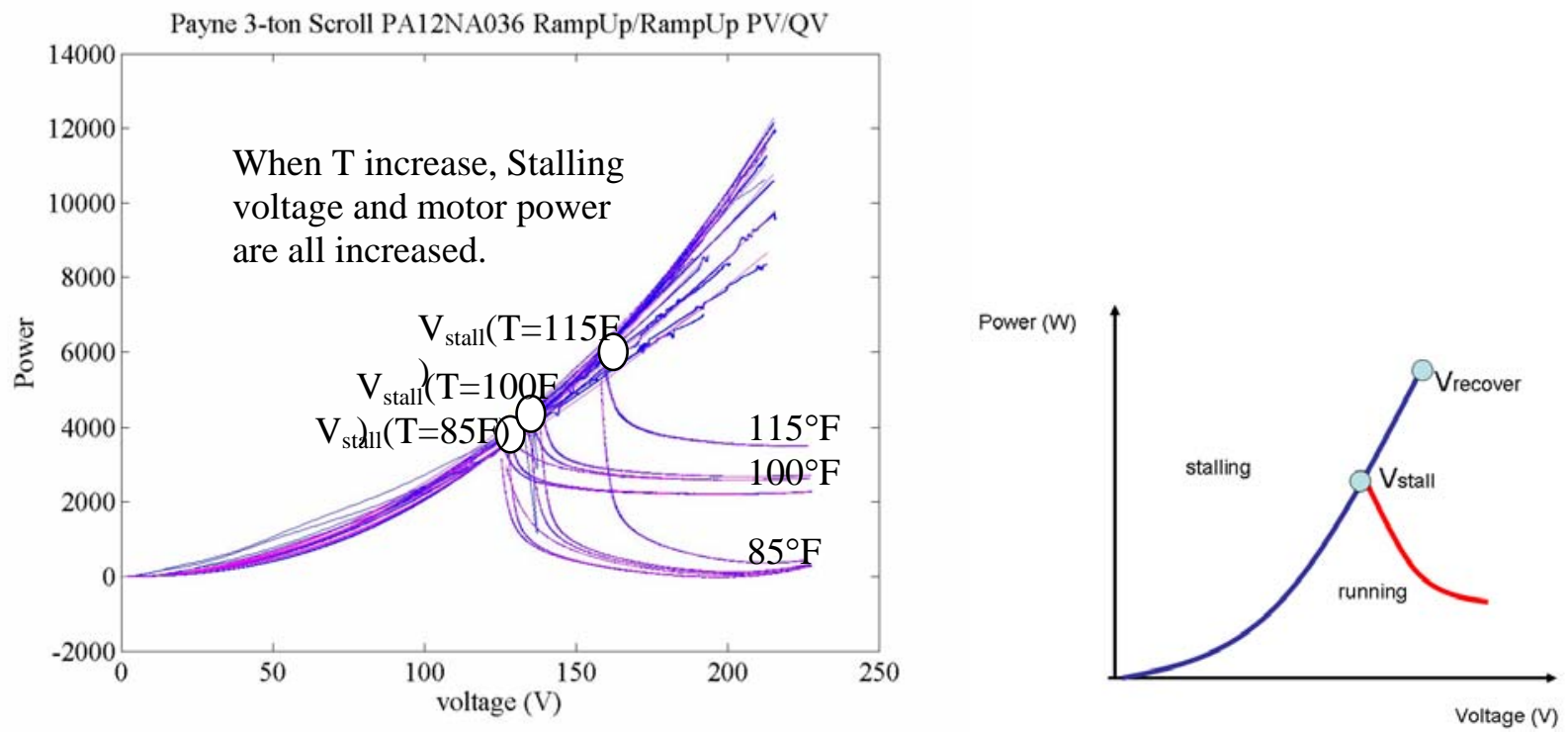

Figure 29: The temperature sensitivity of an A/C compressor

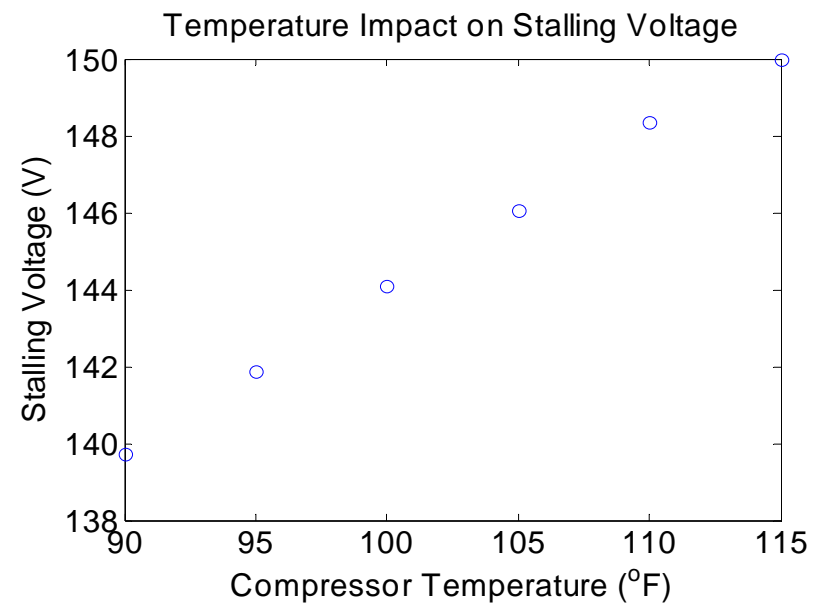

Figure 30: The temperature sensitivity of an A/C compressor 


\section{Conclusion}

Using the IPCC A1B climate change scenarios and the DOE-2 energy building simulation program, this study shows that by mid-century, building yearly energy consumption and the peak load will increase in the Southwest (Phoenix, Salt Lake City, and Boulder). Moreover, the peak load months will spread out to not only the summer months but also spring and autumn months. The Pacific Northwest (Portland, Vancouver, Calgary, and Billings) will be hotter in the summer months. As a result, the penetration and use of a/c systems in the Pacific Northwest is likely to increase significantly over the years. Consequently, some locations that traditionally supply only a small fraction of cooling load in summer months may shift from winter peaking to summer peaking because of the reduction of heating load and increase in cooling load. Overall, the Western U.S. grid may see more simultaneous peaks across the North and South in the summer months.

Increased cooling load results in a significant increase in the motor load, which consumes more reactive power and requires stronger voltage support from the grid. In the southern part of the United States, slow-voltage recovery (SVR) phenomena have been observed frequently in distribution feeders supplying heavy a/c loads. The detrimental impact of the SVR events has been studied and discussed in reports by Lu, Yang, and Huang (2008) and Bravo et al. (2007). This study suggests an increasing need for the industry to implement new technology to increase the efficiency of the temperature-sensitive loads and apply proper protection and control to prevent the increasingly adverse impacts of a/c motor loads.

Our future research will focus on the following three aspects: 1) consider more climate factors in building energy consumption to obtain a better correlation of the load estimation in the California coastal areas; 2) include the heating load study; 3) extend our study to all 78 cities across the Western U.S. grid; and 4) study the social impacts of the climate change. 


\section{References}

EIA. 2007. Net Generation by Energy Source by Type of Producer. Energy Information Administration. [Online]. Available: http://www.eia.doe.gov/cneaf/electricity/epa/epat1p1.html

Huang, Y.J. 2006. The Impact of Climate Change on the Energy Use of the US Residential and Commercial Building Sectors. LBNL report, Lawrence Berkeley National Laboratory, Berkeley, CA.

HowStuffWorks, Inc. 2008. How Power Grids Work. Available:

http://science.howstuffworks.com/power.htm

IPCC. 2000. IPCC Fourth Assessment Report: Topic 1. Available: http://www.grida.no/climate/ipcc/

IPCC. 2000. IPCC Special Report on Emissions Scenarios. Available: http://www.ipcc.ch/pdf/specialreports/spm/sres-en.pdf

Hirsch, J.J. 2006. DOE-2 introduction. Available: http://www.doe2.com/

Fred Buhl. 1999. DOE-2 Weather Processor. LBNL Simulation Research Group. http://gundog.lbl.gov/dirun/2001weath.pdf

Chinn, Gary. 2006. “Modeling Stalled Induction Motors.” Proc. of 2006 PES Transmission and Distribution Conference and Exhibition, Dallas, TX, pp. 1325-1328.

Lu, N., Y. Xie, and Z. Huang. 2008. “Air-conditioner Performance Model Development.” PNNL-17796, Pacific Northwest National Laboratory, Richland, WA.

Lu, N., B. Yang, and Z. Huang. 2008a. Evaluation of Southern California Edison Air-Conditioner Stalling Solutions. PNNL-17686, Pacific Northwest National Laboratory, Richland, WA.

Bravo, R., R. Yinger, and L. Gaillac. 2006. Conditioner Stalling Unit Level Solutions Test Report. Southern California Edison, Rosemead, CA. 


\section{Appendix}

\section{Temperature Sensitivity Curves}




\section{Appendix}
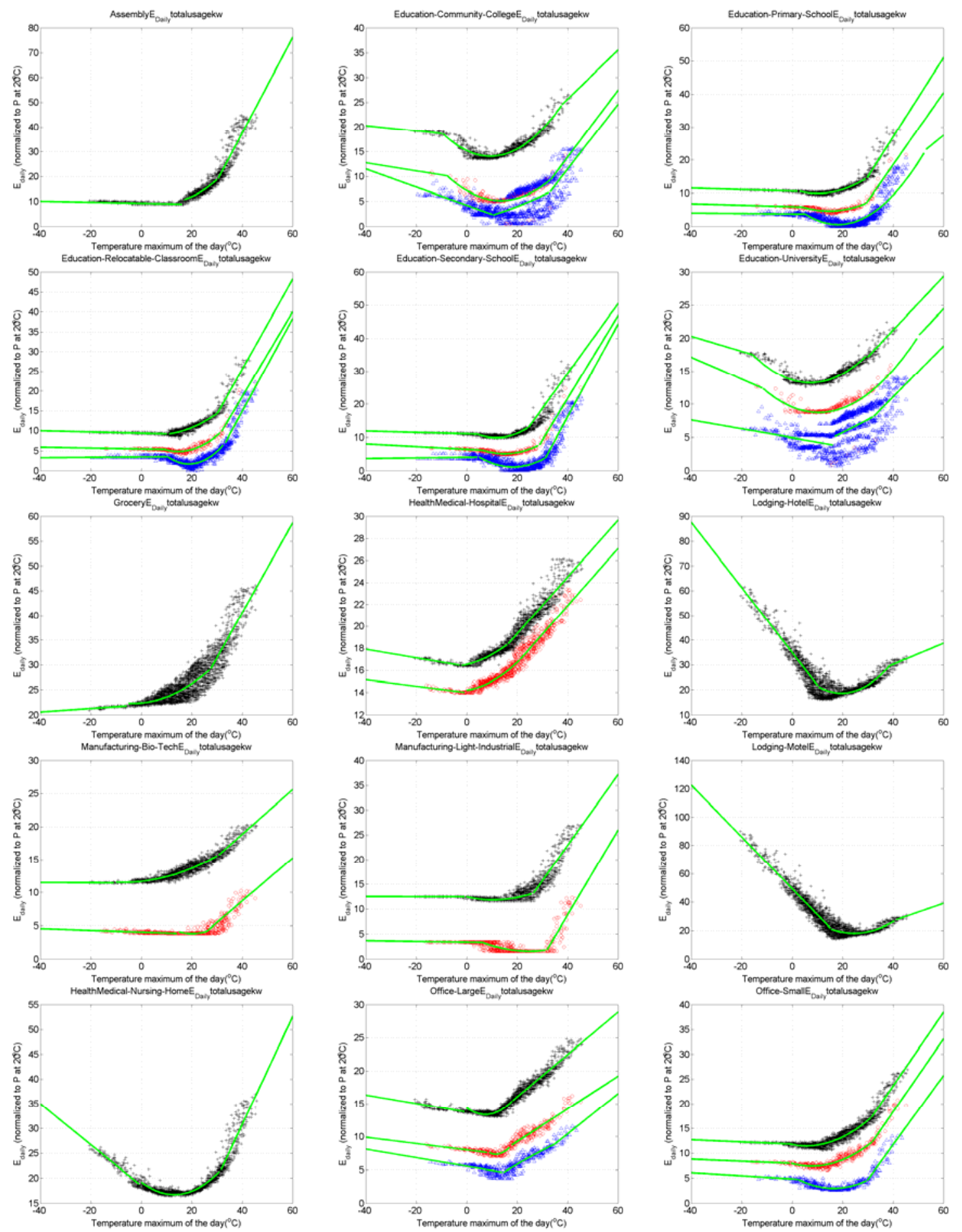

Figure 31: The temperature sensitivity curve of daily building consumptions for base case derived from the 7 inland cities. (Black: weekday; Blue: weekend; Red: holiday) 

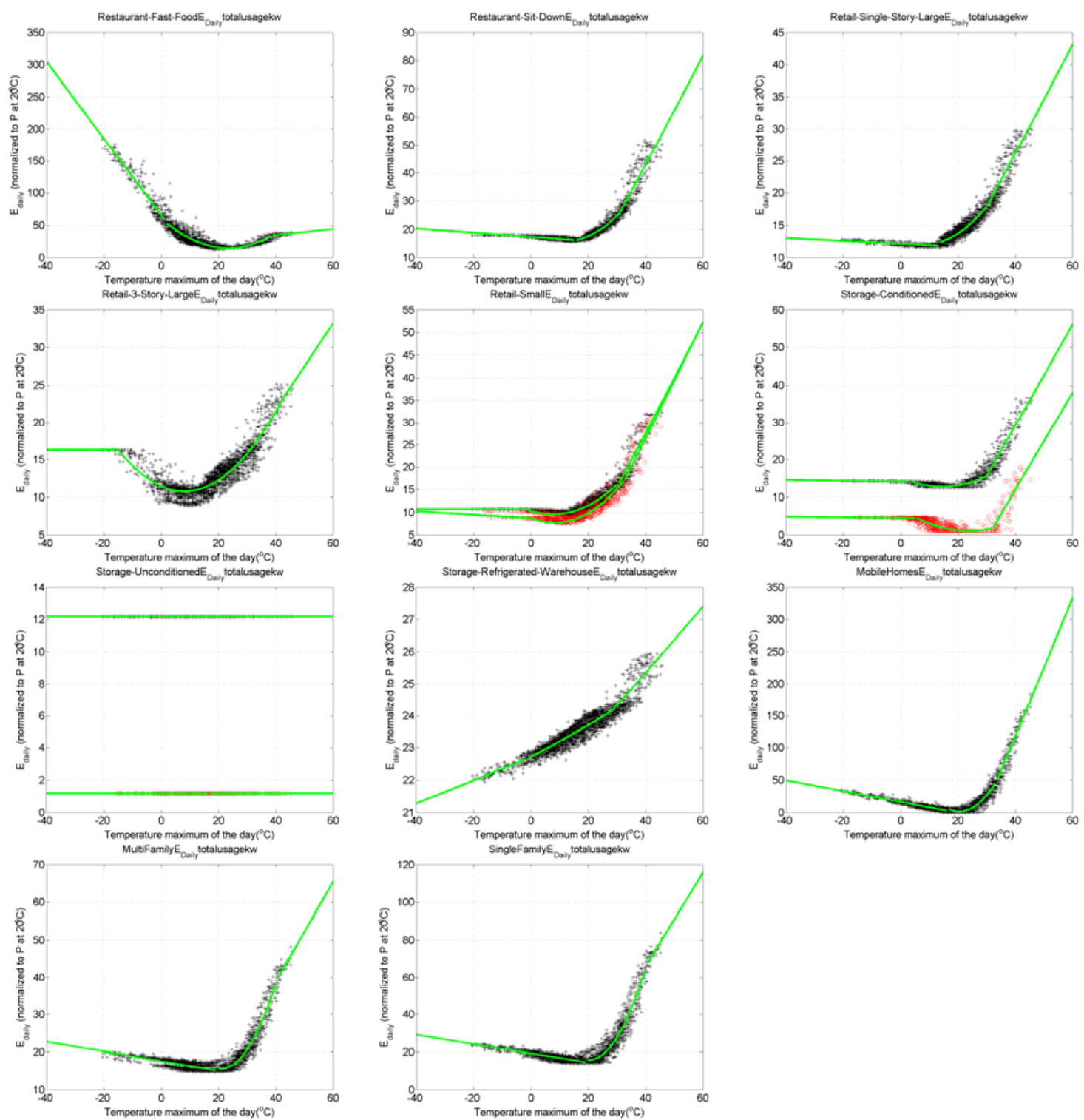

Figure 31 (continued): The temperature sensitivity curve of daily building consumptions for base case derived from the 7 inland cities. (Black: weekday; Blue: weekend; Red: holiday) 

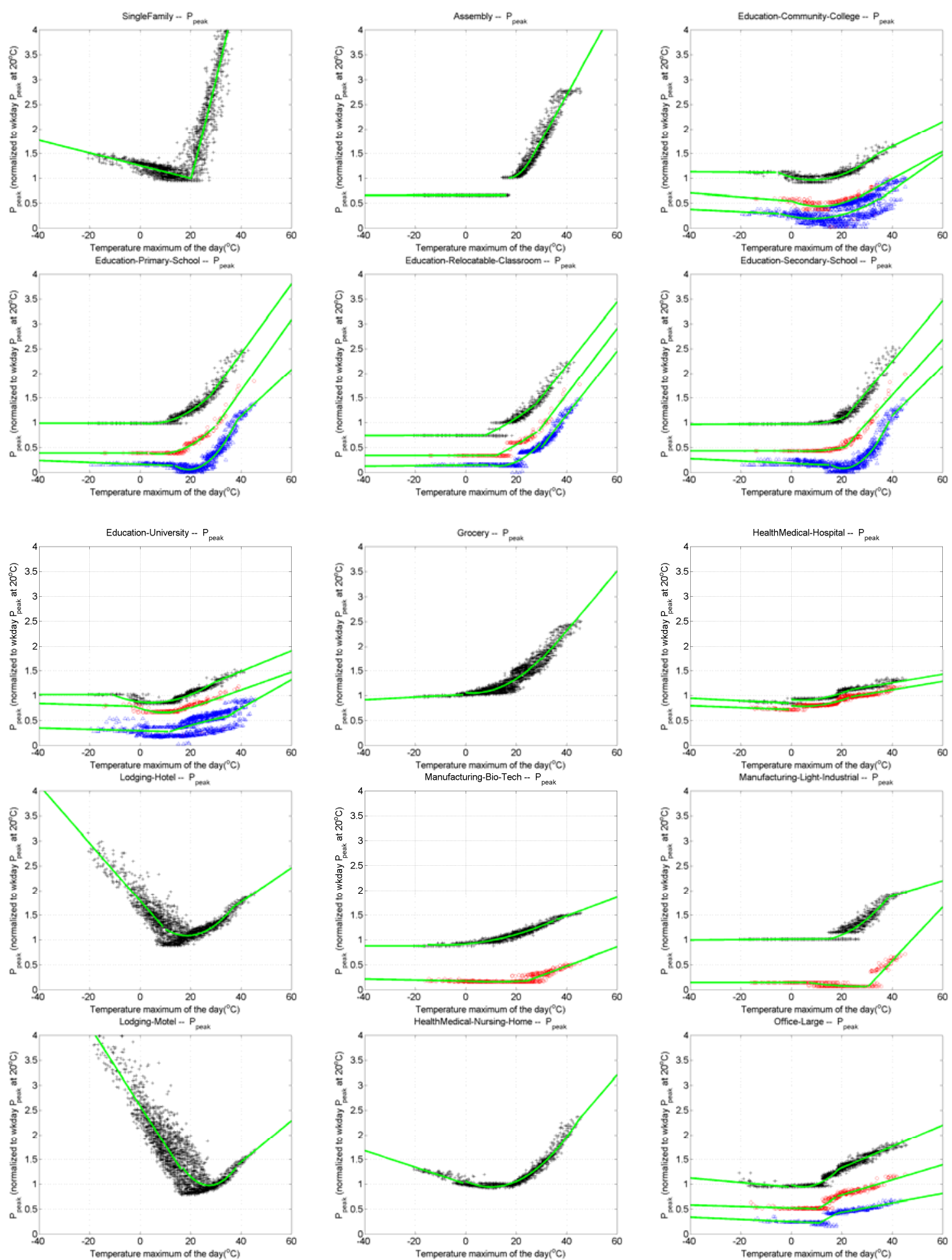

Figure 32: The temperature sensitivity curve of building peak load for base case derived from the 7 inland cities. (Black: weekday; Blue: weekend; Red: holiday) 

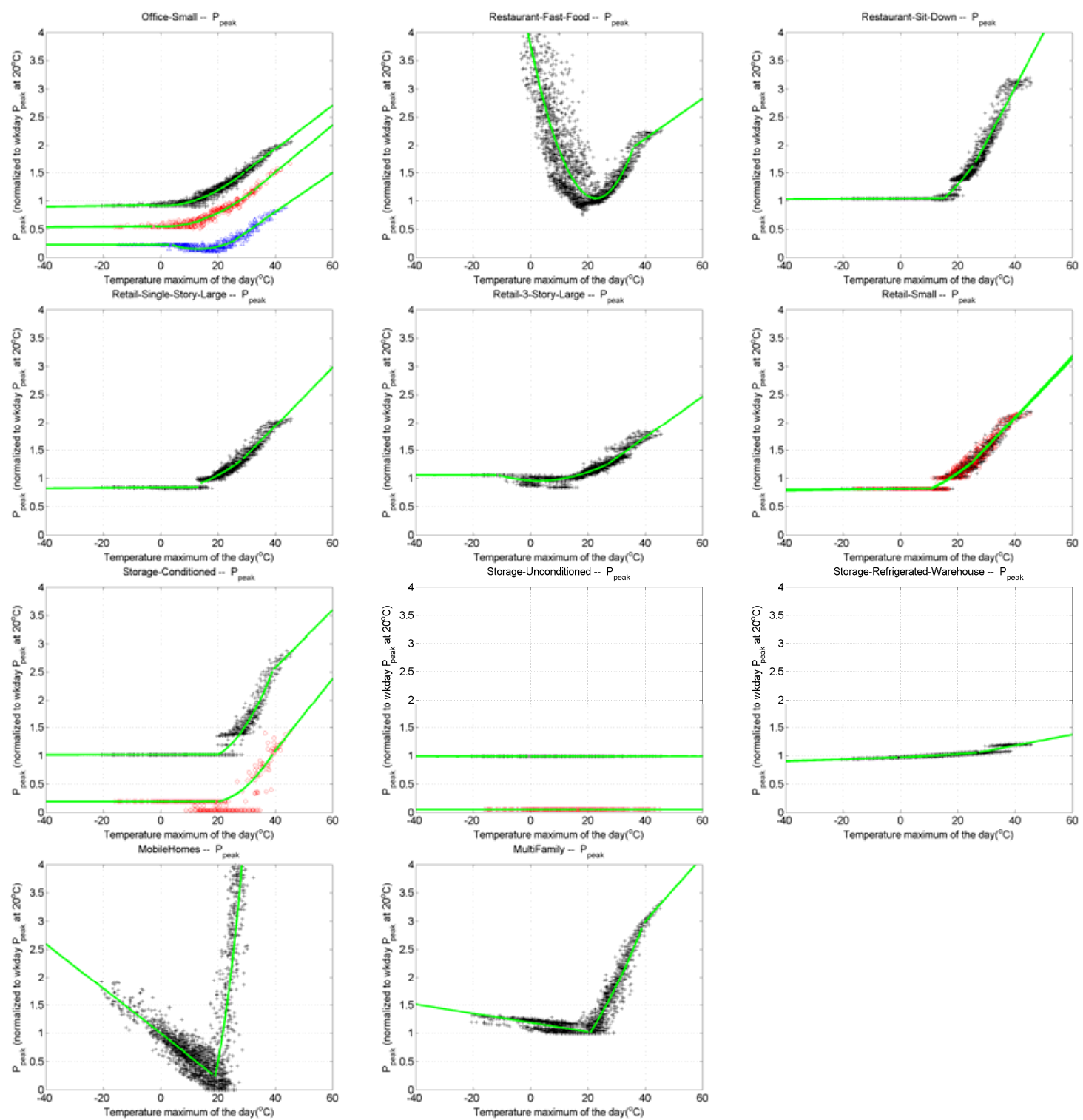

Figure 32 (continued): The temperature sensitivity curve of building peak load for base case derived from the 7 inland cities. (Black: weekday; Blue: weekend; Red: holiday) 

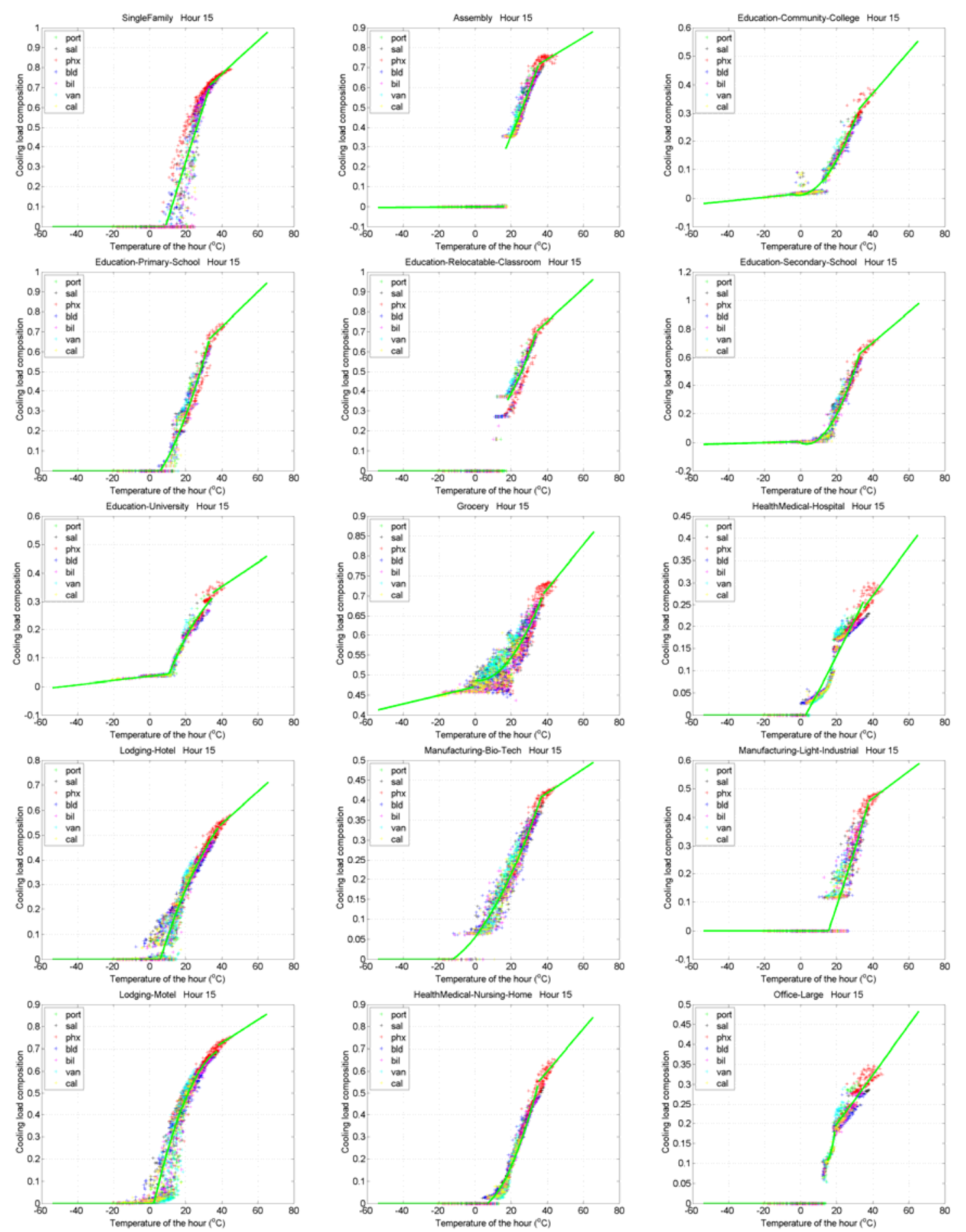

Figure 33: The temperature sensitivity curve of building peak load for base case derived from the 7 inland cities. (Black: weekday; Blue: weekend; Red: holiday) 

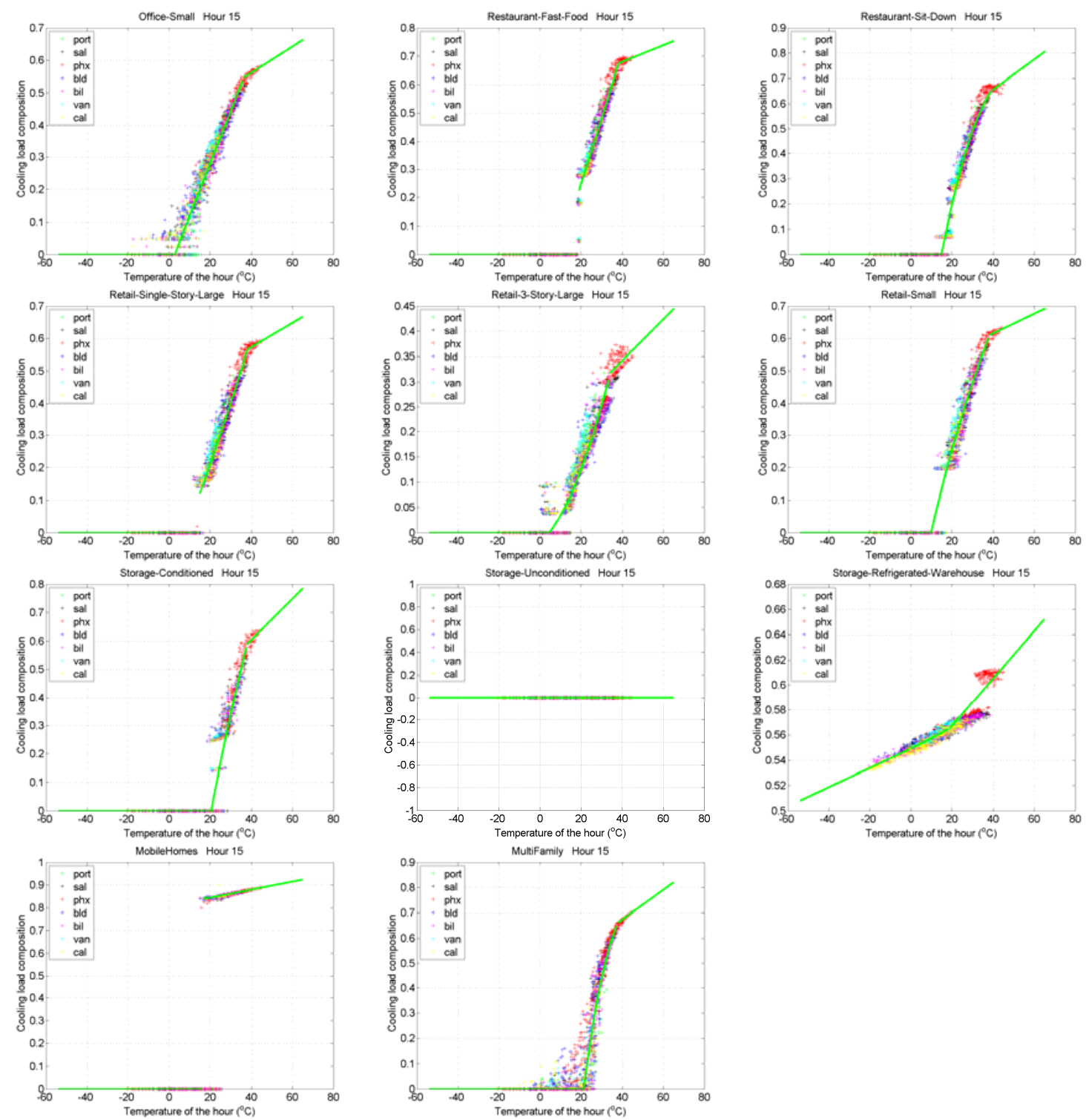

Figure 33 (continued): The temperature sensitivity curve of building peak load for base case derived from the 7 inland cities. (Black: weekday; Blue: weekend; Red: holiday) 

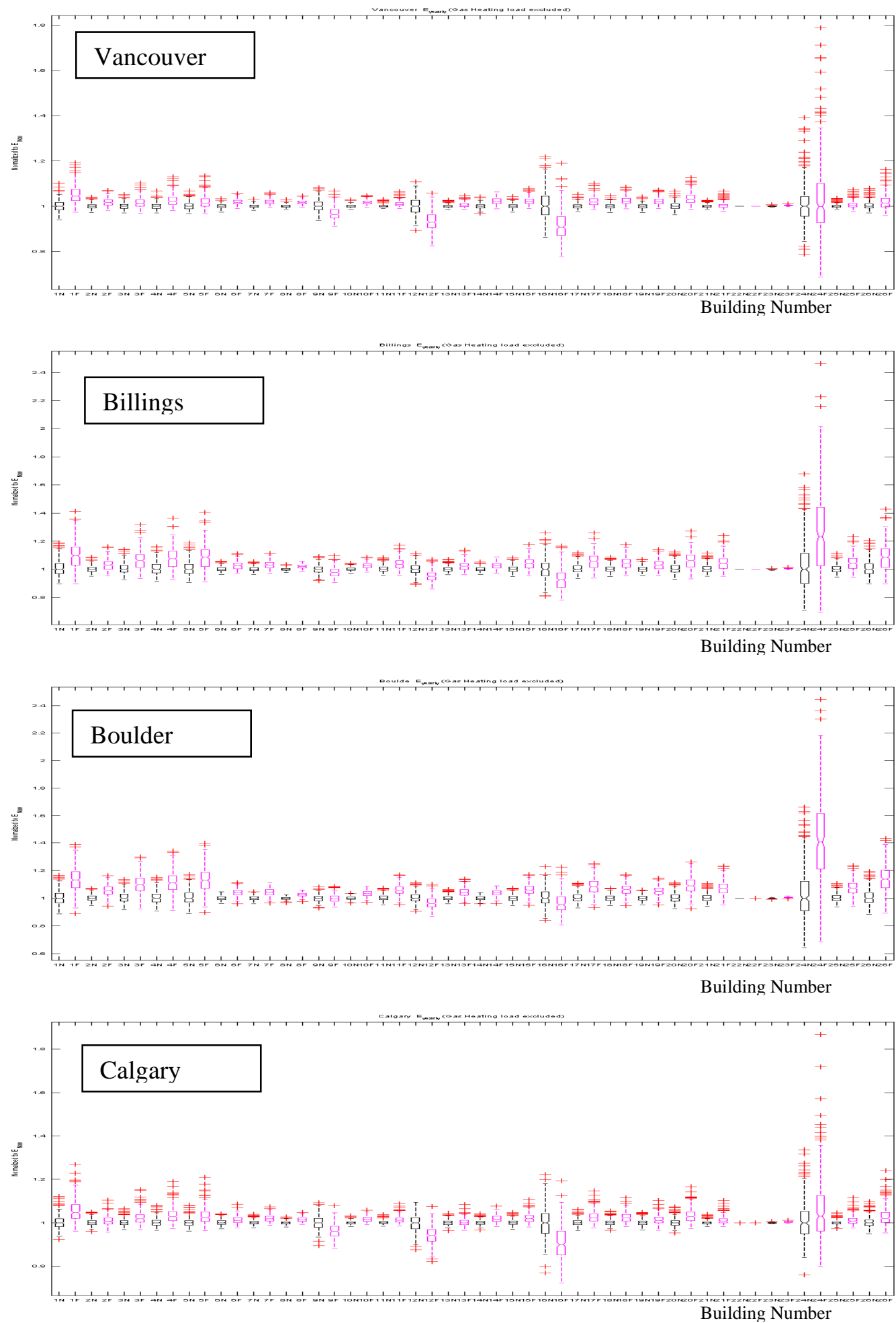

Figure 34: The box plot of building yearly energy consumption for base case Now and Future derived from the 7 inland cities. (Black: Now; Magenta: Future) 

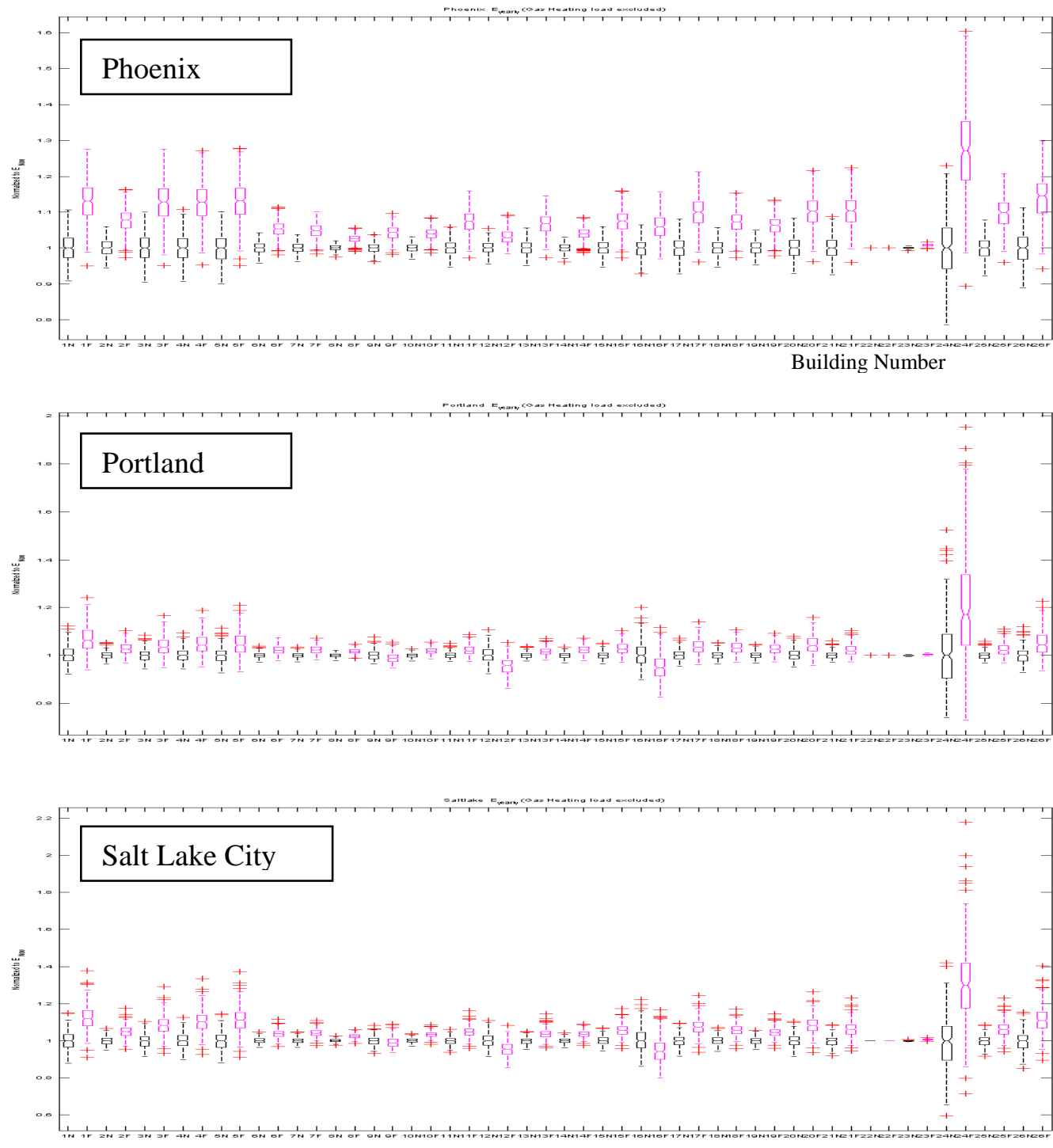

Building Number

Figure 34 (continued): The box plot of building yearly energy consumption for base case Now and Future derived from the 7 inland cities. (Black: Now; Magenta: Future) 


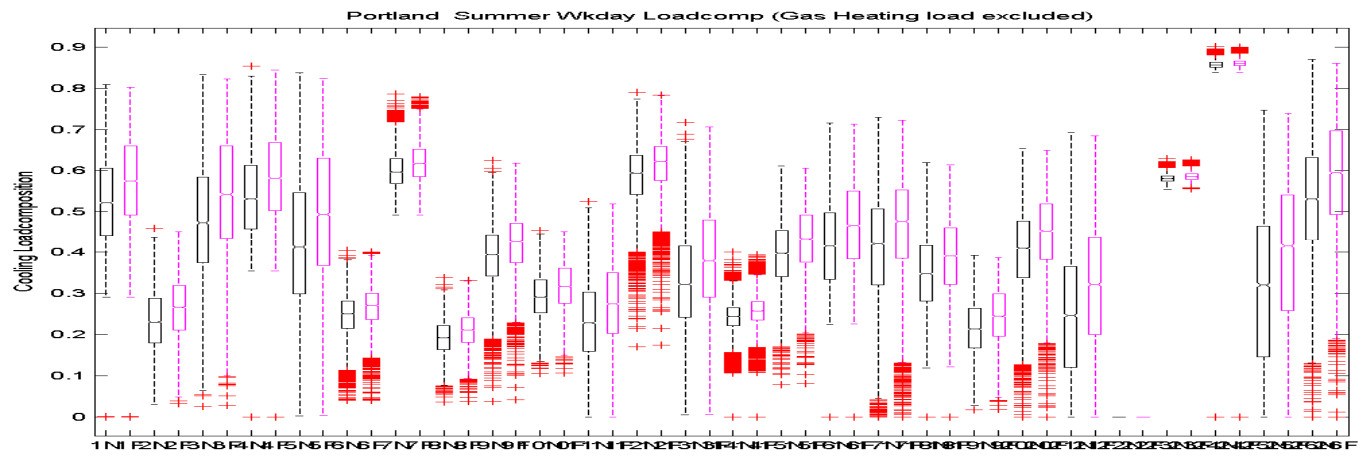

Building Number

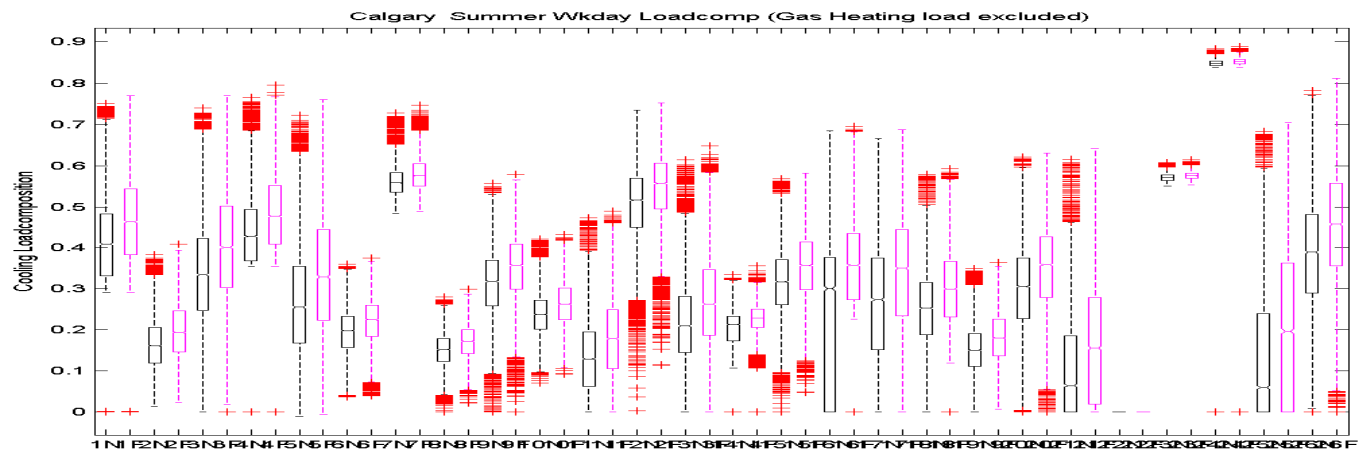

Building Number

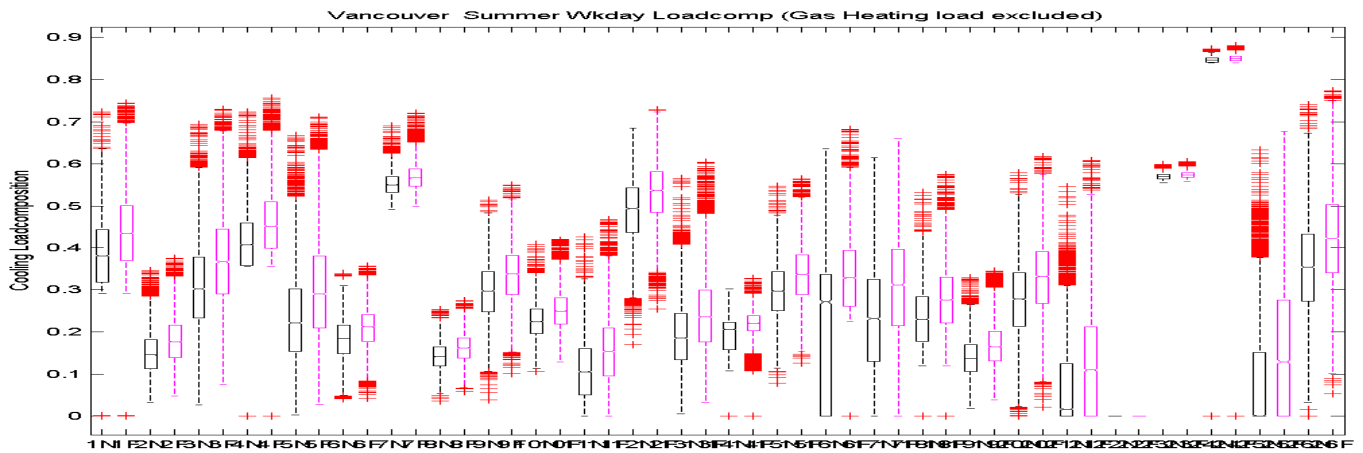

Building Number

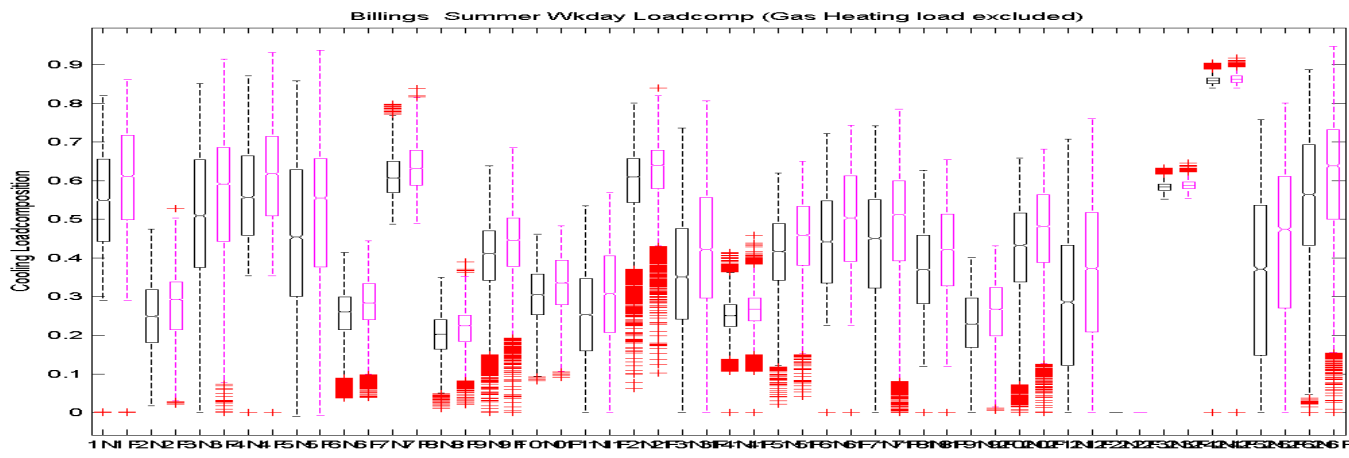

Building Number

Figure 35: The box plot of building summer load composition at Hour 15 for Now and Future derived from the 7 inland cities. (Black: Now; Magenta: Future) 


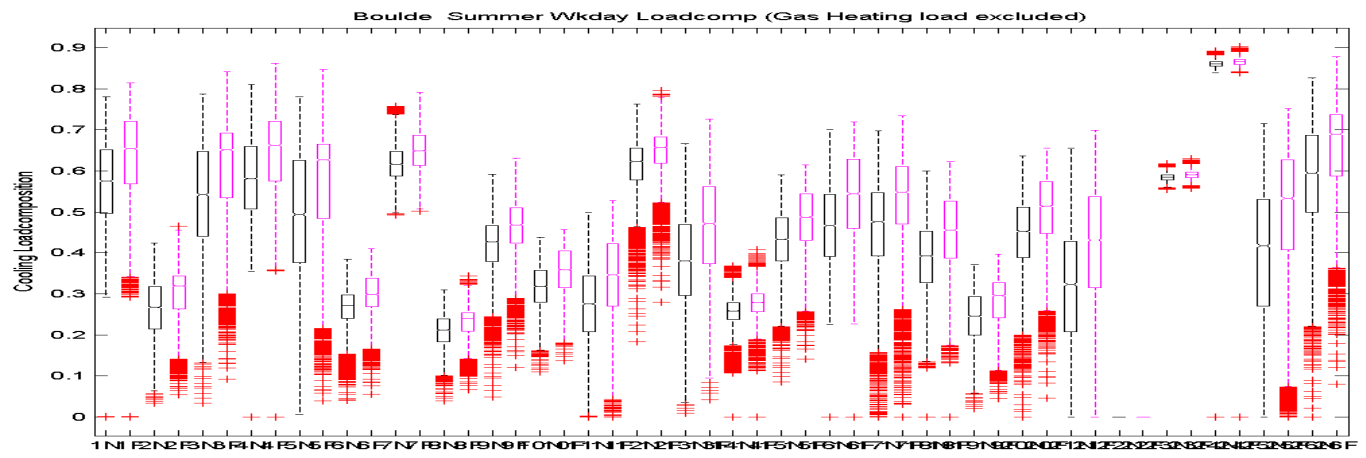

Building Number

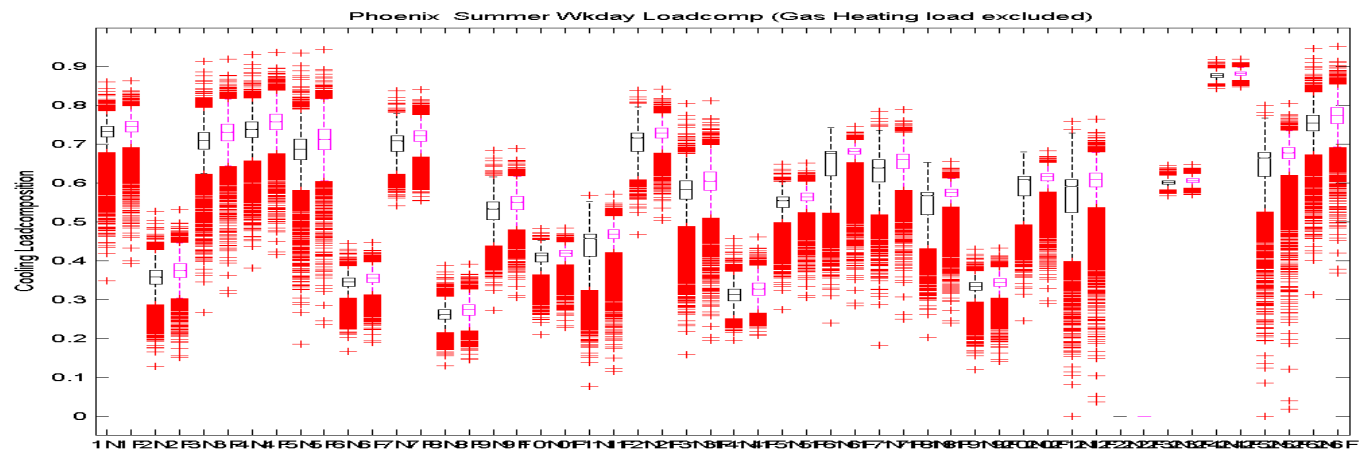

Building Number

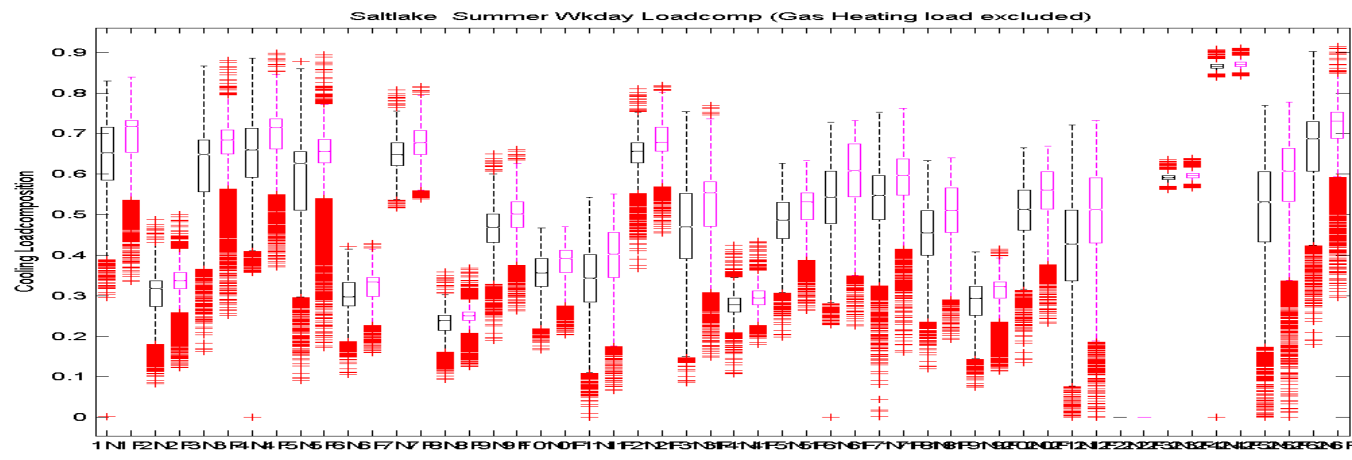

Building Number

Figure 35 (continued): The box plot of building summer load composition at Hour 15 for Now and Future derived from the 7 inland cities. (Black: Now; Magenta: Future) 

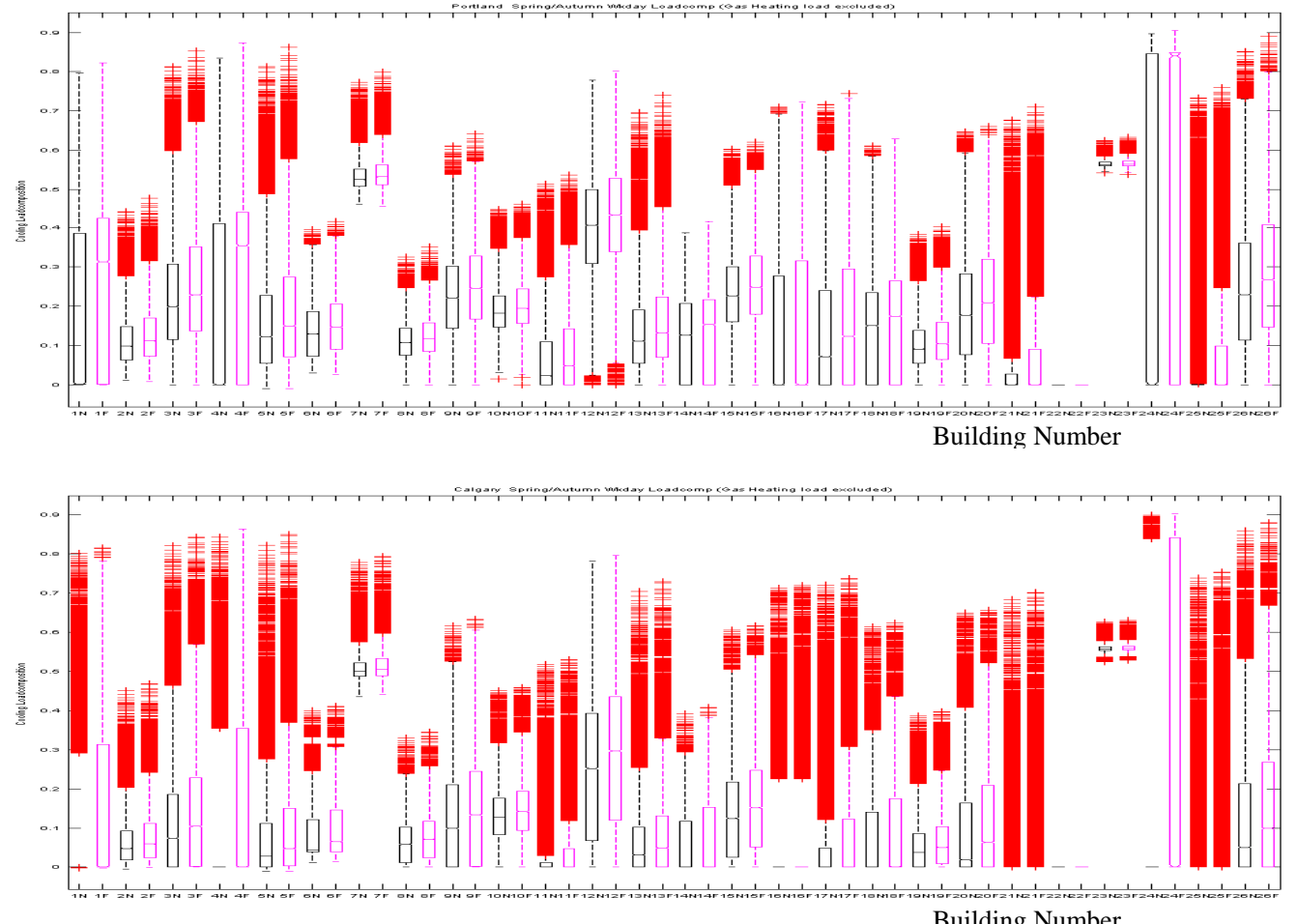

Building Number

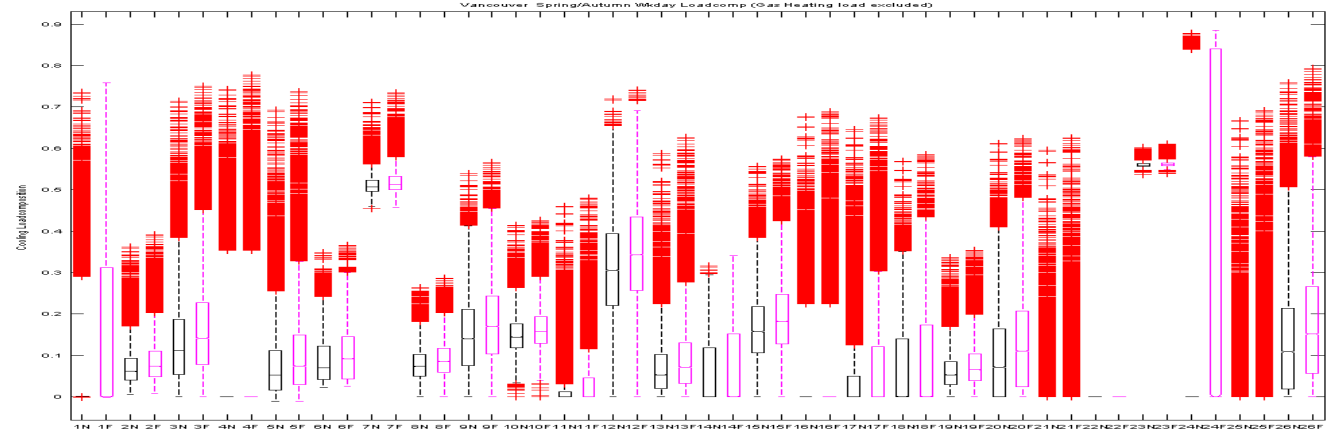

Building Number

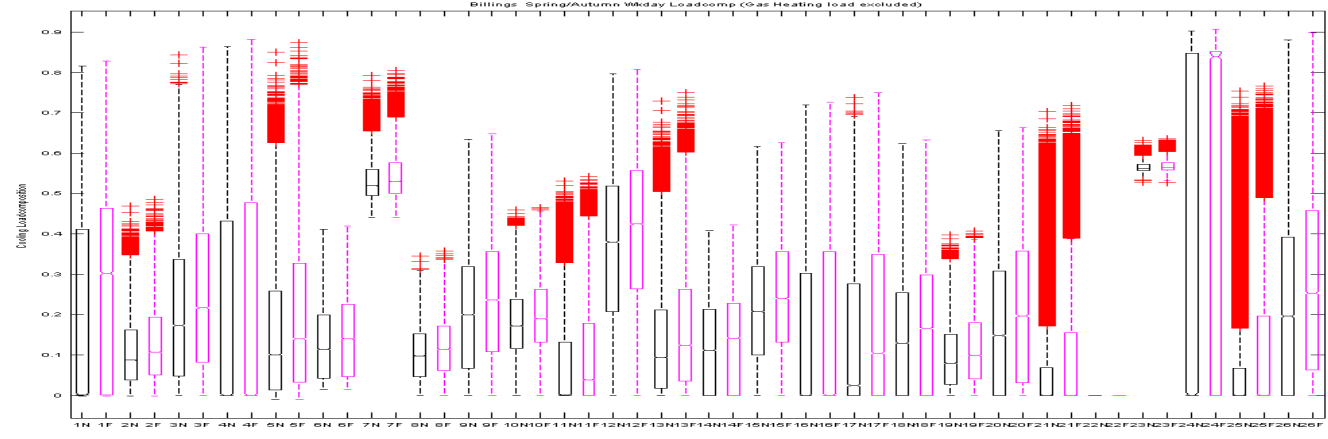

Building Number

Figure 36: The box plot of building spring/autumn load composition at Hour 15 for Now and Future derived from the 7 inland cities. (Black: Now; Magenta: Future) 


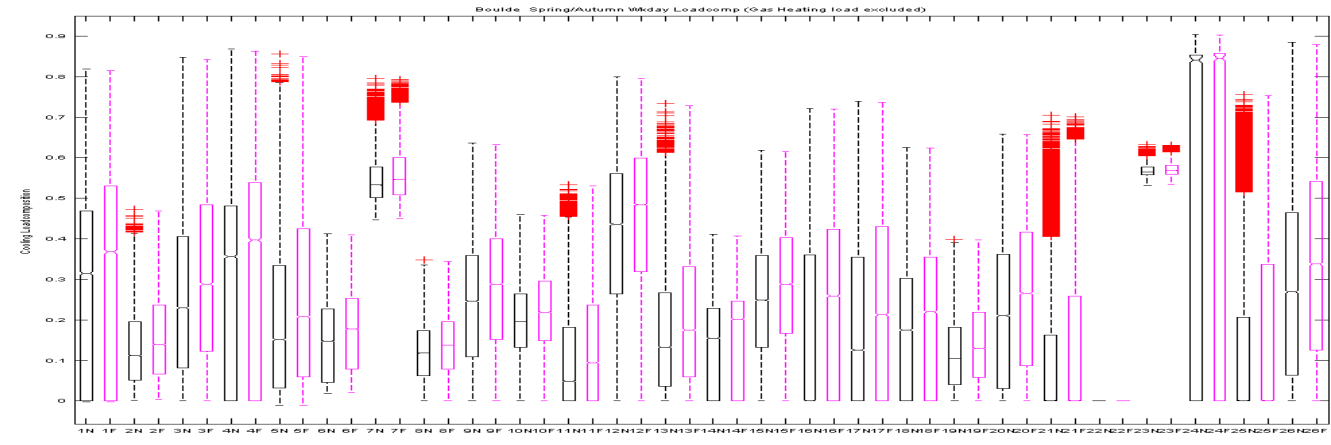

Building Number

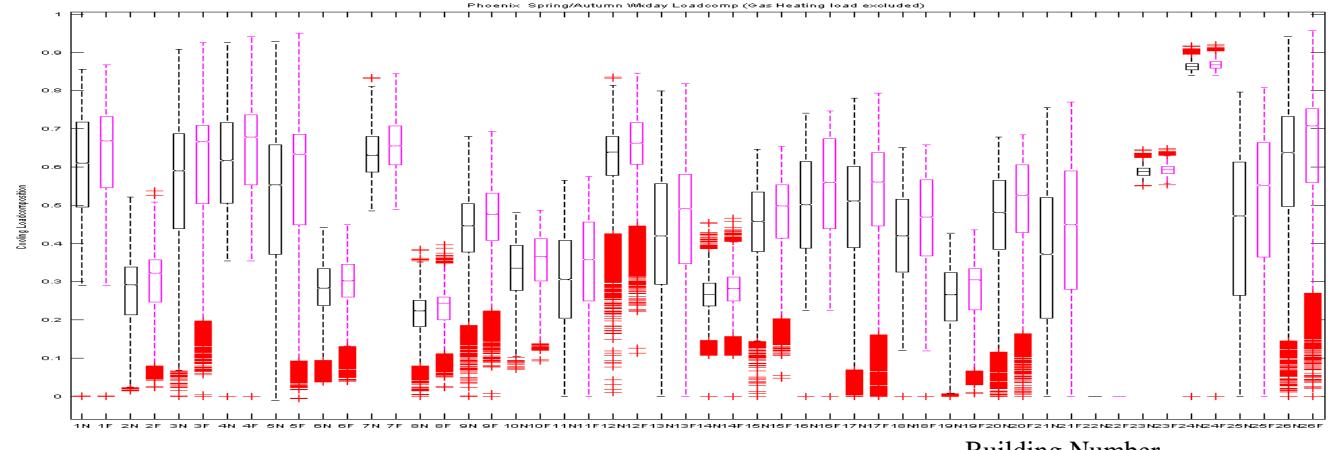

Building Number

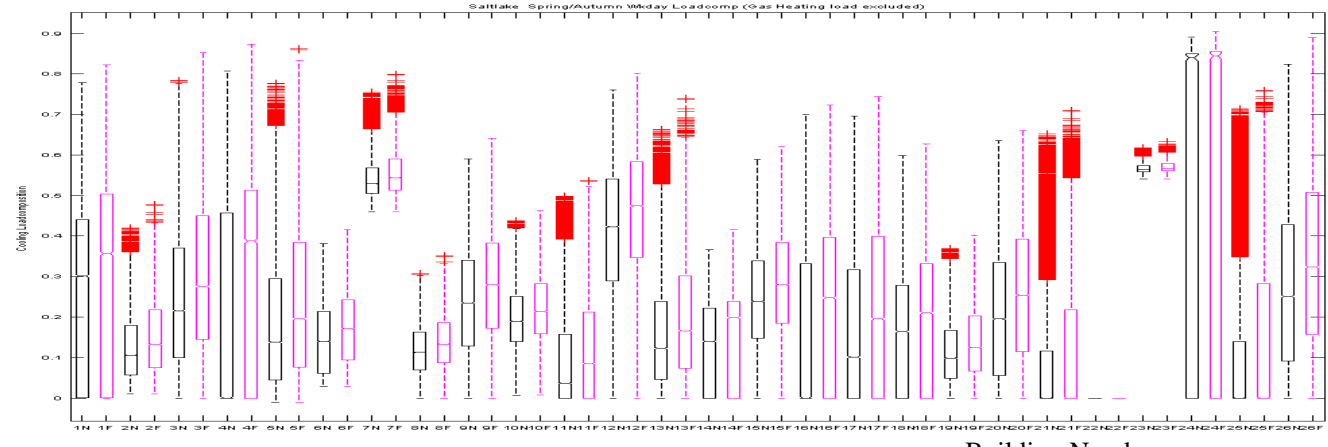

Building Number

Figure 36 (continued): The box plot of building spring/autumn load composition at Hour 15 for Now and Future derived from the 7 inland cities. (Black: Now; Magenta: Future) 